\title{
SAMUEL KOPP
}

\section{Adaptação de Vídeo através de Redes de Serviços Sobrepostos}




\section{SAMUEL KOPP}

\section{Adaptação de Vídeo através de Redes de Serviços Sobrepostos}

Dissertação apresentada no Departamento de Engenharia de Computação e Sistemas Digitais da Escola Politécnica de Universidade de São Paulo para a obtenção do título de Mestre em Engenharia. 


\section{SAMUEL KOPP}

\section{Adaptação de Vídeo através de Redes de Serviços Sobrepostos}

Dissertação apresentada no Departamento de Engenharia de Computação e Sistemas Digitais da Escola Politécnica de Universidade de São Paulo para a obtenção do título de Mestre em Engenharia.

Orientadora: Profa. Dra. Regina Melo Silveira 
Dedico esta dissertação aos meus pais, meu irmão e minha namorada que, com esmero, sempre me apoiaram durante essa jornada. 


\section{Agradecimentos}

A Deus, que me guia e abençoa.

A meus pais Arminio Kopp e Helena Stecko Kopp, por estarem sempre ao meu lado, regozijando nos momentos de alegria e incansáveis nos momentos difíceis.

A meu irmão Leonardo, de quem segui os passos, ao me engajar na área da computação.

A minha amada namorada Aline de Oliveira dos Santos, a qual teve muita paciência comigo, principalmente nos últimos meses desta jornada.

À professora Regina Melo Silveira, por sempre me motivar, ensinar, e abrir portas de novas oportunidades pelas quais pude crescer na vida profissional e pessoal.

À professora Tereza Cristina Carvalho, pelo incentivo no meu engajamento acadêmico.

Ao Professor Wilson Ruggiero, pela oportunidade de trabalho no LARC, que possibilitou o aperfeiçoamento da minha formação profissional e como pesquisador

A todos os professores, pois me instruíram no caminho da riqueza intocável, o conhecimento.

Aos meus amigos David, Hélcio, Lucas, Marcos Simplicio, Reinaldo e Ricardo por todos os momentos de alegria e descontração, intercalados com muito trabalho.

A Selma e Sílvia, que diariamente dão condições e muita simpatia no desenrolar das atividades cotidianas.

Aos amigos e colegas de projeto, por partilhar a amizade e o muito trabalho que contribuiu imensamente para o meu crescimento.

À todos pesquisadores e colegas do LARC pela troca de experiência e por tornar deste laboratório um ótimo ambiente de trabalho.

A todos aqueles que estiveram presentes, de maneira direta ou indireta e contribuíram para a realização e concretização deste trabalho, meus sinceros agradecimentos.

"Que tudo que aprendemos em redes, seja usado para nunca perdermos a nossa comunicação", lan Korolkovas. 
"Para se conhecer a sabedoria e a instrução; para se entender, as palavras da prudência.

Para se receber a instrução do entendimento, a justiça, o juízo e a eqüidade; Para dar aos simples, prudência, e aos moços, conhecimento e bom siso; O sábio ouvirá e crescerá em conhecimento, e o entendido adquirirá sábios conselhos; O temor do SENHOR é o princípio do conhecimento; os loucos desprezam a sabedoria e a instrução." 


\section{Resumo}

A adaptação de vídeo é uma técnica amplamente explorada na provisão de conteúdos de forma que atendam adequadamente os mais diversos cenários de consumo, caracterizados por diferentes requisitos e restrições de rede, terminal e preferências do usuário. Entretanto, sua aplicação em sistemas de distribuição de vídeo de alta demanda, como CDNs, é abordada de forma simplista pelas propostas existentes, pois não consideram os diversos aspectos de otimização do uso da rede.

Este trabalho trata estas deficiências propondo um serviço de adaptação de vídeo que explora o conceito de contexto, ao elaborar uma adaptação baseada em perfis dos usuários. Além disso, a proposta de adaptação está totalmente integrada a distribuição por redes sobrepostas, sendo possível associar a adaptação em tempo-real à transmissão por multicast e ao caching, o que garante a otimização do uso dos recursos de rede na distribuição dos fluxos de vídeo. Como forma de demonstrar a viabilidade e os benefícios desta proposta, são realizados testes experimentais através de uma implementação de referência deste serviço. 


\section{Abstract}

Video adaptation is a technique extensively explored for providing content so that it meets different requirements and constraints of network, user's terminal and preferences, providing better quality of experience. However, its use in high-demand video distribution systems is not sufficiently explored and is usually tackled in a simple way. This is due to the fact that current solutions do not deals with its applicability systemically.

This work presents an approach, which explores video adaptation and the concept of context, elaborating a video adaptation service based in users profile. Moreover, the adaptation proposal presented here is totally integrated to CND (content network distribution) using overlay networks, being possible the association with real-time adaptation to the transmission using multicast and caching. This work focuses on presenting the architecture of that service and its operation. The proposal validation is performed by putting the identified requirements for its application against its provided functionalities and the test results in a implementation of this service. 


\section{Lista de Figuras}

1 Redução da resolução temporal . . . . . . . . . . . . . . . . . . . . 21

2 Redução da resolução espacial . . . . . . . . . . . . . . . . . . . . 22

3 Redução da precisão da imagem "Lena" (adaptado de (YOUSSEF, 2010)) . 22

4 Grupo de Imagens (Group of Pictures - GOP) (adaptado de (HLAVác, 2010)) 23

5 Amostragem de cores 4:4:4, 4:2:2, 4:1:1 e 4:2:0 (adaptado de (MUNSIL; SPEARS, 2003)) . . . . . . . . . . . . . . . . . . . . . 24

6 (a) imagem original; (b) simulação da deficiência; (c) imagem adaptada; (d) simulação da deficiência na imagem adaptada (adaptado de: (NAM et al., 2005)) . . . . . . . . . . . . . . . . . . . . . 25

7 Visão geral do MPEG-21 DIA (adaptado de: (ISO/IEC 21000-7, 2004)) . . . 26

8 Ferramentas do MPEG-21 DIA (adaptado de: (ISO/IEC 21000-7, 2004)) . . 27

9 Rede sobreposta implementada na camada de aplicação . . . . . . . . . 39

10 Visão geral da arquitetura Oversea . . . . . . . . . . . . . . . . . . . . 42

11 Mensagem OCP . . . . . . . . . . . . . . . . . . . . . . . 44

12 Rede Ipê com Serviço Sobreposto de Multicast (adaptado de (RNP, 2010)) 45

13 Visão geral do funcionamento do serviço de adaptação integrado com serviço multicast . . . . . . . . . . . . . . . . . . 47

14 Elementos do serviço de adaptação inseridos na arquitetura Oversea . . . 48

15 Requisição de vídeo com os serviços de multicast e adaptação integrados 50

16 Campo service body do OCP com as informações para a adaptação. . . . . 53

17 Cenário utilizado na comparação das estratégias. . . . . . . . . . . . . . 55

18 Operações de adaptação realizadas . . . . . . . . . . . . . . . . 56

19 Volume de dados armazenados. . . . . . . . . . . . . . . . 57

20 Taxa de acerto (hit ratio) do cache. . . . . . . . . . . . . . . 58

21 Utilização dos enlaces . . . . . . . . . . . . . . . . . . . . . . . . . . 59

22 Mensagem OCP . . . . . . . . . . . . . . . . . . . 69

23 Mensagem OCP . . . . . . . . . . . . . . . . . . . 70 


\section{Lista de Tabelas}

1 Exemplos de redes sobrepostas, adaptado de (CLARK et al., 2006) . . . 40

2 Perfis de adaptação considerados . . . . . . . . . . . . . . . . 48

3 Exemplo de regras utilizadas para enquadramento aos perfis. . . . . . . . . 54

4 Instantes da avaliação. . . . . . . . . . . . . . . . . . . . . . 55

$5 \quad$ Informações de Contexto . . . . . . . . . . . . . . . . . . . . 71

6 Informações enviadas aos agentes de adaptação . . . . . . . . . . . . . 72

7 Instantes da avaliação. . . . . . . . . . . . . . . . . . . . . 73

8 Operações de adaptação realizadas: adaptação prévia $\ldots$. . . . . . . . . 73

9 Operações de adaptação realizadas: adaptação personalizada . . . . . . . 74

10 Operações de adaptação realizadas: serviço proposto . . . . . . . . . . . 74

11 Volume de dados armazenados: adaptação prévia . . . . . . . . . . . 75

12 Volume de dados armazenados: adaptação personalizada . . . . . . . . . 75

13 Volume de dados armazenados: serviço proposto . . . . . . . . . . 76

14 Taxa de acerto (hit ratio) do cache: adaptação prévia . . . . . . . . . . . 76

15 Taxa de acerto (hit ratio) do cache: adaptação personalizada . . . . . . . 76

16 Taxa de acerto (hit ratio) do cache: serviço proposto . . . . . . . . . . 77

17 Utilização dos enlaces: adaptação prévia . . . . . . . . . . . . . . 77

18 Utilização dos enlaces: adaptação personalizada . . . . . . . . . . . . . 78

19 Utilização dos enlaces: serviço proposto . . . . . . . . . . . . . . . . 78 


\section{Lista de Abreviações e Siglas}

BOS Basic Overlay Services

BSD Bitstream Syntax Description

BSDLink Bitstream Syntax Description Link

CC/PP Composite Capabilities/Preference Profiles

CDN Content Distribution Network

DIA Digial Item Adaptation

DIAC DIA Configuration

ED Enhanced Definition

FGS Fine-Grained Scalable

FHD Full High Definition

GOP Group of Pictures

HD High Definition

ISO International Organization for Standardization

LARC Laboratório de Arquitetura e Redes de Computadores

LD Low Definition

MA Metadata Adaptability

MC Motion Compensation

MIB Management Information Base

MPEG Motion Picture Expert Group

OCP Oversea Communication Protocol

Oversea Scalable and Effective Architecture for Overlay Networks

PSNR Peak Signal-to-Noise Ratio

QoE Quality of Experience

QoS Qualidade de Serviço

RDD Rights Data Dictionary

RDF Resource Description Framework 
REL Rights Expression Language

RNP Rede Nacional de Ensino e Pesquisa

RTSP Real Time Streaming Protocol

RVD Rede de Vídeo Digital

SD Standard Definition

SM Session Mobility

SNMP Simple Network Management Protocol

SNR Signal to Noise Ratio

SON Service Overlay Networks

SVC Scalable Video Coding

UCD (MPEG-21) Universal Constraints Description

UCD (SNMP) University of California, Davis

UED Usage Environment Description

UMA Universal Multimedia Access

VMS Video Management System

VoD Video on Demand

W3C World Wide Web Consortium 


\section{Sumário}

1 Introdução 11

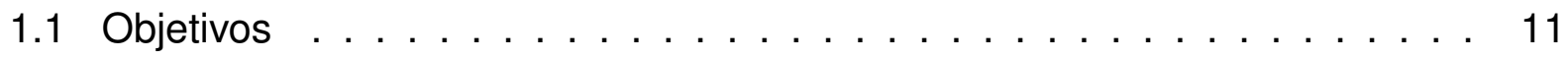

1.2 Justificativa e Motivação . . . . . . . . . . . . . . . . . . . . . . . 12

1.3 Organização do Trabalho . . . . . . . . . . . . . . . . . . . 13

2 Adaptação de vídeo $\quad 14$

2.1 Introdução . . . . . . . . . . . . . . . . . . . . . . . . . . . . . . . . 14

2.2 Estado da Arte . . . . . . . . . . . . . . . . . . . . . . . . . . . 14

2.3 Taxonomia das Operações de Adaptação de Vídeo . . . . . . . . . . . . . . 19

2.4 Parâmetros de Codificação . . . . . . . . . . . . . . . . . . . . . 21

2.5 MPEG-21 DIA - Digial Item Adaptation . . . . . . . . . . . . . . . . . . . . . 24

3 Adaptação de Vídeo em CDNs 29

3.1 Técnicas de Otimização de CDNs . . . . . . . . . . . . . . . . . . . . 29

3.2 Demandas por Adaptação de Vídeo . . . . . . . . . . . . . . . . . . . . . 30

3.3 Impactos da Adaptação de Vídeo . . . . . . . . . . . . . . . . . . . . 33

3.4 Estratégias de Adaptação de Vídeo . . . . . . . . . . . . . . . . . . . . . . . 34

3.5 Trabalhos relacionados . . . . . . . . . . . . . . . . . 35

3.6 Discussão . . . . . . . . . . . . . . . . . . . 36

4 Redes Sobrepostas $\quad 38$

4.1 Conceito, Benefícios e Desafios . . . . . . . . . . . . . . . . . 38

4.2 Redes Sobrepostas na Internet . . . . . . . . . . . . . . . . . . . 40

4.3 Redes de Serviços Sobrepostos . . . . . . . . . . . . . . . . . . . . 41

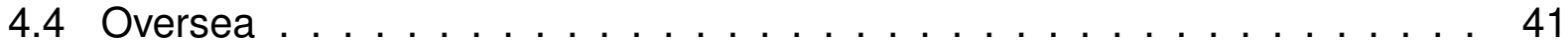

4.4.1 Visão geral da arquitetura . . . . . . . . . . . . . . . . 42

4.4.2 OCP - Oversea Communication Protocol . . . . . . . . . . . . . . . 43

4.4.3 Plataforma de Gerência de Vídeo . . . . . . . . . . . . . . . . . . . . 44

5 Serviço de Adaptação de Vídeo 46 
5.1 Visão geral . . . . . . . . . . . . . . . . . . . . . . 46

5.2 Elementos do Serviço de Adaptação . . . . . . . . . . . . . . . . . 48

5.2.1 Módulo de Orquestração . . . . . . . . . . . . . . . . . . . . 49

5.2 .2 Agente de Adaptação . . . . . . . . . . . . . . . . . . . . 49

5.3 Gerenciamento dos Perfis de Adaptação . . . . . . . . . . . . . . . . 50

5.3 .1 Negociação da adaptação . . . . . . . . . . . . . . . . 50

6 Avaliação $\quad 52$

6.1 Implementação do serviço de adaptação . . . . . . . . . . . . . . . . . 52

6.1 .1 Módulo de Orquestração . . . . . . . . . . . . . . . . . . . . 52

6.1 .2 Agente de Adaptação . . . . . . . . . . . . . . . . . . . . 54

6.2 Cenário de avaliação . . . . . . . . . . . . . . . . . . . . 54

6.3 Resultados Experimentais . . . . . . . . . . . . . . . . . . 56

6.4 Análise dos Resultados . . . . . . . . . . . . . . . . . . . 59

$\begin{array}{lll}7 \text { Conclusão } & 61\end{array}$

7.1 Contribuições . . . . . . . . . . . . . . . . . . . . . . 62

7.2 Trabalhos Futuros . . . . . . . . . . . . . . . . . 62

$\begin{array}{ll}\text { A Melhorias no Protocolo OCP } & 69\end{array}$

$\begin{array}{ll}\text { B Metadados Utilizados } & 71\end{array}$

$\begin{array}{ll}\text { C Detalhamento dos Resultados dos Testes } & 73\end{array}$ 


\section{Introdução}

A crescente demanda por aplicações multimídia evidencia a necessidade de sistemas de distribuição de vídeo cada vez mais eficientes. Tal fato pode ser comprovado ao analisarmos como os grandes publicadores de vídeo na Internet, tais como Youtube, CNN, MTV Networks, distribuem seus conteúdos. Estes utilizam Redes de Distribuição de Conteúdo (Content Distribution Network - CDN) que exploram as técnicas de cache e multicast para viabilizar o acesso à seus conteúdos aos usuários de forma escalável.

Entretanto, a Internet é marcada pela heterogeneidade de redes e pela diversidade de dispositivos com que os usuários podem acessar os conteúdos, como PCs, laptop, palmtops, smartphones, etc. Desta forma, é necessário que hajam mecanismos de adaptação de mídias que considerem o contexto do usuário, para que este possa acessar tais conteúdos de maneira adequada. Porém, o uso de tais mecanismos de adaptação de vídeo ainda é bastante limitado.

Tal situação ocorre pois, embora a adaptação de vídeo possa beneficiar os usuário no acesso aos conteúdos, a sua implementação em CDNs encontra diversos obstáculos, dos quais destacam-se: (i) o custo computacional no processamento da adaptação, (ii) o volume de dados adicionais a serem armazenados e (iii) o impacto nas técnicas de cache e multicast.

\subsection{Objetivos}

Considerando tal panorama, este trabalho apresenta um serviço de adaptação que visa tratar os problemas da utilização da adaptação de vídeos em CDNs, utilizando uma abordagem baseada no uso de perfís de adaptação e agentes de adaptação distribuídos ao longo da rede.

A utilização de perfís de adaptação permite que diversos usuários, que tenham condições de acesso semelhantes, sejam atendidos pela mesma adaptação. Esta adaptação é realizada por agentes distribuídos formando uma Redes de Serviços Sobrepostos (Overlay 
Service Networks). O uso deste conceito permite que o serviço de adaptação atue de forma integrada com os demais serviços de distribuição de conteúdo, como: cache e multicast.

Como forma de demonstrar os benefícios deste serviço, foi implementado um protótipo do serviço proposto e realizado um conjunto de testes comparando tal serviço com outras estratégias de adaptação.

Este serviço de adaptação de vídeo pode ser utilizado na distribuição de vídeo em diversas aplicações como: bibliotecas de vídeo, locadoras virtuais, transmissões de vídeo ao vivo, sistema de IPTV (Internet Protocol TV), entre outros.

\subsection{Justificativa e Motivação}

O crescimento da utilização do vídeo como veículo de entretenimento e disseminação de informação, conhecimento e cultura, tem motivado muitas pesquisas na área de vídeo digital, a fim de tornar mais rico o consumo do conteúdo multimídia, aumentando a qualidade e a interatividade no seu acesso. Neste contexto é criado o conceito UMA (Universal Multimedia Access) que expressa um ambiente no qual qualquer conteúdo pode ser acessado a qualquer momento e em qualquer local (VETRO; CHRISTOPOULOS; EBRAHIMI, 2003).

No entanto, a aplicação deste conceito em um sistema de distribuição de vídeo requer o uso de serviços de adaptação de vídeo, que ainda possue diversos desafios, dentre estes a integração do serviço de adaptação de vídeo em CDNs. A integração deste serviço em sistemas de distribuição de conteúdo constituí um dos grandes entraves para que esta seja amplamente utilizada.

Apesar deste tópico ser explorado em diversos trabalhos, as soluções existentes ainda não atendem a todos os requisitos das CDNs de larga escala contextualizadas na Internet atual, pois se baseiam principalmente no uso de vídeos escaláveis, que embora tenham grandes benefícios, ainda não são uma realidade na Internet, além de outros problemas descritos em (LI; LIU, 2003). 
Assim, o desafio de integrar o serviço de adaptação de vídeo de forma que considere os requisitos de otimização de uma CDN, representa o principal motivo do desenvolvimento deste trabalho.

\subsection{Organização do Trabalho}

Este trabalho é organizado de maneira a mostrar o desenvolvimento e validação do serviço de adaptação de vídeo proposto, contextualizando a sua relevância no estado da arte.

No capítulo 2 é feito o levantamento do estado da arte da área de adaptação de vídeo, e apresentada uma taxonomia das operações de adaptação de vídeo, e os parâmetros que podem ser alterados nas operações de adaptação. Em sequência, é realizada no capítulo 3 uma discussão a respeito dos requisitos e estratégias de implementação de adaptação de vídeo em um sistema de distribuição de vídeo, concluindo com uma análise de outros trabalhos que abordam este assunto.

O capítulo 4 apresenta as Redes de Serviços Sobrepostos e seus benefícios; também é descrito a arquitetura Oversea (Scalable and Effective Architecture for Overlay Networks) (UCHOA et al., 2007b) e a Plataforma de Gerência de Vídeo (UCHOA et al., 2007a) desenvolvida no LARC, as quais são utilizadas na implementação do protótipo do serviço de adaptação proposto neste trabalho.

A visão geral do serviço de adaptação proposto e principal contribuição deste trabalho, são apresentados no capítulo 5, juntamente com a descrição dos elementos que compõem o serviço. A avaliação deste serviço é discutido no capítulo 6 através de um conjunto de testes realizados no protótipo implementado. Ao final, no capítulo 7 , é realizada uma conclusão deste trabalho, na qual são destacandas as principais contribuições alcançadas através do seu desenvolvimento e sugestões para trabalhos futuros. 


\section{Adaptação de vídeo}

Como já foi mencionado, a adaptação de vídeo é parte fundamental para que seja possível aumentar a qualidade dos serviços de distribuição de vídeo, atendendo as necessidades dos usuários em contextos específicos. Por este motivo, neste capítulo é feito um levantamento do estado da arte da área de adaptação de vídeo. É apresentado também uma taxonomia das operações de adaptação de vídeo, seguido de uma revisão dos parâmetros de codificação que podem ser alterados por estas operações. Finalizando o capítulo é feito uma breve descrição da principal padronização desta área, o MPEG-21 DIA.

\subsection{Introdução}

A adaptação de vídeo potencializa o uso de aplicações multimídia viabilizando o acesso de seus conteúdos em diversos contextos. Embora seja frequentemente associada apenas à adaptação de nível de sinal do vídeo (seção 2.2), esta abrange também outras questões, como a semântica da mídia e seu contexto.

Nos últimos anos, muitos trabalhos de pesquisa tem tido como foco este tema, sugerindo classificações e levantando os principais requisitos para sua caracterização, como será mostrado a seguir.

\subsection{Estado da Arte}

Como mencionado anteriormente, vários desafios surgem na especificação e elaboração de um serviço eficiente e escalável de distribuição de vídeo digital de forma adaptável. Chang e Vetro destacam estes principais desafios, agrupados a seguir de acordo com as finalidades destes em um sistema (CHANG; VETRO, 2005; VETRO; TIMMERER, 2005): 
Qualidade de Experiência (QoE) - Para melhorar a qualidade de experiência (QoE) do usuário no consumo de um determinado conteúdo, são necessários mecanismos para adaptar a mídia e métricas para avaliar a satisfação do usuário no seu consumo. Podemos elencar como desafios nesta área:

- Adaptação de nível de sinal - Processo no qual é gerado um novo fluxo de vídeo mais adequado ao uso para aquele determinado contexto, através de mudanças nos parâmetros de codificação (seção 2.4). Estas operações podem ser realizadas através de transcodificação ou seleção de camadas (quando são usados codecs escaláveis). Apesar desta área ser explorada a bastante tempo, ainda existem diversos desafios e recentes inovações. Exemplos: (i) a otimização das técnicas de transcodificação, reduzindo o custo computacional por meio da reutilização das operações de predição dos vetores de movimento (XIN; LIN; SUN, 2005); (ii) aprimoramento dos mecanismos de adaptação para vídeos escaláveis para aumentar a eficiência de compactação como mostram os testes realizados por $\mathrm{Li}$, nestes o MPEG-FGS (Fine-Grained Scalable) (RADHA; SCHAAR; CHEN, 2001) gera um fluxo de vídeo com um volume de dados $29 \%$ maior que o MPEG-4 sem escalabilidade (LI; LIU, 2003); (iii) adaptação baseadas em transformações por BSD (Bitstream Syntax Description) (VETRO, 2004) e (iv) acessibilidade para deficientes visuais (NAM et al., 2005; RO; YANG, 2004).

- Conversão de modalidade - Além da necessidade de ajustar os parâmetros de codificação do vídeo, como resolução e taxa de transmissão, para atender as condições de acesso ao conteúdo, em alguns casos, pode ser desejável mudar a forma como o conteúdo é apresentado, alterando o formato do arquivo ou fluxo de vídeo. Diversos cenários poderiam ser beneficiados com tal adaptação, em que um conteúdo em vídeo pode ser convertido para uma apresentação sequencial de alguns quadros do vídeo sincronizados com o áudio.

- Condensação Temporal Drástica - Aumento expressivo da velocidade de exibição do vídeo (Rapid Fast-Forward ou video skimming). Apesar de aparentemente ser uma tarefa simples, tal operação em vídeo digital pode ser muito complexa, pois aumentar a taxa de exibição implica em um consumo maior tanto da capacidade de processamento para decodificar o vídeo como também da largura de banda necessária para acessar o fluxo. Em casos onde o fator de condensação é muito elevado, os requisitos de recursos computacionais podem ser extremamente ele- 
vados, sendo necessários mecanismos capazes de fazer uma subamostragem da mídia original, antes desta ser transmitida.

- Resolução de ambiguidades na especificação de operações de adaptação - Em alguns casos, a definição de uma determinada operação de adaptação de vídeo por meio de uma ferramenta, pode ter uma interpretação dúbia, ex: "descartar $10 \%$ dos coeficientes de quantização". Esta definição não especifica exatamente quais coeficientes devem ser descartados, que dependendo da implementação, pode ser executada de forma diferente, não apresentando o resultado esperado. Para tratar esta questão, são identificadas por Chang algumas estratégias, como a utilização de transformações baseadas em camadas de vídeos escaláveis (CHANG; VETRO, 2005).

- Definição de Medidas de Satisfação do Usuário - As medidas convencionais como PSNR (Peak Signal-to-Noise Ratio) não são adequadas para identificar a satisfação do usuário, pois para mensurar a satisfação do usuário, é necessário também considerar fatores perceptuais e semânticos. Uma possível abordagem é utilizar as preferências do usuário combinadas com medidas objetivas e informações semânticas relacionadas ao conteúdo, visto que o tipo de conteúdo - filme, matéria jornalística, evento esportivo - implica em diferentes expectativas de qualidade por parte do usuário (CHANG; VETRO, 2005).

- Relação entre Satisfação do Usuário, Adaptação e Recursos - Outro grande desafio é a identificação de qual adaptação é mais adequada para alcançar a satisfação do usuário através dos recursos disponíveis. Para isso, é necessário criar modelos capazes de analisar as características da mídia, as restrições do ambiente, as preferências do usuário e informações semânticas do conteúdo; identificar se deve ser realizada alguma adaptação, e a partir dos modelos de satisfação do usuário, escolher qual adaptação deve ser realizada mediante os recursos computacionais disponíveis para efetuar tais operações (CHANG; VETRO, 2005).

Integração de Sistemas - Para viabilizar a utilização da adaptação de vídeo em CDNs, é essencial que os mecanismos de adaptação estejam integrados com estes sistemas. Algumas questões críticas nesta área são: 
- Transporte e Negociação de Descritores - Para que a adaptação seja realizada de forma esperada, é essencial que os descritores que definem como a adaptação deve ser feita, sejam transmitidos e negociados corretamente entre todos os elementos envolvidos. Melhorias realizadas no MPEG-2 Systems (MACINNIS, 1994) permitem que descritores do MPEG-21 DIA (ISO/IEC 21000-7, 2004) sejam transmitidos juntamente com os demais metadados. Além disso, outros protocolos, como RTSP (Real Time Streaming Protocol), também podem fazer uso destes descritores. Contudo, ainda são necessários esforços para promover formas de compatibilizar tais sistemas.

- Arquiteturas Fim-a-Fim Integradas - O desenvolvimento de arquiteturas fim-a-fim que integrem os diversos serviços envolvidos na distribuição do conteúdo é crucial para que um sistema possa se beneficiar de mecanismos de adaptação de forma otimizada e efetiva. Estas precisam ser capazes de gerenciar as mídias e preferências dos usuários, monitorar o estado dos elementos envolvidos na transmissão e adaptação do conteúdo, e utilizando essas informações, serem capazes de relacioná-las e tomar decisões de como tratar a mídia de forma a maximizar a satisfação do usuário, considerando os aspectos de segurança e otimização no uso dos recursos da rede.

Segurança - A adaptação de vídeo também pode ser útil para tratar de questões de segurança de acesso aos conteúdos. Considera-se os seguintes desafios:

- Direitos - A preservação de direitos (rights) autorais e de acesso é um ponto crítico para CDNs. Estes podem oferecer diversos tipos de serviços, disponibilizando conteúdos diferenciados aos seus usuários. Ex: utilizar serviços de adaptação para reduzir a resolução espacial do vídeo para garantir que apenas os usuário de um serviço "premium" assistam os conteúdos em alta definição, enquanto os demais usuário somente em resolução padrão. Para expressar estes direitos podem ser usados a Rights Expression Language - REL e Rights Data Dictionary - RDD (WANG et al., 2005). Entretanto ainda existem diversos desafios na sua utilização, como a relação entre as definições de direitos e os parâmetros de codificação que devem ser utilizados em cada contexto.

- Sigilo - O sigilo de determinados conteúdos é um fator essencial em determinadas situações, como por exemplo no caso de aplicações de telemedicina onde 
exames médicos, devem ser mantidos em sigilo devido a questões éticas. Para casos semelhantes, são necessárias operações de criptografia que satisfaçam estes requisitos. Para tratar questões similares, existem pesquisas com utilização de codecs escaláveis que combinam técnicas de criptografia progressiva (WEE; APOSTOLOPOULOS, 2003). Entretanto, exitem muitos desafios nesta área, como o gerenciamento de chaves em ambientes dinâmicos .

Semântica - A utilização de informações semânticas de um conteúdo é muito importante para que este possa ser localizado de forma eficiente. Além disso, tais informações podem ser exploradas pela aplicação durante o consumo da mídia. Os seguintes aspectos ainda não estão completamente resolvidos:

- Inserção de Metadados Semânticos na Mídia - Adiciona informações semânticas na mídia para serem utilizadas por mecanismos de adaptação. Estas informações devem preferencialmente estar em formatos interoperáveis, como MPEG-7 (CHANG et al., 2001). Entretanto, além da especificação do formato, é fundamental o desenvolvimento de ferramentas de anotação (RYU; SOHN; KIM, 2002) que auxiliem na identificação e marcação destas informações nas mídias.

- Adaptação de Nível Estrutural da Mídia - Utiliza os elementos que formam o fluxo de vídeo para extrair informações, por exemplo: mudanças de cenas para detectar eventos. Tais informações podem ser úteis para as ferramentas de anotação - ferramentas que relacionam metadados à mídia. Além disso, este tipo de adaptação pode ser utilizado para produzir outros tipos de adaptação, exemplo: conversão de modalidade, descrito na seção 2.3.

- Adaptação Baseada em Eventos Semânticos - Adapta o conteúdo conforme o contexto semântico da utilização da mídia, agregando informações relevantes ao conteúdo de acordo com o histórico de uso do sistema ou as preferências do usuário, exemplo: em um evento esportivo, poderia ser exibido um quadro com informações da classificação das equipes ou associar propaganda relacionadas com o assunto do conteúdo. 


\subsection{Taxonomia das Operações de Adaptação de Vídeo}

A adaptação do vídeo pode ser feita de diversas formas de acordo com o contexto no qual o usuário está inserido. A seguir é apresentada uma taxonomia das operações de adaptação utilizadas para prover ao usuário a versão do vídeo mais adequado para o seu consumo (LACHNER et al., 2007).

Transcodificação - É denominada "transcodificação" a operação onde um vídeo codificado em um determinado formato é convertido em um formato diferente. Neste, tipicamente são alterados os parâmetros de codificação resultando em um vídeo mais apropriado para o contexto onde será consumido.

Um caso típico desta operação é a conversão de um vídeo MPEG-2 720x576 (usado em DVDs) em MPEG-4 320×240 (usado no YouTube). Este processo é feito através da decodificação do vídeo, seguido de redução da resolução, finalizando com a recodificação. Tal processo geralmente é usado para reduzir o a taxa de bits do vídeo, permitindo que este seja enviado em um enlace de rede com menor capacidade de transmissão.

Um dos problemas desta operação é o alto custo de processamento (CHANG; VETRO, 2005; KALVA, 2004). No entanto, Vetro identifica diversas pesquisas que reduzem este custo através de métodos de redução de resolução estando ainda o vídeo comprimido, desde que o formato do vídeo original e do vídeo resultante seja mantido (VETRO; CHRISTOPOULOS; SUN, 2003).

Seleção de camadas/Escalar - Esta operação tem sido explorada em diversos trabaIhos na redução da taxa de bits como forma alternativa à transcodificação, pois o custo computacional para a realização desta operação é bem menor, se comparado com a transcodificação. No entanto, só é possível utilizar esta operação em vídeos escaláveis, exemplo: o H.264 SVC (SCHWARZ; MARPE; WIEGAND, 2007).

Os vídeos escaláveis são compostos por uma camada básica, que possui os elementos necessários para decodificação do vídeo em resolução baixa, e camadas adicionais, que 
possuem elementos que associados à camada básica, aumentam a qualidade do vídeo.

Usando esta característica dos vídeos escaláveis, o princípio desta operação é gerar um novo fluxo de vídeo a partir da camada básica ao agregar somente as camadas complementares de interesse a fim de obter a resolução desejada. Entretanto, esta técnica de codificação de vídeo também tem alguns problemas.

Segundo $\mathrm{Li}$, os codecs escaláveis geram um fluxo de vídeo com uma taxa de bits $29 \%$ maior quando comparados à vídeo não escalável na mesma qualidade. Isto ocorre devido a necessidade de inserção de dados adicionais (ex: para sincronismo das camadas) em cada camada complementar, incorrendo em overhead, e consequentemente em uma maior penalidade de banda (LI; LIU, 2003).

Outro problema é que os tipos de adaptação possíveis para um fluxo de vídeo escalável é limitado pela quantidade de camadas adicionais, restringindo assim os cenários em que apenas este modelo de operação é suficiente para atender as necessidades de adaptação. Além disso, ainda são poucas as implementação destes codecs, de forma que poucos clientes sejam compatíveis com esses fluxos.

Remoção e Mesclagem - Diferentemente das operações "Transcodificação" e "Seleção de camadas", estas operações não atuam na adaptação de nível de sinal, mas na estrutura da mídia. Basicamente, estas operações podem remover faixas de áudio adicionais ou multiplexar um fluxo de vídeo a outro de áudio.

Sumarização e Conversão de Modalidade - Estas operações resultam em conteúdos alternativos à mídia original. Tipicamente, a sumarização extrai quadros do vídeo e apresenta como uma sequência de imagens ao passo que a conversão de modalidade pode converter um texto em voz sintetizada (text-to-speech). 


\subsection{Parâmetros de Codificação}

Os parâmetros de codificação do vídeo, alterados pelas operações de adaptação, impactam diretamente tanto na qualidade do vídeo como no volume de dados e nos requisitos computacionais para exibi-los. Estes parâmetros estão descritos a seguir:

Resolução Temporal - A resolução temporal é a frequência em que os quadros de um vídeo são exibidos. Para garantir a percepção de movimento em um vídeo, o valor desta taxa varia entre 24 à 30 quadros por segundo conforme o ambiente de exibição (ex: sala de cinema, TV, DVD). No entanto, vídeos de baixa definição podem apresentar taxas mais baixas, 15 quadros por segundo, enquanto os vídeos de alta definição (HDTV) podem ser codificados em taxas mais altas, de até 60 quadros por segundo. A figura 1 exemplifica 0 resultado de uma operação de adaptação de vídeo onde é reduzido a resolução temporal.

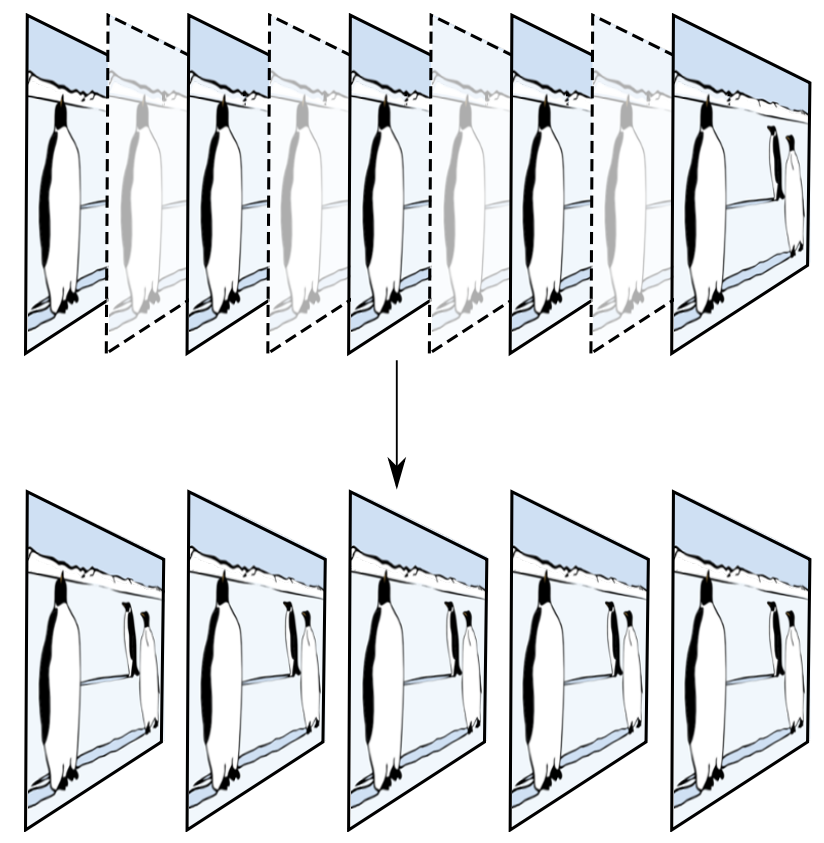

Figura 1: Redução da resolução temporal

Resolução Espacial - A resolução espacial é o tamanho em que o vídeo é codificado, medido em pixels. Este parâmetro frequentemente é alterado quando o fluxo é ajustado para terminais com uma tela de tamanho reduzido, ou quando existem restrições na largura da banda da rede. A figura 2 mostra um exemplo da alteração deste parâmetro. 


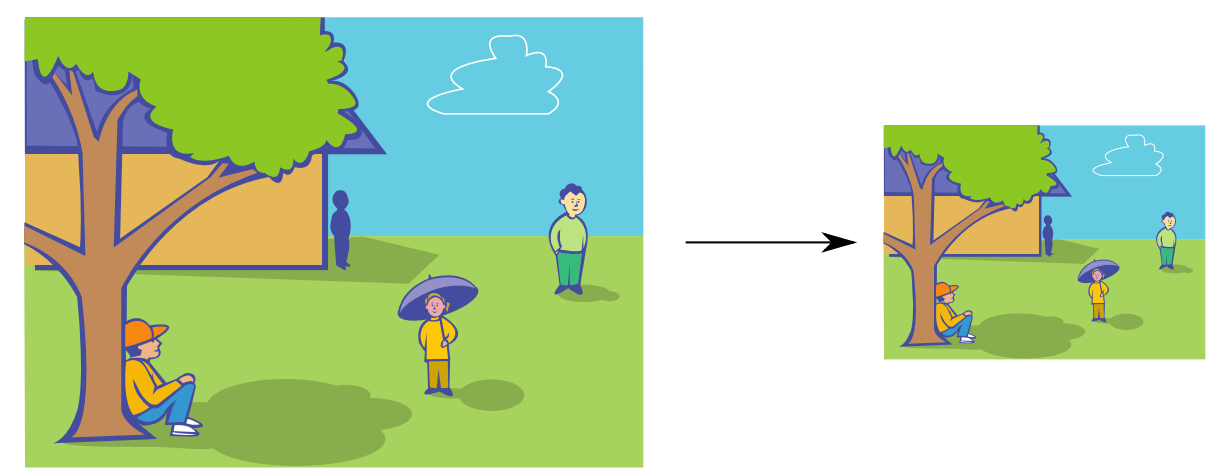

Figura 2: Redução da resolução espacial

Precisão - A precisão está relacionada ao processo de quantização dos coeficientes obtidos pela DCT (Discrete Cosin Trasformation) aplicada sobre os quadros (frames) do vídeo. Estes coeficientes são divididos por um "fator de quantização" e a alteração deste fator de quantização, pode ser medida pela taxa de sinal/ruído (Signal to Noise Ratio $S N R$ ). A figura 5 mostra a imagem "Lena" quantizada com fatores diferentes.

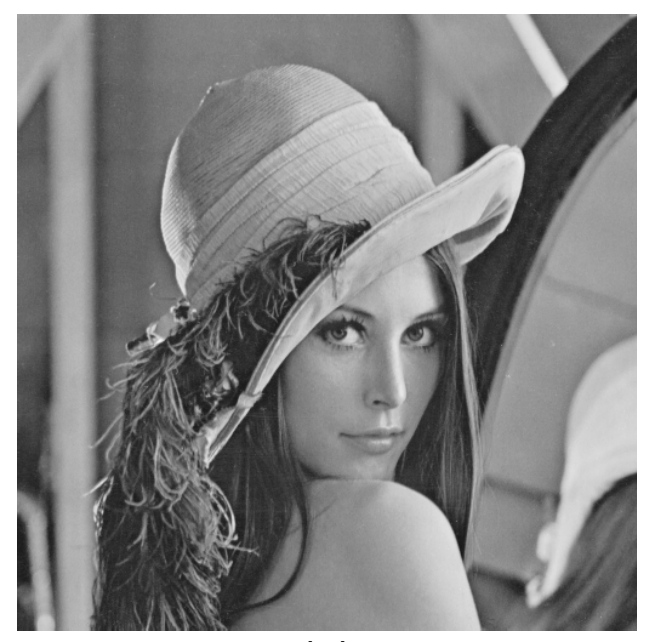

(a)

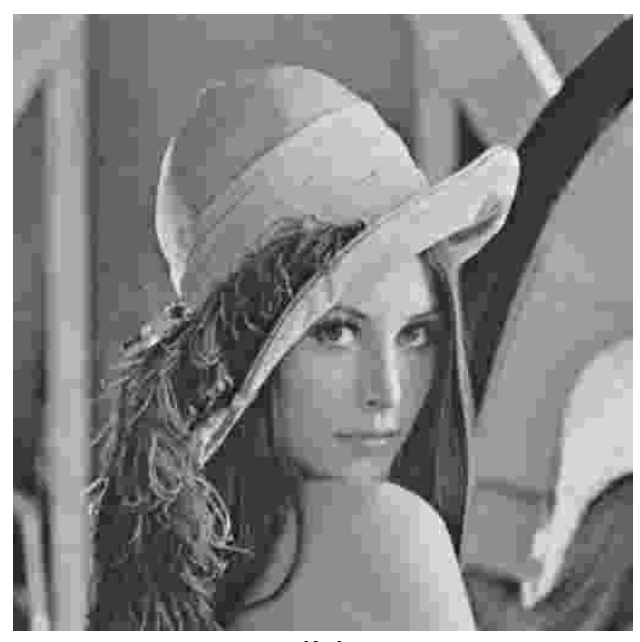

(b)

Figura 3: Redução da precisão da imagem "Lena" (adaptado de (YOUSSEF, 2010))

Grupo de Imagens (Group of Pictures - GOP) - Uma das técnicas da compressão de vídeo digital mais utilizada atualmente (MPEG-1, MPEG-2, MPEG-4 e H.26x) é a Compensação do Movimento (Motion Compensation - MC) que cria um grupo de imagens (Group of Pictures - GOP) removendo a redundância de informação entre essas. O GOP é formado por três tipos de imagens/quadros: (i) os quadros I (Intra coded) contém todos os dados de uma imagem, podendo ser exibido independentemente de outros quadros; (ii) os quadros $\mathrm{P}$ (Predicted) codificados referenciando informações de quadros I ou P 
anteriores; (iii) os quadros B (Bi-directional predicted) codificados a partir de dois outros quadros, anterior e posterior.

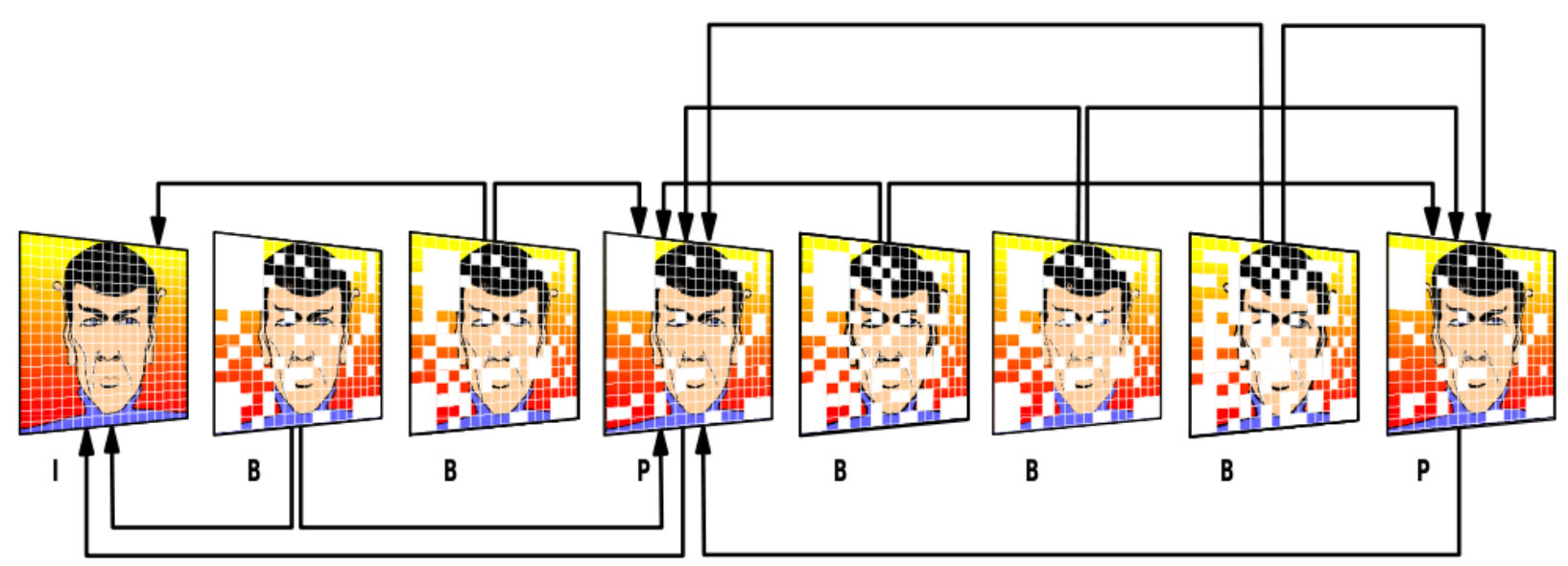

Figura 4: Grupo de Imagens (Group of Pictures - GOP) (adaptado de (HLAVác, 2010))

Esta técnica permite aumentar significativamente a taxa de compressão do vídeo, mas também aumenta a complexidade da codificação, consequentemente eleva os requisitos computacionais para codificar e decodificar o vídeo. Em casos onde o dispositivo de exibição tem recursos limitados, normalmente o vídeo é codificados apenas com quadros I e P, reduzindo assim a memória necessária para decodifica-lo.

Amostragem de Cores (Color Sampling) - A amostragem das cores é a relação entre os componentes de crominância e a luminância do vídeo. A maioria dos contexto utilizam a relação 4:2:0, amostragens diferentes são usada apenas em contextos como estúdios, HDTV e nos novos padrões de cinema digital (2K e 4K).

Cores - A adaptação deste parâmetro é utilizada com pouca frequência, mas que pode ser usada para tratar questões como a acessibilidade para deficientes visuais. Esta é uma área com diversas pesquisas nas quais são necessários trabalhos interdisciplinares (NAM et al., 2005) e (RO; YANG, 2004). A figura 6 mostra um exemplo de adaptação realizado nestes trabalhos com pacientes com sintomas de "perda de detalhes fino" (Ioss of fine detail), em que são alterados o contraste da imagem. 
$4: 4: 4$

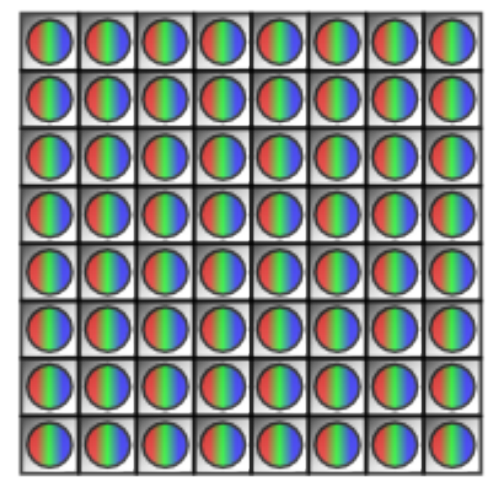

$4: 2: 2$

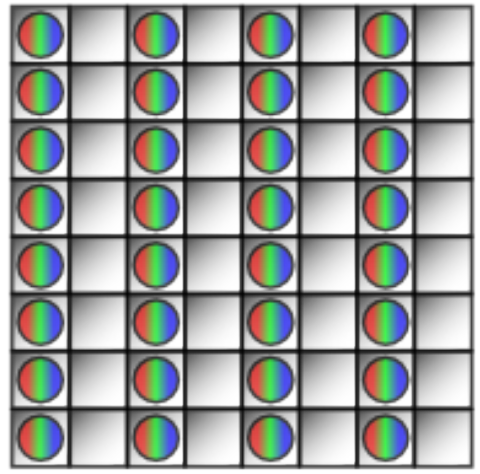

$4: 2: 0$

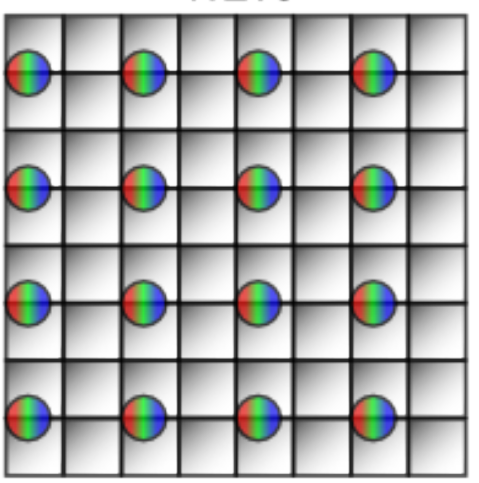

\section{Legenda}

1 pixel - usado na amostragem da luminância ' $Y$ '

$1+1$ pixel - usado na amostragem da crominância ' $\mathrm{Cb}^{\prime}+{ }^{\prime} \mathrm{Cr}$ '

Figura 5: Amostragem de cores 4:4:4, 4:2:2, 4:1:1 e 4:2:0 (adaptado de (MUNSIL; SPEARS, 2003))

\subsection{MPEG-21 DIA - Digial Item Adaptation}

Diversos padrões foram desenvolvidos nos últimos anos para a área de vídeo digital, dentre eles podemos citar como os mais relevantes os padrões desenvolvidos pelo MPEG (Motion Picture Expert Group) da ISO (International Organization for Standardization) (MPEG-1, MPEG-2, MPEG-4, MPEG-7 (CHANG et al., 2001) e MPEG-21(BURNETT et al., 2003)); o RDF (Resource Description Framework) e o CC/PP (Composite Capabilities/Preference Profiles)(KLYNE et al., 2004) do World Wide Web Consortium (W3C) e o TV-Anytime (KLYNE et al., 2004). Dentre estes, o MPEG-21 apresenta o "Big Pic- 


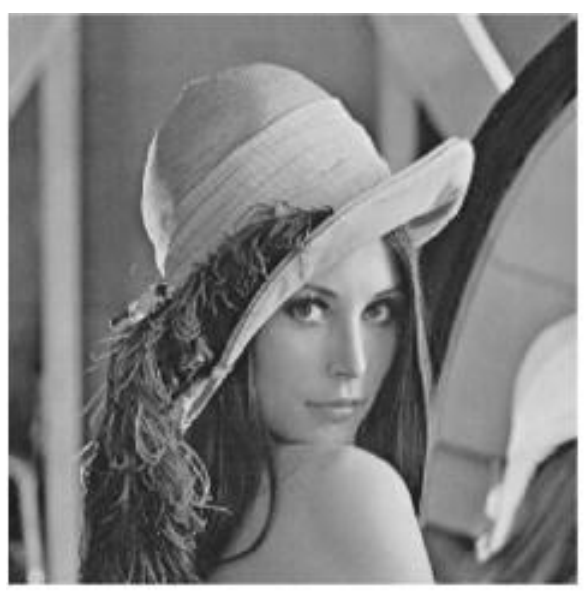

(a)

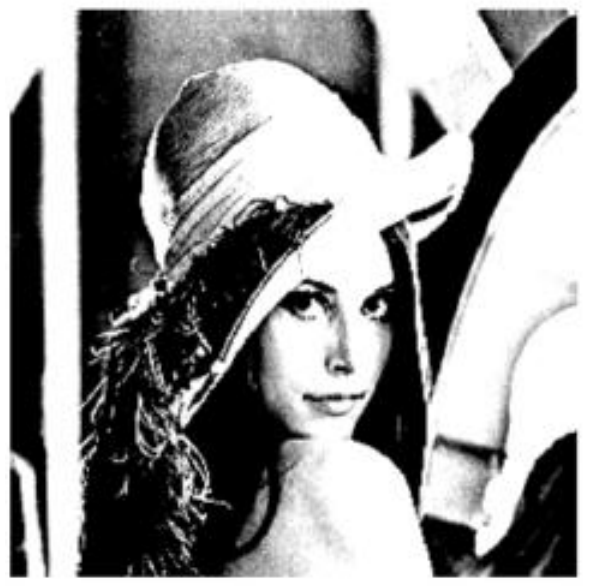

(c)

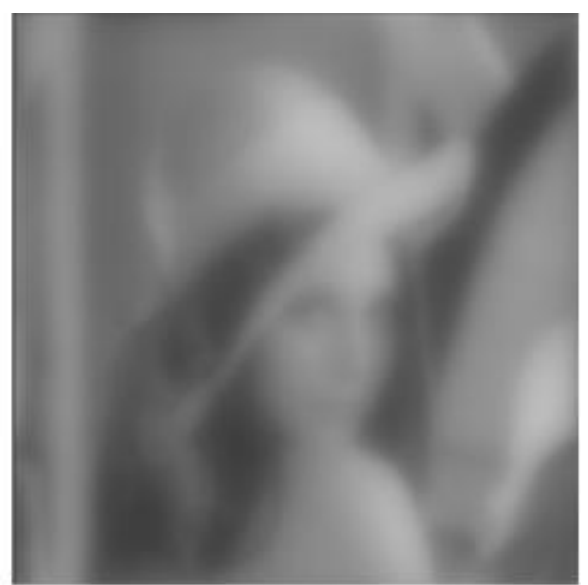

(b)

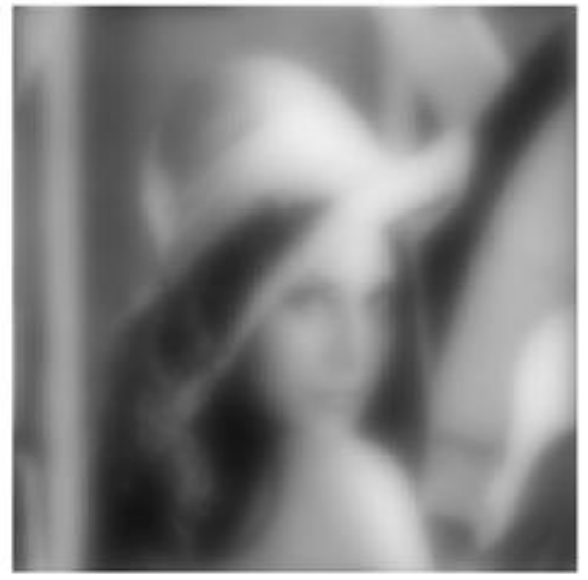

(d)

Figura 6: (a) imagem original; (b) simulação da deficiência; (c) imagem adaptada; (d) simulação da deficiência na imagem adaptada (adaptado de: (NAM et al., 2005))

ture" de como todos os elementos envolvidos na produção, distribuição e consumo do conteúdo multimídia se relacionam (ASADI, 2005), definindo um arcabouço que abrange todos estes elementos. Este padrão é dividido em 17 partes, sendo que o MPEG-21 DIA (Digial Item Adaptation) trata do processo de adaptação (ASADI, 2005).

A especificação do MPEG-21 DIA define um conjunto de ferramentas a serem utilizadas pelas engines de adaptação para realizá-la de acordo com as condições do contexto em que o usuário está inserido. Para isso, especifica os descritores que dão suporte as operações de adaptação, de forma que as aplicações sejam interoperáveis tanto entre si, como também com as diversas implementações de adaptação. A figura 7 mostra visão geral do MPEG-21 DIA. 


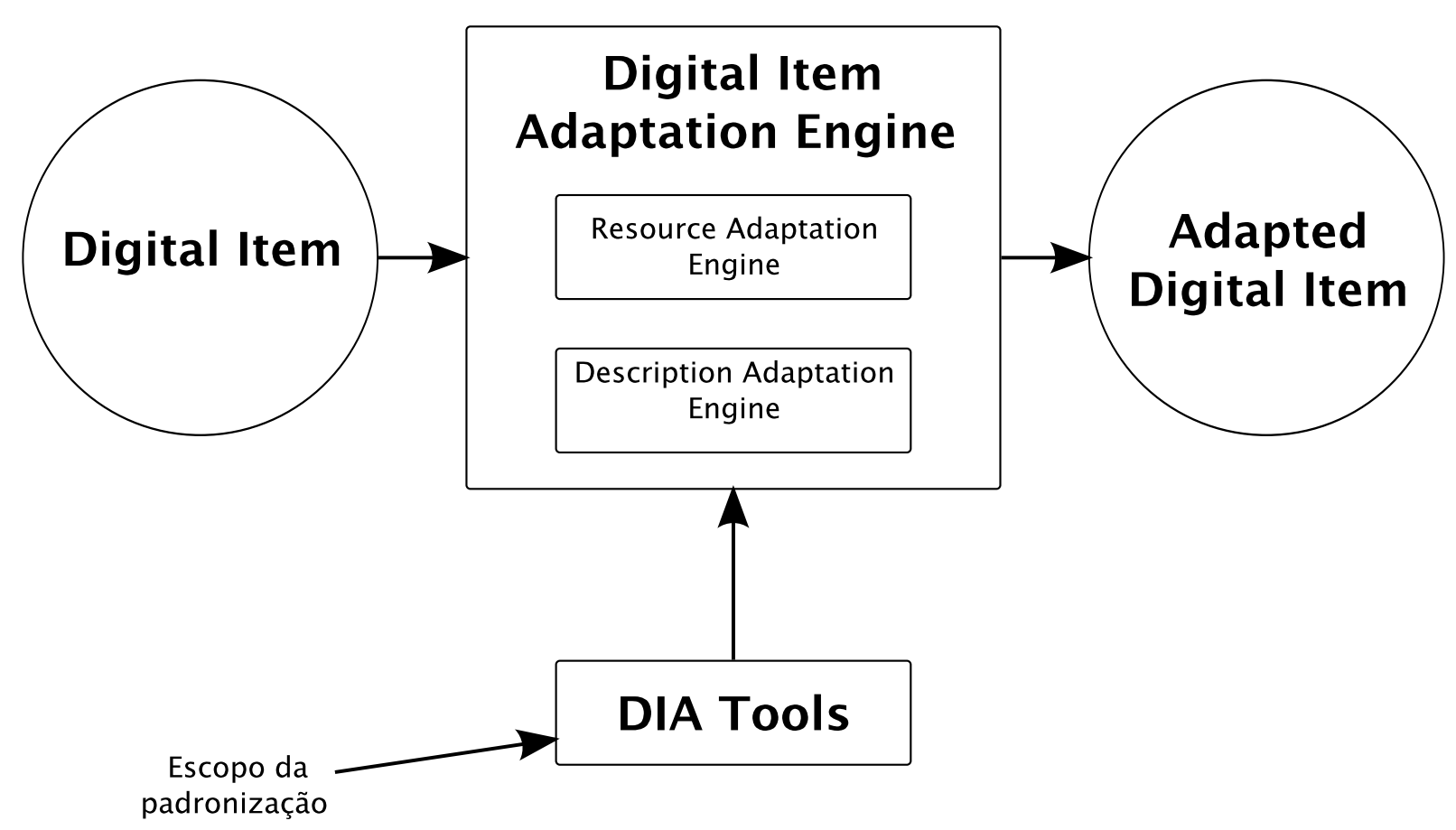

Figura 7: Visão geral do MPEG-21 DIA (adaptado de: (ISO/IEC 21000-7, 2004))

O MPEG-21 DIA é subdivido em oito categorias que podem ser utilizadas independentemente, indicadas a seguir e ilustradas na figura 8.

Usage Environment Description (UED) - A maior categoria do MPEG-21 DIA, descreve o ambiente onde a mídia será consumida. Sendo assim, define um conjunto de metadados que descrevem as capacidades e restrições da rede, do terminal de acesso, do usuário e do ambiente de utilização.

Bitstream Syntax Description Link (BSDLink) - O BSDLink permite relacionar as informações do contexto de utilização da mídia (UED) com os parâmetros de qualidade de serviço (AdaptationQoS) de forma que as (engines) de adaptação podem aplicar operações de adaptação na mídia de maneira dirigida utilizando as informações que descrevem o fluxo da mídia $(B S D)$. 


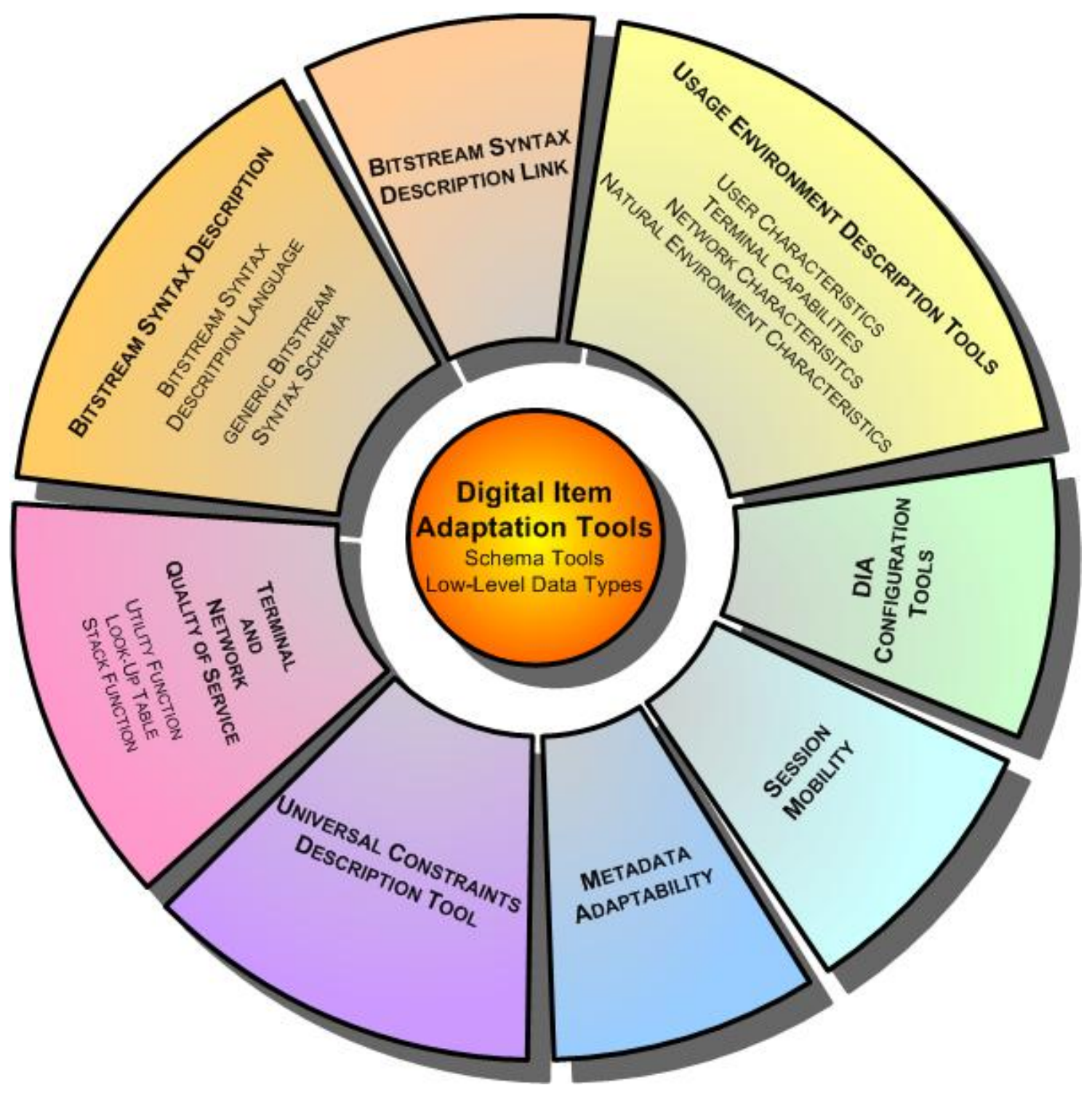

Figura 8: Ferramentas do MPEG-21 DIA (adaptado de: (ISO/IEC 21000-7, 2004))

BSD (Bitstream Syntax Description) - Esta categoria descreve o fluxo de dados da mídia (bitstream) em uma estrutura de alto nível utilizada pelas (engines) de adaptação de forma conjunta com o (BSDLink).

Terminal and Network Quality of Service (AdaptationQoS)- A quarta categoria do MPEG-21, define as relações entre restrições e limitações de qualidade (ex: larbura de banda, resolução da tela do terminal de acesso) e as operações de adaptação necessárias para adequar a mídia a essas restrições. Consequentemente, permite definir o trade-off entre a qualidade do vídeo e as condições pelas quais este está sendo assistido. 
Universal Constraints Description (UCD) - O UCD permite descrever os limites e restrições de otimização para a realização da adaptação. Esta ferramenta pode ser utilizada de forma conjunta com o UED e o AdaptationQoS para definir qual adaptação deve ser aplicada em cada contextos.

Metadata Adaptability (MA) - Na sexta categoria são definidos descritores utilizados como dicas para reduzir a complexidade na adaptação dos metadados da mídia.

Session Mobility (SM) - O Session Mobility especifica as informações do estado de uma sessão de consumo da mídia em um dispositivo possibilitando ao usuário migrar para outro dispositivo de forma adaptada.

DIA Configuration (DIAC) - Por último, a oitava categoria, provê um conjunto de descritores utilizados como sugestão para a escolha da adaptação e como as engines de adaptação podem aplicá-las.

Após esta revisão das técnicas de codificação de vídeo e o padrão MPEG-21, que dá suporte à adaptação, veremos em maiores detalhes como é possível otimizar uma CND, quais as estratégias de adaptação que podem ser utilizadas, assim como impactos de sua utilização. Serão mostrados e analisados também os trabalhos correlatos nesta área. 


\section{Adaptação de Vídeo em CDNs}

Conforme visto na seção 2.2, a adaptação de vídeo pode ser explorada em diversos contextos e possuí diversos desafios a serem tratados. Dentre estes desafios, este trabalho atua na elaboração de um serviço capaz de integrar a adaptação de vídeo à uma CDN de forma eficiente.

A integração de um serviço de adaptação neste cenário apresenta alguns obstáculos causados pelo impacto da adaptação de vídeo nas técnicas de otimização imprescindíveis a essas aplicações. A seguir é descrito como estas técnicas de otimização atuam nas CDN; os fatores deste contexto que demandam por um serviço de adaptação de vídeo e como este serviço de adaptação pode afetar as técnicas de otimização.

\subsection{Técnicas de Otimização de CDNs}

As CDNs são sistemas computacionais construídos para aumentar a disponibilidade das mídias distribuídas por provedores de conteúdo, para isso, explora algumas técnicas de otimização descritas a seguir:

Cache - Esta técnica é usada nas CDNs para prover serviços como o de "Vídeo sob Demanda" (Video on Demand - VoD) de forma escalável. Basicamente, consiste em distribuir servidores geograficamente, de forma que cada um dos servidores possa atender um conjunto de usuários que estejam nas proximidades, sendo que todos os servidores estão conectados ao servidor principal (ou fonte). Desta maneira, os servidores terão réplicas do conteúdo para que possam atender de forma eficiente as solicitações provenientes daquela região. Os usuários do serviço de distribuição de vídeo serão direcionados para o servidor geograficamente mais próximo (CRANOR et al., 2001). A replicação do conteúdo nos servidores pode ser feita sob demanda (pull-based) ou préagenda (push-based). Os principais benefícios desta técnica são: (i) minimizar o número de acessos ao servidor fonte, (ii) reduzir o tráfego na rede e (iii) diminuir a latência de acesso ao conteúdo para o usuário. 
Multicast - A técnica multicast é utilizada para prover serviços como o "Vídeo ao Vivo" (Live Streaming). O conceito por traz desta técnica é construir uma estrutura de entrega em árvore pela qual os dados são repassados aos usuários que acessam o conteúdo de forma a evitar o envio redundante do fluxo de vídeo pelos enlaces. A principal diferença entre as técnicas de cache e multicast é que no cache cada usuário recebe o fluxo de vídeo a partir do início do vídeo, enquanto no multicast, o usuário começa a receber o fluxo a partir do instante em que ele solicita ao servidor sua entrada no grupo multicast, e passa a receber o fluxo atual de exibição do vídeo, perdendo o que já foi transmitido. Apesar de haver uma implementação desta técnica de forma nativa na camada IP (IP Multicast), por razões tanto técnicas como mercadológicas, normalmente as CDNs utilizam implementações em redes sobrepostas (Overlay Networks) (LAO et al., 2005), conforme discutido no capítulo 4.

\subsection{Demandas por Adaptação de Vídeo}

Embora o uso das técnicas de cache e multicast possam melhorar o acesso ao vídeo pelo usuário, outros fatores podem prejudicar o seu consumo. O primeiro fator está relacionado com uma das características inerentes ao vídeo digital, que tanto o volume de dados como o custo computacional para a exibição do vídeo podem variar conforme os parâmetros utilizados na sua codificação, já que estamos considerando aqui um cenário onde os usuários podem acessar os conteúdos através de terminais com características distintas, como dispositivos móveis: palmtops, ipads, celulares e smartphones. Além disso, os elementos que compõem as CDNs (servidores, roteadores, switchs e enlaces de rede), devido aos estados de carga distintos, apresentam diferentes taxas de latência e perda de pacotes. Tal situação impacta diretamente no QoE do usuário, podendo algumas vezes não atender as suas expectativas.

Para contornar estes problemas é necessário que as CDNs implementem mecanismos para realizar a adaptação do vídeo considerando as diversas restrições que podem impactar no acesso e consumo dos vídeos (KROPFBERGER, 2004; VETRO; TIMMERER, 2005). Estas características, descritas a seguir, são mapeadas nos descritores do MPEG21 DIA, pertencentes à categoria UED. 
Características da Rede - As características da rede podem ser classificadas em duas categorias: capacidades e condições.

- Capacidades da rede - características que tem um perfil de estado estático, e normalmente descrevem as capacidades máximas da rede, como: largura máxima de banda e a largura mínima garantida. Estas informações precisam ser verificas apenas no processo de estabelecimento da sessão de consumo da mídia, não sendo necessária a monitoração do seu estado durante a sessão.

- Condições da rede - características que tem um perfil de estado dinâmico, como: largura de banda disponível, taxa de perda de pacotes, atraso, variação de atraso. Estas características tendem a alterar seu estado durante a sessão de conexão, sendo recomendado a monitoração enquanto esta estiver ativa.

Características do Terminal - O dispositivo pelo qual o usuário consome a mídia é denominado "Terminal". Este pode ser: computador pessoal, setop-box, PDAs, celulares, smartphones, etc. Entre as características que influenciam na adaptação podemos citar:

- Codecs suportados - Além de especificar os diferentes tipos de codecs (ex: MPEG1, MPEG-2, MPEG-4), é importante discriminar quais as configurações dos parâmetros de codificação que são suportadas para cada codec. Normalmente, dispositivos móveis suportam um conjunto mais restrito de configuraççoes dos parâmetros devido à capacidade limitada de processamento e memória.

- Características de Entrada e Saída (Input-Output) - São os recursos de reprodução de vídeo do dispositivo do usuário: resolução, frequência de atualização (em frames por segundo), profundidade de cores.

- Capacidades do Dispositivo - Características como: capacidade de processamento, memória, consumo de energia e capacidade da bateria.

Características do Usuário - Estas características descrevem o perfil do usuário, tanto suas preferências como suas restrições. 
- Preferências de Apresentação - características que descrevem as preferências do usuário de como o vídeo deve ser exibido, que podem estar relacionadas ao terminal pelo qual o usuário está consumindo a mídia, podendo haver um conjunto de preferências de apresentação para cada terminal pelo qual ele pode interagir com o sistema.

- Características de Acessibilidade - estas características, diferentemente das "preferências de apresentação", descrevem restrições de apresentação que o usuário possui devido a deficiências audiovisuais. A utilização destas características pode ser usada para garantir maior compreensão do conteúdo através da adaptação do vídeo para compensar problemas visuais, como o daltonismo (RO; YANG, 2004), (NAM et al., 2005).

- Características de localização - as características de localização são agrupadas em duas categorias. (i) mobilidade, que descreve o perfil de movimento do usuário ao longo do tempo, sendo possível após algumas medições, classificar o usuário em perfis como: sem mobilidade, mobilidade em baixa velocidade (pedestre), mobilidade em alta velocidade - em veículos - (ii) destino, que descreve para onde o usuário está indo, podendo verificar possíveis rotas pelo qual pode passar e quais serviços estão disponíveis nestes lugares (VETRO, 2004). Estas características podem ser utilizadas em técnicas para definir, por exemplo, a necessidade do uso de correção de erros (forward error correction - FEC) (KROPFBERGER, 2004) ou maior buffer no cliente.

Características Naturais do Ambiente - As características naturais do ambiente descrevem o meio onde o usuário se encontra, sendo utilizadas tanto como parâmetros para a busca de conteúdo, como para adaptar a apresentação do conteúdo. Entretanto, estes ajustes normalmente são realizados pelo próprio terminal do usuário, adequando, por exemplo, o brilho da tela e o volume do som conforme a luminosidade do ambiente e o ruído do local.

Segurança - Outro fator que, em alguns contextos, pode implicar na necessidade de adaptação é o tratamento de questões de segurança (preservação de direitos de acesso e sigilo)(VETRO; TIMMERER, 2005; PEREIRA; BURNETT, 2003). Para estes casos, a restrição quanto à qualidade de acesso à mídia pode não estar relacionada às condições 
da rede, mas à necessidade de garantir que determinados conteúdos ou níveis de maior qualidade sejam acessíveis apenas para um grupo de usuários - ex: assinantes de um serviço. Além disso, funcionalidades de segurança como sigilo, por exemplo, podem ser necessárias para aplicações médicas ou sistemas de segurança patrimonial.

\subsection{Impactos da Adaptação de Vídeo}

Os diversos fatores citados ocorrem em muitas situações nas quais o uso de serviços de adaptação pode beneficiar tanto os usuários, por melhorar o QoE no consumo da mídia, como provedores de conteúdo, por expandir o número de possíveis usuários atendidos por seus serviços. No entanto, estas operações também podem causar impactos negativos na infraestrutura, devendo ser considerados na elaboração de um serviço de adaptação de vídeo. Os principais impactos são indicados a seguir:

Custo Computacional - As operações de adaptação de vídeo, principalmente a transcodificação, envolvem muitas operações matemáticas. Além disso, como a mídia de vídeo representa uma grande massa de dados, o volume dessas operações também é grande.

Volume de Dados Armazenados - Outro fator em que a adaptação de vídeo pode impactar negativamente em serviços de vídeo sob demanda, é o volume de dados armazenados nos servidores, podendo afetar tanto o servidor fonte, como os servidores de cache. Este problema se torna mais evidente à medida que são diponibilizadas mais versões do vídeo, pois para cada versão adaptada do vídeo é necessário armazenar uma cópia no servidor fonte, sendo replicadas também nos servidores cache.

Múltiplos Fluxos - O terceiro problema em que incorre devido a adaptação de vídeo é a necessidade de suportar a coexistência de múltiplos fluxos do mesmo vídeo mas em versões diferentes. Este fato afeta tanto a técnica de cache como a de multicast, que em vez de transmitir apenas um fluxo de vídeo por conteúdo, transmite as diversas versões adaptadas do mesmo. 


\subsection{Estratégias de Adaptação de Vídeo}

As operações de adaptação realizadas para atender a estes requisitos podem ser realizadas de diversas forma, variando tanto a localização onde é feita, como quando é executada, conforme a classificação a seguir.

Classificação Espacial - Em relação ao fator espacial, a adaptação pode ser classificada como centralizada ou distribuída. Uma classificação análoga a esta é apresentada em (MA et al., 1999), nomeadas como server based e proxy based, respectivamente.

- Centralizada / Server Based - Neste modo de operação, a adaptação é feita apenas no servidor primário do vídeo, ou em um elemento próximo a este.

- Distribuída / Proxy Based - Neste modo, a adaptação é feita em elementos distribuídos pela rede posicionados próximo ao cliente.

Classificação Temporal - Quanto ao fator temporal, a adaptação pode ser classificada como síncrona ou assíncrona. Smith sugere uma classificação onde os fatores temporais são identificados como on-the-fly e adaptive delivery (SMITH; MOHAN; LI, 1999).

- Assíncrona / Adaptive Delivery - Na forma assíncrona, as operações de adaptação são realizadas independentemente das solicitações, em um processo agendado, no qual são geradas diversas versões do vídeo, com parâmetros de codificação diferentes e armazenadas em um repositório. No instante da solicitação do vídeo, é feita apenas uma seleção da versão disponível mais adequada para cada cliente e então transmitida.

- Síncrona / On-the-fly - Na forma síncrona, as operações de adaptação são realizadas no instante da transmissão, não sendo necessário manter no repositório diversas versões do mesmo vídeo.

Usando estas classificações, podem ser definidas as seguintes estratégias para a inclusão de um serviço de adaptação em uma rede de distribuição de vídeo: 
Centralizada e Assíncrona - Nesta estratégia, é gerada uma versão do vídeo para cada tipo de adaptação previsto e armazenada em servidores centrais para depois serem transmitidas conforme solicitado. Tal solução, apesar de ter um custo de processamento reduzido, aumenta o volume de dados a serem armazenados além de minimizar os benefícios das técnicas de cache. Além disso, para disponibilizar outros tipos de adaptação, é necessário gerar novas versões de cada vídeo, não sendo possível utilizar esta estratégia em serviços de "Vídeo ao Vivo".

Centralizada e Síncrona - Esta estratégia se diferencia da estratégia anterior por executar as operações de adaptação de acordo com as requisições. O benefício desta estratégia, além de minimizar o custo de armazenamento, é que flexibiliza os tipos de adaptações que podem ser providas, sendo possível utilizá-las para serviços de "Vídeo ao Vivo". Apesar disso, por ser executada de forma centralizada, também minimiza os benefícios das técnicas de cache nos serviços de "Vídeo sob Demanda", e multicast para serviços de "Vídeo ao Vivo". Ademais, apresenta um custo de processamento elevado conforme as operações utilizadas para realizar a adaptação, principalmente em casos de transcodificação.

Distribuída e Síncrona - De forma oposta às estratégias anteriores, esta foca em minimizar o impacto da adaptação nas técnicas de cache e multicast, pois as operações de adaptação são executadas na borda da rede, em servidores distribuidos próximos aos clientes. Todavia o custo de processamento para realizar as adaptações pode ser elevado dependendo de quais operações são realizadas. As pesquisas atuais (seção 3.5) estão focadas no uso de operações de "Seleção de camadas" para reduzir o custo de processamento da adaptação.

\subsection{Trabalhos relacionados}

Conforme visto, a adaptação de vídeo em contextos como CDNs é de grande importância, assim como a diversidade de desafios na sua aplicação. Estes fatores tem motivado diversos grupos de pesquisa a explorarem as múltiplas facetas desta questão. Dentre 
os esforços mais notáveis, destaca-se o ADMITS (Adaptation in Distributed Multimedia IT Systems), um dos primeiros a tratarem a adaptação de vídeo em um sistema de distribuição de vídeo(BöSZöRMéNYI et al., 2003). O principal o objetivo deste projeto foi o desenvolvimento de um sistema multimídia distribuído capaz de adaptar as mídias de forma personalizada. Dentre seus principais resultados, destaca-se a elaboração de diversos conceitos e metadados envolvidos neste contexto, que contribuíram na especificação do MPEG-21.

Após este, outros trabalhos buscaram tratar a questão de adaptação de vídeo, explorando o uso de codecs escaláveis (SCHWARZ; MARPE; WIEGAND, 2007). Eberhard apresenta um arcabouço de distribuição de mídias escaláveis que dá suporte à adaptação do vídeo, tanto em serviços de vídeo sob demanda, como para serviços de vídeo ao vivo, usando IP Multicast (EBERHARD et al., 2009). Porém, como o uso do IP Multicast é um fator limitante por diversas questões (DIOT et al., 2000; LAO et al., 2005), sua aplicação é restrita a sistemas fechados e fortemente estruturados.

Iqbal elaborou um trabalho que também explora a linha de codecs escaláveis, esse entretanto, é baseado em redes P2P (IQBAL; SHIRMOHAMMADI, 2009). Tal abordagem é interessante, pois viabiliza o seu uso em um contexto mais amplo, como a Internet. No entanto, o uso desta estratégia não é adequado para CDNs, pois trata o uso dos recursos de rede de forma ineficiente e sua robustez é limitada à regularidade dos peers.

Como forma de tratar estes problemas inerentes as redes P2P, em (LAN, 2009) é proposto o uso de um modelo de redes sobrepostas híbridas, definindo o uso de um elemento, distribuído de forma estruturada, denominado "MP" (Multiple Description Coding based P2P video Proxy).

\subsection{Discussão}

Estes trabalhos colaboraram em diversos aspectos nas pequisas de adaptação de vídeo, consequentemente, na construção de um sistema com os requisitos anteriormente mencionados. 
Dentre as caraterísticas interessantes dos trabalhos descritos acima, destaca-se o suporte à adaptação de vídeo de forma independente do codec (desde que seja um codec escalável), fazendo-se uso do gBSD(generic Bitstream Syntax Descriptions) (PANIS et al., 2003). Contudo, o uso apenas de codecs escaláveis restringe a sua aplicabilidade, pois, além de possuírem uma taxa de compressão inferior aos codecs "não escaláveis" (LI; LIU, 2003), sua penetração no ambiente Web ainda é baixa. Além disso, estes trabalhos não atentam para a questão do gerenciamento integrado com os demais serviços de uma rede de distribuição de conteúdo.

Apesar destes projetos contribuírem nas pesquisas da adaptação de vídeo, ainda não atendem a todos os requisitos identificados para solucionar o problema apresentado. $A$ questão de adaptar a mídia considerando as técnicas de otimização de distribuição de vídeo não é tratada nestes trabalhos, mas é fundamental para que o sistema seja escalável, como descrito anteriormente. Além disso, não é tratado o gerenciamento de todos os serviços envolvido de forma integrada.

Para satisfazer tais requisitos, é importante investigar como integrar os resultados destas pesquisas, em um sistema de distribuição de conteúdo, considerando os demais componentes da rede e os serviços já providos por esta. 


\section{Redes Sobrepostas}

Como descrito anteriormente, para que um sistema de distribuição de vídeo possa atender a todos os usuários de forma satisfatória, utilizando a infraestrutura de maneira otimizada, é necessário que a CDN seja provida de um serviço de adaptação que considere as técnicas de cache e multicast e atue de forma integrada à essas.

Para atender a estas demandas, este trabalho se baseia no MPEG-21 DIA, e propõe o uso de redes de serviços sobrepostos (overlay service network) como estratégia para prover a integração do serviço de adaptação com os demais serviços envolvidos na distribuição de conteúdo.

Assim, o objetivo deste capítulo é apresentar o conceito de redes sobrepostas, os benefícios e desafios desta abordagem e qual a sua importância no contexto deste trabalho. Além disso, também será apresentada a arquitetura Oversea, que é utilizada neste trabalho.

\subsection{Conceito, Benefícios e Desafios}

Segundo Li, a definição de rede sobreposta é: "Uma rede sobreposta é uma rede virtual construída sobre uma rede existente" (LI, 2005). Os nós desta rede virtual são elementos conectados à rede subjacente (ex: servidores conectados à uma rede), e os enlaces da rede virtual são os caminhos entre os nós através da rede existente, ilustrado na figura 9.

A idéia de redes sobrepostas não é recente, sendo utilizada para a criação da própria Internet, pois esta é uma rede sobreposta sobre as redes de telecomunicações, com o objetivo de adicionar o suporte de comutação de pacotes (ANDERSEN et al., 2002; LI, 2005; CLARK et al., 2006).

Li e Clark (LI, 2005; CLARK et al., 2006) relatam alguns benefícios da abordagem de redes sobrepostas, podendo ser destacados: 


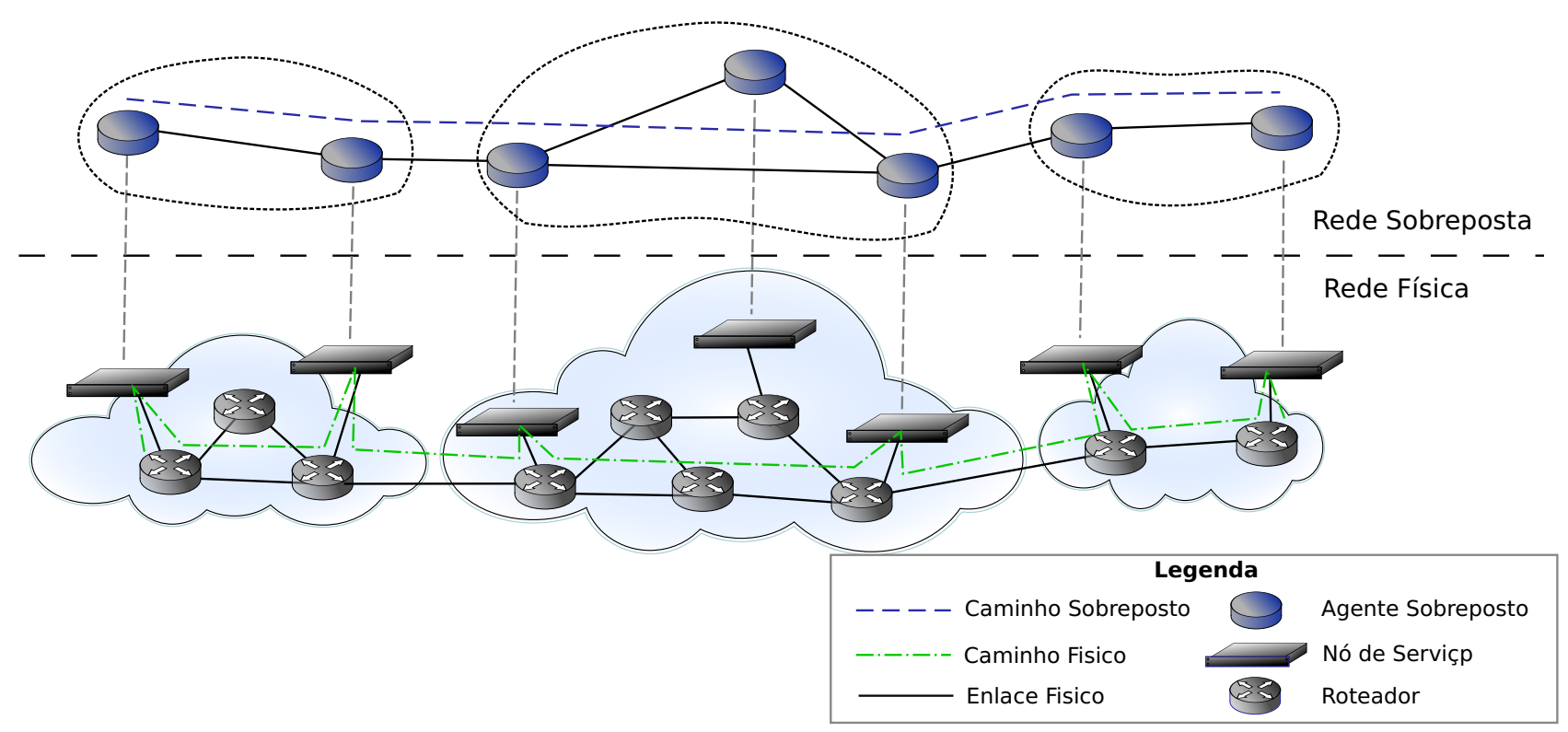

Figura 9: Rede sobreposta implementada na camada de aplicação

- Permite adicionar novos serviços à infraestrutura de rede;

- Opera de forma transparente para a rede subjacente, sendo desnecessário fazer alterações nesta;

- Utiliza informações da própria infraestrutura, como informações de alto nível para prover melhores serviços;

- Faz uso de recursos dos nós sobrepostos para agregar serviços mais sofisticados, como criptografia e cache;

- Possibilita a evolução de forma incremental de um serviço, adicionando gradativamente nós à rede sobreposta;

Entretanto, existem diversos desafios na pesquisa de redes sobrepostas:

- A adição de mecanismos de controle da rede sobreposta incorre na geração de sobrecarga (overhead) de comunicação de gerenciamento (LI, 2005);

- A definição da capacidade do enlace e a medição do grau de ocupação, pois os enlaces entre os nós sobrepostos normalmente são compostos por diversos enlaces da camada inferior (podendo passar por diversos enlaces físicos e roteadores), sendo assim, a medição deste parâmetro pode ser complexa e contextual; 
- A coexistência de diversas redes sobrepostas pode ocasionar redundância em operações de medição, sendo importe que haja um sistema de gerenciamento comum entre estas e que explore informações de monitoração advindas da rede subjacente (ex: rede IP) (LI, 2005);

Associado a isso, ainda devemos considerar outras questões, como as elencadas por Clark (CLARK et al., 2006) que discute em seu trabalho problemas de escopo mercadológico e político, como: (i) a escolha do caminho entre dois nós pela rede sobreposta pode ser contraria às políticas BGP definidas pelos ISPs, que são baseadas em questões operacionais e de custo e (ii) qual entidade deve regulamentar um serviço provido por uma rede sobreposta que tem abrangência global (ex: como deve definir/recolher impostos de um serviço de IPTV com abrangência internacional).

\subsection{Redes Sobrepostas na Internet}

A utilização de redes sobrepostas para o desenvolvimento de aplicações avançadas na Internet é uma abordagem cada vez mais frequente. Alguns exemplos destas redes podem ser vistas na tabela 1.

Tabela 1: Exemplos de redes sobrepostas, adaptado de (CLARK et al., 2006)

\begin{tabular}{|l|c|}
\hline Tipo & Exemplo \\
\hline P2P para compartilhamento de arquivos & Napster, Gnutella \\
\hline $\begin{array}{l}\text { Rede de Distribuição de conteúdo } \\
\text { (Content Distribuition Network - CDN) }\end{array}$ & Akamai, Digital Island \\
\hline Roteamento otimizado e com resiliência & RON, Akamai SureRoute \\
\hline Segurança e privacidade & Tor, I2P, Freenet, Entropy \\
\hline Experimental & PlanetLab, I3 \\
\hline Multicast & Narada, Overcast, MBone \\
\hline Outras & Email, Skype \\
\hline
\end{tabular}

Esta tabela demonstra a possibilidade de utilização das redes sobreposta em serviços de grande escala e com bom desempenho, como é o caso do Akamai, Skype e PlanetLab. 


\subsection{Redes de Serviços Sobrepostos}

A facilidade de criar redes sobrepostas resultou no surgimento de diversas redes, conforme pode ser visto na tabela 1. Entretanto, a existência de diversas redes sobrepostas independentes, onde cada uma é criada para a adição de apenas uma nova funcionalidade (ex: serviço de multicast) pode gerar sobrecarga de tráfego de controle, podendo causar efeitos indesejáveis sobre a rede, impactando a própria aplicação (LI, 2005).

Para tratar este problema, são propostos em (LI; MOHAPATRA, 2004; SAMIMI et al., 2007) soluções que definem serviços comuns entre diversas redes sobrepostas de propósitos específicos. Desta forma, os serviços usados para criar as redes sobrepostas, como: descoberta de topologia e monitoração de elementos; são executados de forma coordenada, diminuindo a sobrecarga de sinalização. Tal organização de redes sobrepostas específicas utilizando um conjunto de serviços compartilhados é definida por Li como de redes de serviços sobrepostos (overlay services networks - OSM) (LI; MOHAPATRA, 2004).

\subsection{Oversea}

O Oversea (Scalable and Effective Architecture for Overlay Networks) (UCHOA et al., 2007b) é uma arquitetura para redes de serviços sobrepostos desenvolvida pelo LARC ${ }^{1}$, através do projeto GT Overlay ${ }^{2}$, projetada com o objetivo de evoluir a RVD ${ }^{3}$ da RNP ${ }^{4}$. A partir desta arquitetura foi implementada a Plataforma de Gerenciamento de Vídeo usada pela RNP, descrita na seção 4.4.3.

Esta arquitetura é utilizada para a implementação do serviço de adaptação proposto neste trabalho, conforme será descrito na seção 6.1

\footnotetext{
${ }^{1}$ Laboratório de Arquitetura e Redes de Computadores

${ }^{2}$ Grupo de Trabalho em Rede de Serviços Sobreposto, financiado pela RNP

${ }^{3}$ Rede de Vídeo Digital

${ }^{4}$ Rede Nacional de Ensino e Pesquisa
} 


\subsubsection{Visão geral da arquitetura}

O modelo arquitetural do Oversea é estruturado em camadas, propondo um conjunto de serviços básicos sobre os quais outros serviços avançados podem ser implementados, podendo ser agregados de forma orquestrada.

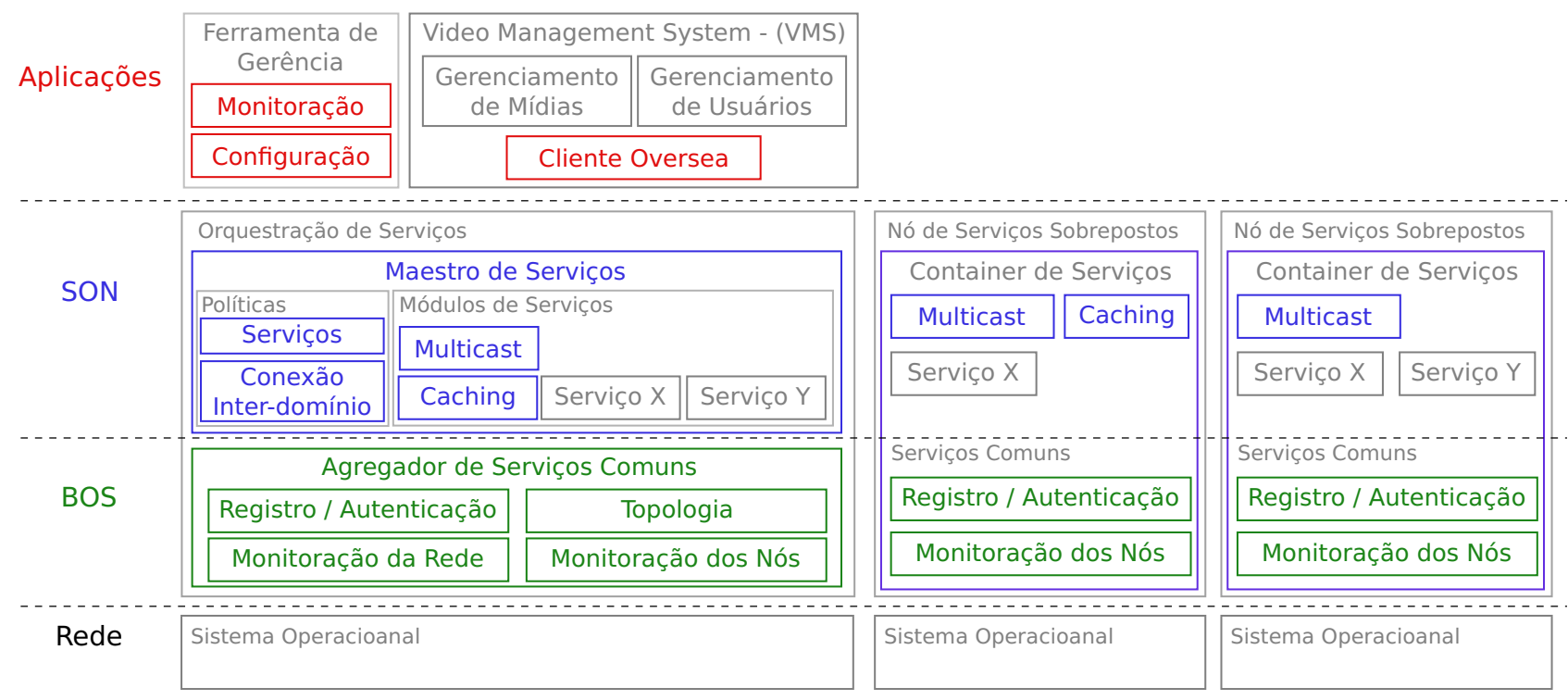

Figura 10: Visão geral da arquitetura Oversea

Como mostrado na figura 10, as aplicações são implementadas na camada superior e podem fazer uso dos serviços implantados nos nós da rede sobreposta. Abaixo, na camada SON (Service Overlay Networks), são implementados os serviços específicos, provendo para as aplicações funcionalidades, tais como a multicast, cache. Na camada BOS (Basic Overlay Services), são implementados serviços comuns da arquitetura, como: registro/autenticação, monitoração da infraestrutura e o gerenciamento da topologia. Inferior a camada BOS está representado o serviço de comutação de pacotes provido pelo sistema operacional, tipicamente TCP/IP.

Utilizando esta arquitetura é possível criar uma plataforma integrando diversas redes sobrepostas. Desta forma, maximiza-se o uso destas redes através de um conjunto de serviços comuns de maneira otimizada, pois evita a redundância nas medições da rede para a descoberta da topologia e na sua monitoração. Consequentemente diminui a troca de mensagens de sinalização pela rede, além de simplificar a implementação de novos serviços. 
A concepção da arquitetura Oversea teve como principal alvo, ser capaz de atender aos requisitos de aplicações multimídias. Para isto, foram considerados quatro principais aspectos: (i) minimizar a latência na requisição de serviços, (ii) desacoplamento entre os serviços, (iii) segurança e (iv) escalabilidade do sistema.

Para tratar os aspectos (i), (ii) e (iii), o modelo de interação entre os componentes foi elaborado de forma que estivessem contidos na mensagem de requisição todos os dados de acesso aos serviços de maneira independente e as informações que garantissem a segurança da comunicação, conforme será descrito na seção 4.4.2.

Além disso, para garantir a escalabilidade do sistema sem que haja um comprometimento do desempenho, é definido que o elemento central da arquitetura - o Maestro de Serviçosseja distribuído, formando Domínios Sobrepostos.

\subsubsection{OCP - Oversea Communication Protocol}

O OCP é projetado para dar suporte à agregação de diversos serviços de uma rede sobreposta com suporte a diversos domínios sobrepostos e atendendo aos requisitos de desempenho, segurança e desacoplamento de serviços, obtido através das melhorias implementadas por este trabalho e descritas no apêndice A. Este define uma mensagem, ilustrada na figura 11, composta por um conjunto de serviços, contendo as informações necessárias para o acesso a cada serviço; um conjunto de nodes (mapeamento do nó sobreposto ao serviço provido por este), agregados em paths de acordo com o domínio sobreposto; e alguns campos utilizados para garantir a segurança da comunicação.

Um dos aspectos importantes a ressaltar do protocolo é que para garantir o desempenho da comunicação, todas as informações de segurança estão contidas na própria mensagem, não sendo necessária a validação desta por um outro elemento (ex: por meio de uso de tokens). No entanto, o detalhamento e análise dos aspectos de segurança está fora do escopo deste trabalho e serão apresentados em trabalhos futuros. 


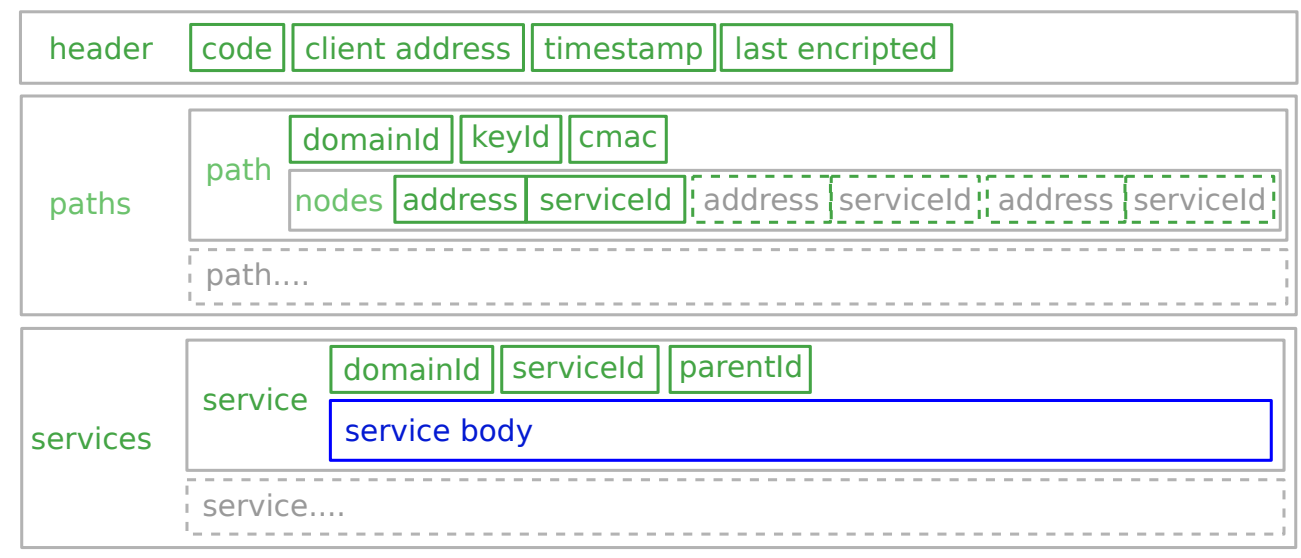

Figura 11: Mensagem OCP

\subsubsection{Plataforma de Gerência de Vídeo}

A Plataforma de Gerência de Vídeo (UCHOA et al., 2007a) usada na RNP, foi desenvolvida pelo LARC, usando a arquitetura Oversea e explorando os padrões MPEG-7 e MPEG-21 (MATUSHIMA, 2007).

Esta plataforma, procura atender a dois objetivos principais: (i) administração dos usuários e do conteúdo multimídia publicado e (ii) gerenciamento (configuração e monitoração) da rede de distribuição de conteúdo multimídia. A distribuição do vídeo suporta os serviços de vídeo sob demanda e vídeo ao vivo por meio de uma rede sobreposta de serviços que implementa as técnicas de cache e multicast.

A Plataforma considera quatro tipos de usuários: (i) Cliente, usuários finais do sistema, que podem realizar busca, navegação e consumo de conteúdo multimídia; (ii) Provedor de Conteúdo, responsável pela publicação de conteúdo multimídia; (iii) Administrador, responsável pela administração dos cadastros e permissões de acesso das principais entidades (usuários, grupos, projetos, mídias) do sistema e; (iv) Gerente, que trata todas as funcionalidades relacionadas à configuração e monitoração da rede de distribuição.

A figura 12 mostra uma transmissão de vídeo através da rede de serviços sobrepostos distribuídos pela rede Ipê, infra-estrutura de rede da RNP. Nesta, o fluxo de vídeo, que tem como fonte um servidor no DF é transmito para clientes no DF, BA e PE. 


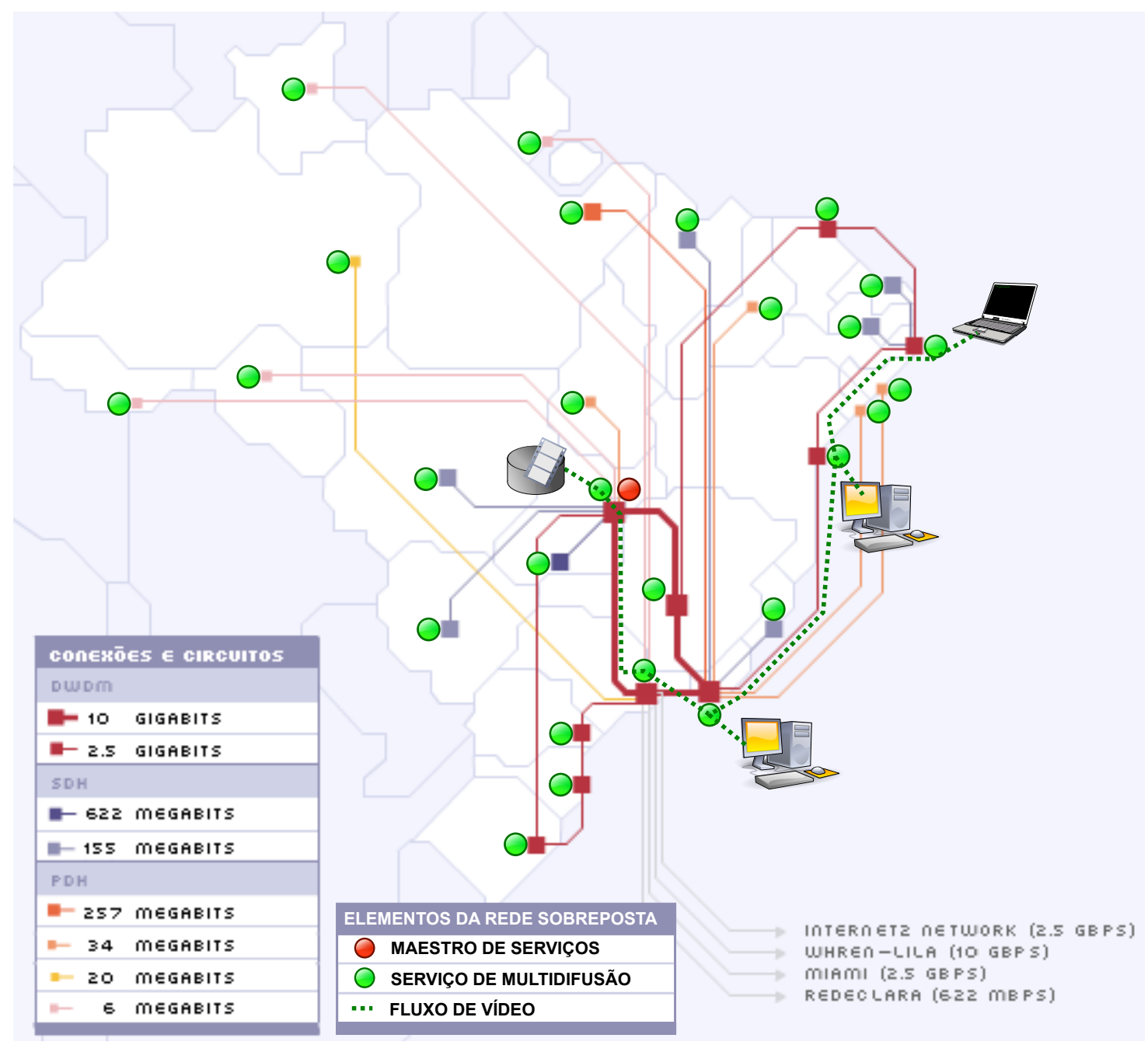

Figura 12: Rede Ipê com Serviço Sobreposto de Multicast (adaptado de (RNP, 2010)) 


\section{Serviço de Adaptação de Vídeo}

Este capítulo apresenta a proposta de serviço de adaptação de vídeo tendo como objetivo atender aos requisitos de adaptação de vídeo de uma CDN com o diferencial de considerar aspectos primordiais neste contexto, como a otimização do uso dos recursos da rede e a atuação de forma integrada com o sistema.

\subsection{Visão geral}

A proposta deste trabalho consiste na elaboração do serviço de adaptação que explore o conceito de redes de serviços sobrepostos e empregue um modelo de adaptação baseado em perfis dos usuários. Desta forma é capaz de atuar de maneira integrada com os demais serviços da CDN, como cache e multicast.

O processo de adaptação é orquestrado por um elemento, integrado à plataforma de gerência da rede, e executado por elementos distribuídos ao longo da rede, instalados em nós da rede de serviços sobrepostos.

A utilização de um modelo de adaptação baseado em perfis, permite que haja um único fluxo adaptado para usuários com as mesmas características de acesso. Assim, é possível usufruir do benefícios de técnicas de multicast e cache, visto que maximiza o uso de um mesmo fluxo. Ademais, tal estratégia permite maior escalabilidade do serviço, fazendo a dissociação do custo computacional para realizar as operações de adaptação e o número de usuários atendidos pela mesma.

A figura 13 ilustra uma rede de distribuição capaz de atender a diversos usuários com caraterísticas diferentes. Neste cenário, os clientes desta rede acessam um vídeo Full $H D$ (1920x1080) por meio de diversos dispositivos: TVs de alta resolução conectadas a um serviço de IPTV (através de um set-top box), computadores pessoais e laptops acessando serviço de distribuição de vídeo via Web, e dispositivos como PDAs e smartphones através de redes móveis. Para garantir que os usuários com maior restrição possam consumir o conteúdo adequadamente, sem afetar o QoE (Quality of Experience) dos demais 
usuários, é utilizado o serviço de adaptação de vídeo proposto, de forma que os usuários que possuem restrições semelhantes de ambiente, recebam o mesmo fluxo de vídeo, adaptado para o seu perfil de acesso, garantindo assim o uso otimizado dos recursos da rede.

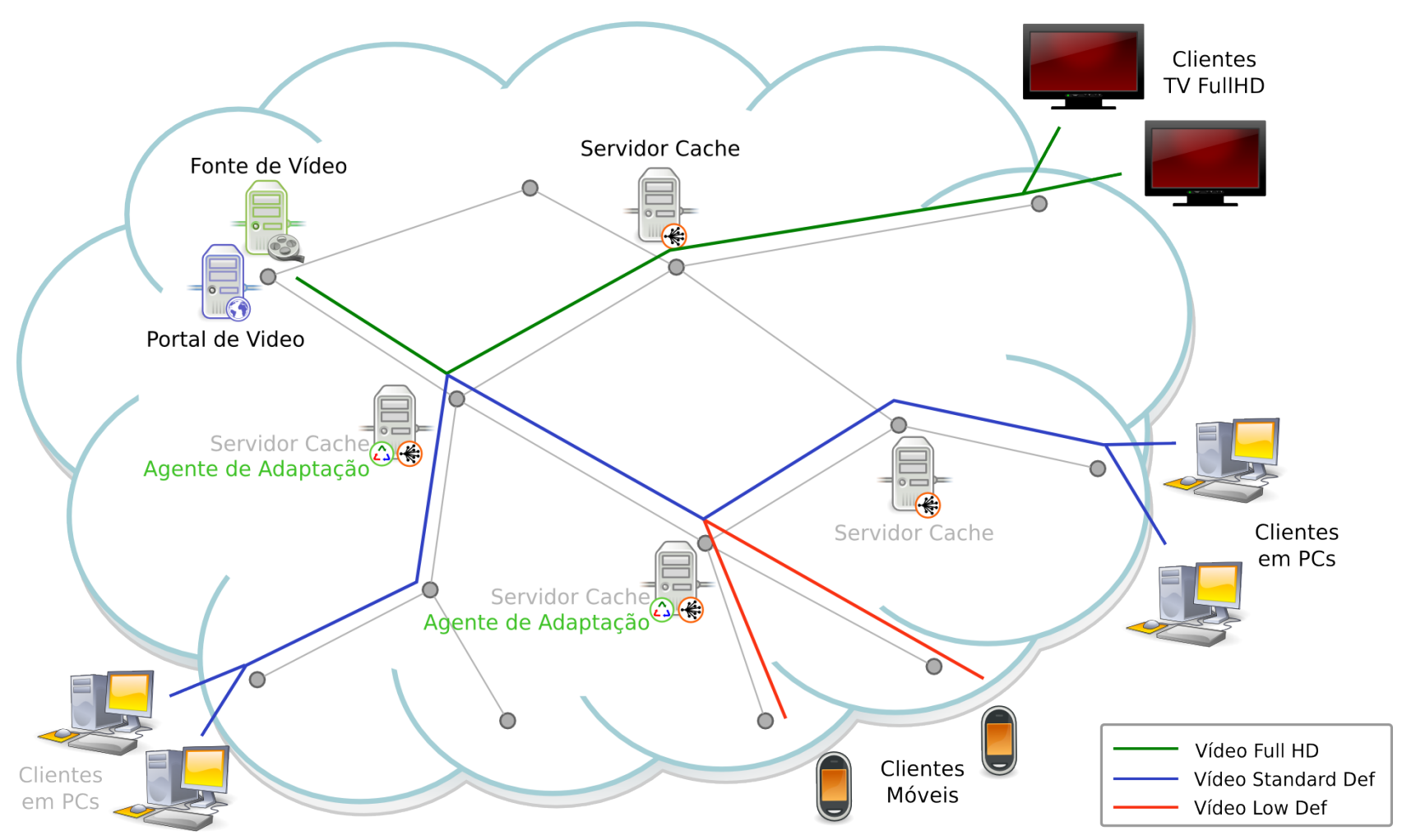

Figura 13: Visão geral do funcionamento do serviço de adaptação integrado com serviço multicast

Para este exemplo, os usuários foram classificados de acordo com a capacidade de banda de conexão e a resolução da tela do dispositivo de acesso. A tabela 2 detalha os perfis considerados. Os clientes (Clientes TV FullHD) que possuem as condições necessárias para exibir o vídeo em sua resolução original, são agrupados no perfil "FullHD”, recebendo o vídeo sem que seja necessário a adaptação. Um segundo conjunto de clientes (Clientes em PCs) não atendem ao requisitos mínimos de resolução de tela, sendo agrupados no perfil "HD", recebendo o vídeo adaptado para este perfil. O terceiro grupo de clientes (Clientes Móveis), possuem maiores restrições, tanto de resolução de tela como de banda, sendo agrupados no perfil "LD", recebendo o vídeo adaptado para baixa resolução.

\footnotetext{
${ }^{1}$ Full HD - Full High Definition, HD - High Definition, ED - Enhanced Definition, SD - Standard Definition, LD - Low Definition
} 
Tabela 2: Perfis de adaptação considerados

\begin{tabular}{|c|c|c|c|}
\hline Perfil & Resolução de Tela & Largura de Banda & Parâmetros de Adaptação \\
\hline \hline Full HD & $\mathbf{R}>=1920 \times 1080$ & $\mathbf{B} \geq 8 \mathrm{Mbps}$ & vídeo original \\
\hline $\mathrm{HD}^{1}$ & $1920 \times 1080>\mathbf{R} \geq 1080 \times 720$ & $8 \mathrm{Mbps}>\mathbf{B} \geq 6 \mathrm{Mbps}$ & $1080 \times 720 / 6 \mathrm{Mbps}$ \\
\hline $\mathrm{ED}^{1}$ & $1080 \times 720>\mathbf{R} \geq 854 \times 480$ & $6 \mathrm{Mbps}>\mathbf{B} \geq 4 \mathrm{Mbps}$ & $854 \times 480 / 4 \mathrm{Mbps}$ \\
\hline $\mathrm{SD}^{1}$ & $854 \times 480>\mathbf{R} \geq 720 \times 480$ & $4 \mathrm{Mbps}>\mathbf{B} \geq 2 \mathrm{Mbps}$ & $720 \times 480 / 2 \mathrm{Mbps}$ \\
\hline $\mathrm{LD}^{1}$ & $720 \times 480>\mathbf{R} \geq 352 \times 240$ & $2 \mathrm{Mbps}>\mathbf{B} \geq 384 \mathrm{Kbps}$ & $352 \times 240 / 384 \mathrm{Kbps}$ \\
\hline
\end{tabular}

Através deste exemplo é possível notar que apesar de 6 clientes utilizarem fluxos adaptados, os agentes de adaptação executam apenas 2 adaptações, tendo seu custo minimizado devido a utilização de perfis e à integração com o serviço de multicast. Além disso, nota-se que devido a integração com o serviço de multicast, o fluxo de vídeo é transmitido apenas uma vez em cada enlace, otimizando assim também a utilização dos recursos da rede.

\subsection{Elementos do Serviço de Adaptação}

Os elementos que compõe o serviço de adaptação de vídeo são denominados Módulo de Orquestração e Agente de Adaptação. Estes estão descritos abaixo de forma contextualizada na arquitetura Oversea, a qual é utilizada para a implementação de referência deste serviço.

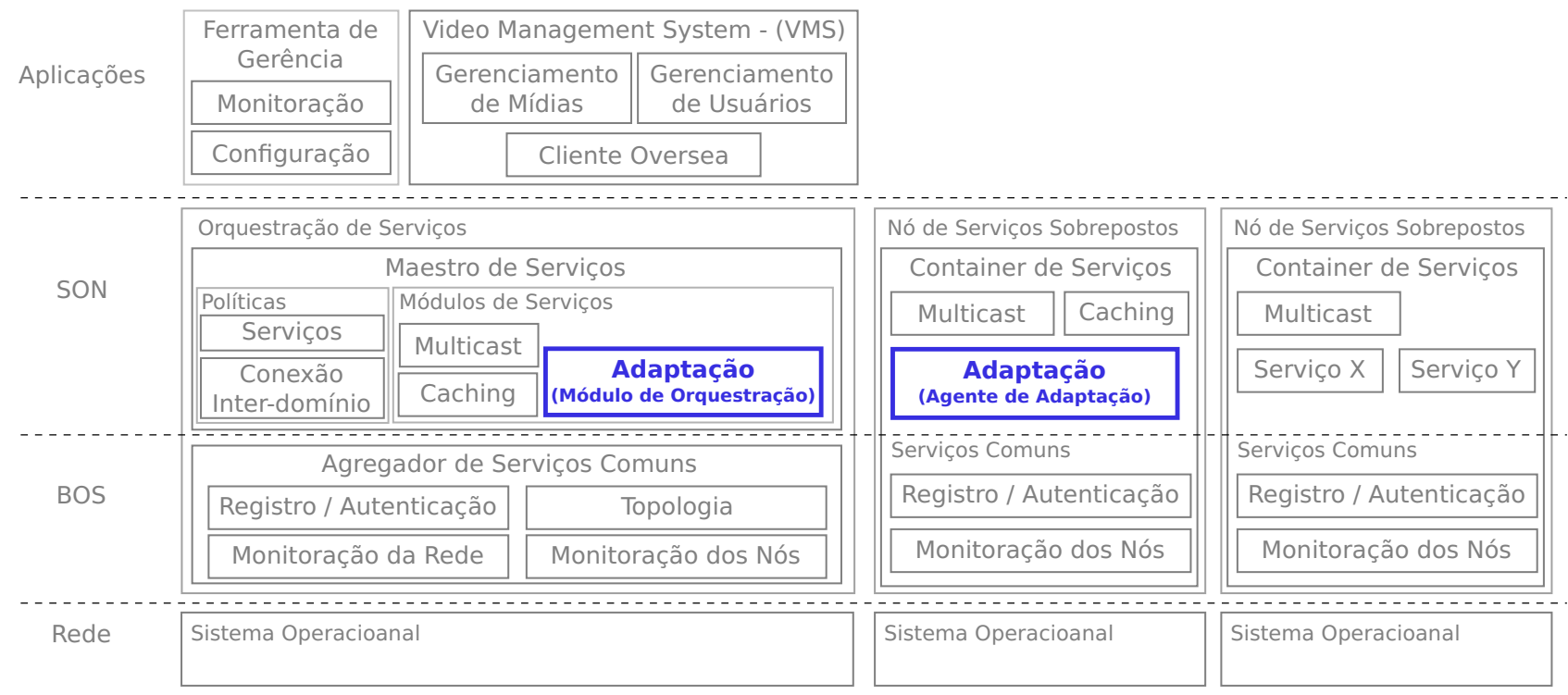

Figura 14: Elementos do serviço de adaptação inseridos na arquitetura Oversea 


\subsubsection{Módulo de Orquestração}

O Módulo de Orquestração é utilizado pelo Maestro de Serviços ${ }^{1}$ para avaliar se há necessidade de adaptação da mídia, definir qual perfil de adaptação é mais adequado para atender o cliente e determinar qual Agente de Adaptação deverá realizar a adaptação do vídeo. Esta tomada de decisão é pautada com base na regras de perfis e nas informações de contexto.

Estas informações provêm basicamente de duas fontes. As características da mídia (resolução, formato, codec, etc..), as restrições do usuário (resolução da tela, capacidade do enlace) e questões relacionadas a direitos de acesso e são repassadas pela aplicação que requisitou o serviço, tipicamente um VMS (Video Management System). Os dados da topologia da rede, distribuição dos agentes, capacidades e condições dos enlaces e nós de serviço são obtidas através de serviços da camada BOS na arquitetura Oversea, por exemplo, do serviço de topologia.

\subsubsection{Agente de Adaptação}

O Agente de Adaptação é o elemento que realiza as operações de adaptação dos fluxos de vídeo, instalado em diversos nós da rede sobreposta. Este recebe do Maestro de Serviço as definições sobre qual adaptação deve ser realizada. Uma característica importante é que as capacidades de adaptação implementadas em cada agente não precisam ser necessariamente iguais.

Em situações específicas, cada nó pode possuir apenas os mecanismos de adaptação adequados para sua localização, por exemplo, um nó de adaptação na entrada de uma rede para dispositivos móveis (celulares, PDAs) precisaria suportar apenas os mecanismos de adaptação adequados para estes dispositivos.

\footnotetext{
${ }^{1}$ Elemento da arquitetura Oversea responsável pela orquestração dos serviços
} 


\subsection{Gerenciamento dos Perfis de Adaptação}

O gerenciamento dos perfis de adaptação é realizado através de uma ferramenta de gerência, utilizada pelo administrador da CDN, que configura um conjunto de regras que serão interpretadas pelo Maestro de Serviços através do Módulo de Orquestração.

Afim de adequar o uso deste serviço de adaptação a diversos contextos, o gerenciamento dos perfis de adaptação foi projetado de forma a ser flexível, permitindo a definição de diversos perfis, e o mapeamento de diversas informações nas regras de enquadramento de usuários.

\subsubsection{Negociação da adaptação}

O processo de negociação da adaptação analisa o contexto de uso do vídeo (ex: características da mídia, restrições do terminal do usuário e condições da rede) e o posicionamento e condições dos agentes de adaptação distribuídos na rede. Assim, o fluxo de execução é segmentado em duas etapas: (i) a associação do usuário a um perfil de adaptação e (ii) a escolha de qual agente de adaptação realizará a adaptação. Os passos da negociação estão enumerados abaixo e ilustrados na figura 15.

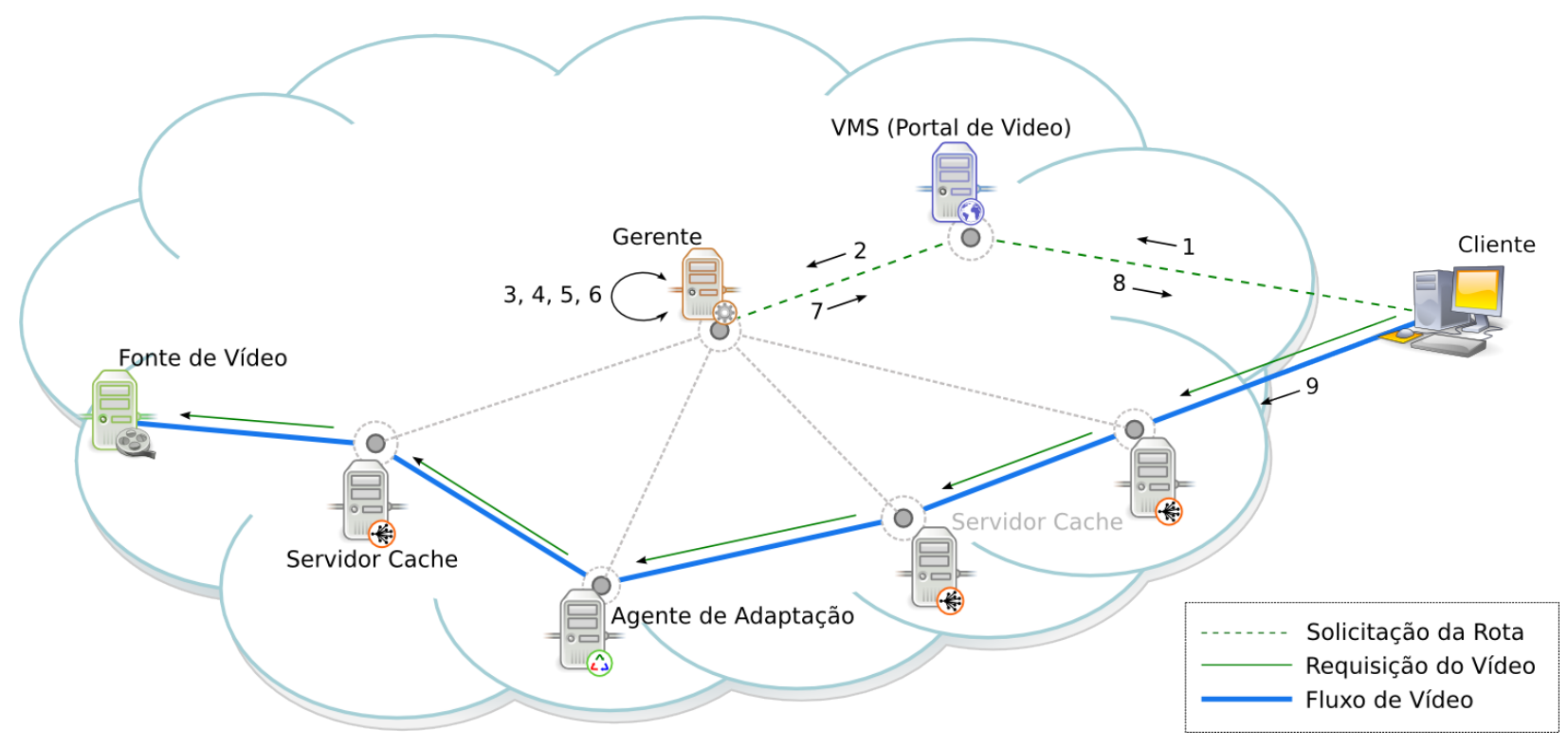

Figura 15: Requisição de vídeo com os serviços de multicast e adaptação integrados 
1. O cliente solicita uma mídia à aplicação de distribuição de vídeo (ex: portal de vídeo). Neste ponto, é identificado as características e restrições do terminal e opcionalmente o perfil do usuário ou tipo de serviço.

2. A aplicação de distribuição de vídeo passa estas informações para o Maestro de Serviços, juntamente com as informações sobre a mídia e o endereço (ex: IP) do terminal do usuário e do servidor onde está hospedado o vídeo.

3. O Maestro de Serviços verifica a localização do usuário (utilizando o serviço de topologia) e as condições da rede até este usuário (consultando o serviço de monitoração).

4. Utilizando o Módulo de Orquestração, identifica se o cliente é capaz de consumir o vídeo em sua resolução original, e no caso de ser necessário realizar alguma adaptação, verifica em qual perfil de adaptação o usuário se enquadra (etapa i).

5. Sendo escolhida uma adaptação, o Maestro de Serviços localiza por meio do serviço de topologia, os agentes de adaptação disponíveis para atender este cliente, e elege qual(is) agente(s) deve(m) realizar algum tipo de adaptação (etapa ii).

6. Caso haja a necessidade de agregar outros serviços (ex: multicast), o Maestro de Serviços utiliza as informações de localização dos serviços já associados para a inclusão destes novos serviços.

7. O Maestro de Serviços responde à aplicação de distribuição de mídia indicando a rota $^{1}$ de acesso ao vídeo.

8. A aplicação, ao receber a rota, redireciona o cliente ao nó que irá atendê-lo.

9. O cliente repassa a requisição de forma cascateada até a fonte do vídeo.

Desta forma, utilizando os elementos propostos neste trabalho é possível realizar a adaptação de vídeo para diferentes contextos utilizando este método de negociação da adaptação.

\footnotetext{
${ }^{1}$ A rota é constituída da sequência dos endereços dos agentes de serviço (multicast / cache e adaptação) escolhidos para realizar a transmissão do vídeo da fonte até o cliente e das informações de acesso aos serviços (identificador da mídia e parâmetros de adaptação).
} 


\section{Avaliação}

Como forma de avaliar a proposta descrita neste trabalho, este capítulo apresenta um conjunto de testes realizados em uma implementação do serviço proposto. Os testes comparam o serviço de adaptação proposto com outras duas estratégias de adaptação que normalmente são utilizadas, a adaptação prévia e adaptação personalizada.

A adaptação prévia, utilizada nas CDNs atuais, consiste em gerar diversas versões de um vídeo, ajustando os parâmetros de codificação para um conjunto de perfis de usuários, de forma que estes possam escolher a versão mais adequada para o seu consumo. A adaptação personalizada por sua vez, é explorada na maioria dos trabalhos de pesquisa em adaptação de vídeo e visa atender cada usuário de forma personalizada, gerando uma versão adaptada para cada usuário de acordo com o seu contexto.

Os valores utilizados na comparação foram obtidos através de testes realizados por meio da implementação do serviço proposto, descrita a seguir. Os resultados são projetados em um cenário, através de simulação, de forma a avaliar os impactos da utilização de cada estratégia.

\subsection{Implementação do serviço de adaptação}

A implementação dos elementos do serviço de adaptação proposto é baseada na arquitetura Oversea de forma que o Módulo de Orquestração foi integrado ao Maestro de Serviços, permitindo assim que este possa agregar este serviço de adaptação aos serviços já implementados na plataforma. Esta implementação é feita utilizando o JAVA, e os componentes são instanciados no Servlet Container Apache Tomcat 6.

\subsubsection{Módulo de Orquestração}

O desenvolvimento do Módulo de Orquestração utiliza um subconjunto dos metadados padronizados pelo MPEG-7 e MPEG-21 para descrever: as informações da mídia, pre- 
ferências do usuário, capacidades do terminal de acesso e capacidades e condições da rede. Para complementar estes dados, são usadas algumas informações definidas pela UCD-SNMP-MIB ${ }^{1}$ como metadados contextuais dos nós da rede sobreposta, necessários para identificar o estado da rede sobreposta. Também foi necessário a elaboração de um conjunto de informações concernentes às funcionalidades dos agentes de adaptação e a inclusão de um novo serviço (serviço de adaptação) ao conjunto de informações gerenciadas pelo serviço de topologia. Além disso, foi definido um conjunto de informações envidadas para o Agente de Adaptação a fim de indicar os parâmetros de adaptação.

Estas informações são transmitidas através do protocolo OCP (4.4), dentro do campo service body, conforme a (figura 16). A lista completa destas informações estão descritas no apêndice $B$.

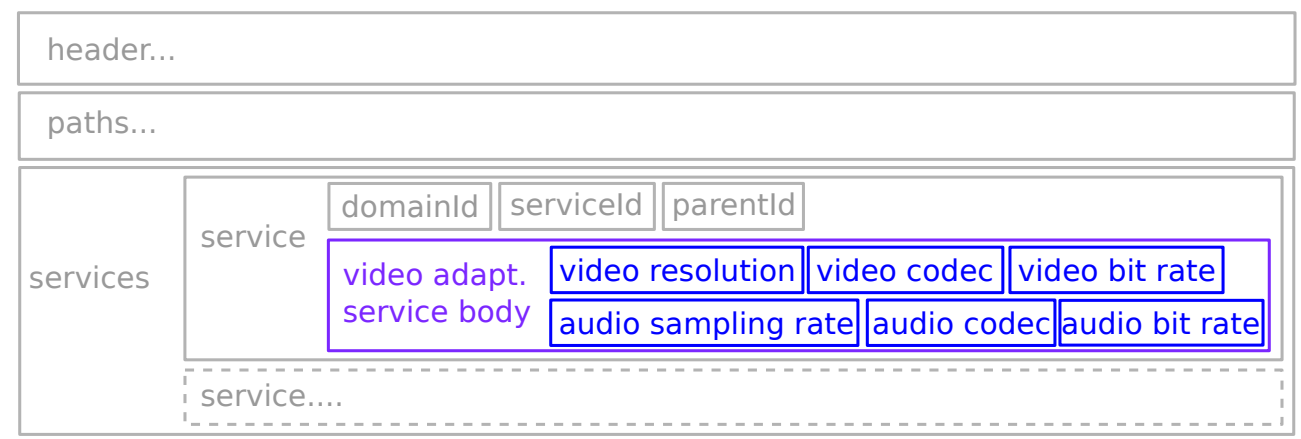

Figura 16: Campo service body do OCP com as informações para a adaptação.

Para a definição das regras de enquadramento dos usuários nos perfis, é usado um modelo no qual pode ser atribuído a um determinado perfil, expressões com operadores $>, \geq,<\mathrm{e} \leq$, associando os atributos aos valores limites para cada situação, conforme 0 exemplo da tabela 3. O conjunto de perfis definidos foram elaborados de acordo com os formatos mais comuns na codificação de vídeo.

\footnotetext{
${ }^{1}$ A MIB (Management Information Base) UCD (University of California, Davis) é um conjunto de informações utilizadas para monitoração de servidores por meio do protocolo SNMP (Simple Network Management Protocol).

${ }^{2}$ mpeg21:dia:DisplayCapabilitiesType

${ }^{3}$ mpeg21:dia:NetworkCondition
} 
Tabela 3: Exemplo de regras utilizadas para enquadramento aos perfis.

\begin{tabular}{|c|c|c|}
\hline Atributo & Operador & Valor \\
\hline \multicolumn{3}{|l|}{ FullHD } \\
\hline Resolution:horizontal' & $\geq$ & 1920px \\
\hline Resolution:vertical ${ }^{2}$ & $\geq$ & 1080px \\
\hline AvailableBandwidth:average 3 & $\geq$ & $8 \mathrm{Mbps}$ \\
\hline \multicolumn{3}{|l|}{ HDTV } \\
\hline Resolution:horizontal $^{2}$ & $\leq$ & 1920px \\
\hline Resolution:vertical $^{2}$ & $\leq$ & 1080px \\
\hline AvailableBandwidth:average $^{3}$ & $\leq$ & $8 \mathrm{Mbps}$ \\
\hline Resolution:horizontal $^{2}$ & $\geq$ & 1080px \\
\hline Resolution:vertical $^{2}$ & $\geq$ & $720 p x$ \\
\hline AvailableBandwidth:average $^{3}$ & $\geq$ & $6 \mathrm{Mbps}$ \\
\hline
\end{tabular}

\subsubsection{Agente de Adaptação}

O Agente de Adaptação, como os demais componentes do serviço, é implementado utilizando a linguagem JAVA, e atende as requisições por meio de um Servlet. Dado que a engine de manipulação do fluxo de vídeo é implementada utilizado o GStreamer (GSTREAMER, 2010), acessado através do gstreamer-java (GSTREAMER-JAVA, 2010), essa implementação permite as seguintes operações de transcodificação do vídeo: redução da resolução, mudança de codec e diminuição de quadros por segundo.

\subsection{Cenário de avaliação}

O cenário utilizado para avaliação e validação da proposta (figura 17) ilustra uma CDN de forma simplificada. A topologia ${ }^{1}$ utilizada é constituída de um anel central, que representa o núcleo da rede, e dois anéis secundários, adjacentes ao anel central. A fonte de vídeo está localizada em um nó que pertence ao núcleo da rede e os clientes estão distribuídos nos demais nós.

Os agentes de adaptação estão posicionados de acordo com cada estratégia. $\mathrm{Na}$ adap-

\footnotetext{
${ }^{1}$ A topologia utilizada foi construída de forma a ter um comportamento semelhante a rede da RNP (backbone) (RNP, 2010), com um anel principal e dois secundários, além de nós adicionais conectados, através de enlaces de menor capacidade, aos nós que pertencem aos anéis da rede.
} 


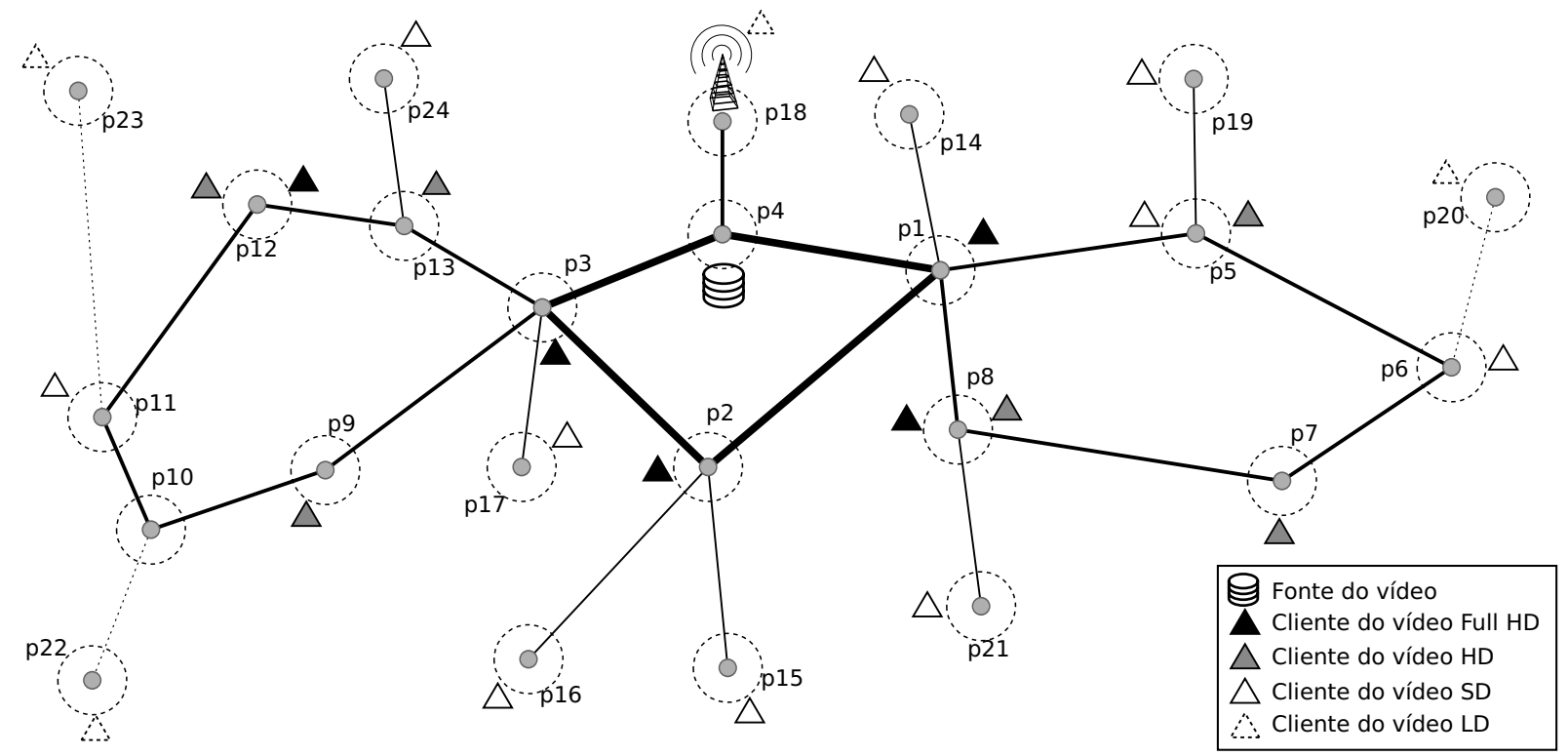

Figura 17: Cenário utilizado na comparação das estratégias.

tação prévia existe apenas um agente de adaptação, localizado junto ao servidor fonte, e na adaptação personalizada, os agentes de adaptação se encontram nos nós onde estão localizados os clientes. No serviço de adaptação proposto os agentes estão localizados nos nós pertencentes aos anéis da rede.

Como forma de avaliar a progressão dos impactos da adaptação neste cenário, são comparados os resultados em instantes diferentes, em que são acrescidas gradativamente outras versões do vídeo e usuários, conforme indicado na tabela 4. No instante 1, a CDN disponibiliza apenas uma versão do vídeo (versão SD), isto é, sem adaptação. No instante 2 são distribuídas as 2 versões (HD e SD); 4 versões no instante 3 (FullHD, HD, SD e LD); no instante 4 são disponibilizados 3 vídeos em 4 versões. A partir do instante 5 são acrecidos o número de usuários que acessam os vídeos, de forma linear.

Tabela 4: Instantes da avaliação.

\begin{tabular}{|c|c|c|c|}
\hline Instante & Vídeos & Versões & Clientes por $\Delta$ (localidade) \\
\hline 1 & 1 & SD & 1 \\
2 & 1 & HD e SD & 1 \\
3 & 1 & FullHD, HD, SD e LD & 1 \\
4 & 3 & FullHD, HD, SD e LD & 1 \\
5 & 3 & FullHD, HD, SD e LD & 2 \\
6 & 3 & FullHD, HD, SD e LD & 3 \\
\hline
\end{tabular}




\subsection{Resultados Experimentais}

A seguir são descritos os resultados obtidos nos testes realizados comparando o serviço propostos com as demais estratégias de adaptação consideradas: adaptação personalizada (Personalizada) e adaptação prévia (Prévia). Através desta comparação é possível demonstrar os impactos que cada estratégia causa ao ser implementada em uma CDN. Os testes executados demonstram o impacto do custo computacional através da quantidade de operações de adaptação realizadas. O volume de dados armazenados é identificado por meio do uso de disco nos servidores fonte e cache. Finalmente, o impacto devido aos múltiplos fluxos é medido através da taxa de acerto (hit ratio) dos servidores de cache e do o uso dos enlaces da rede (consumo total de banda).

O testes realizados utilizam um vídeo que apresenta uma taxa média de $8 \mathrm{Mbps}$ em sua versão FullHD, 6Mbps na versão adaptada para o perfil HD e 2Mbps na versão SD $384 \mathrm{Kbps}$ no perfil LD. O detalhamento dos testes estão descritos no apêndice C.

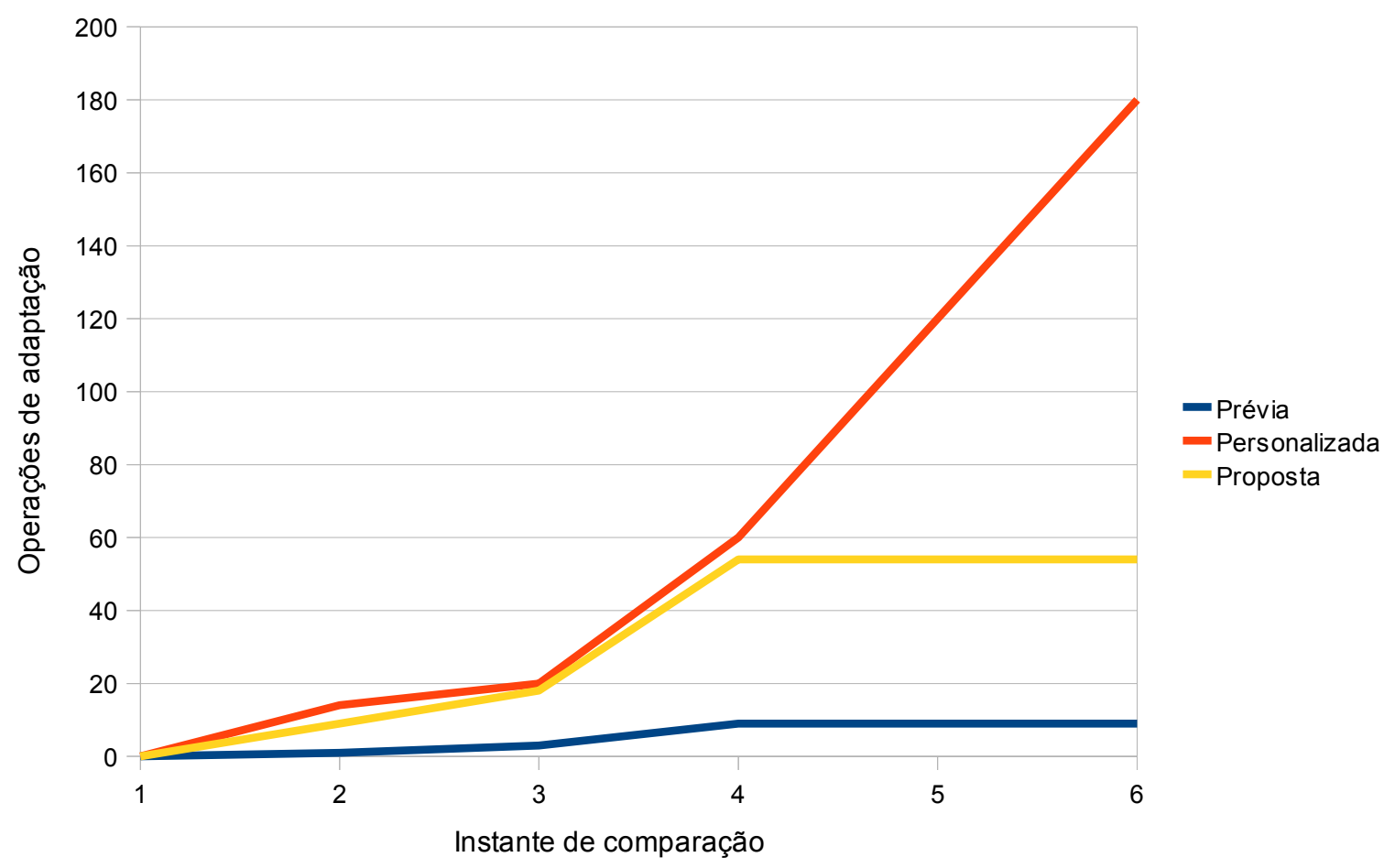

Figura 18: Operações de adaptação realizadas

A figura 18 sumariza a quantidade de operações realizadas para adaptar o vídeo em diferentes situações do uso da rede considerada. Através deste resultado é possível notar 
que a partir do instante 5 , em que aumenta o número de usuários, o serviço de adaptação de vídeo proposto neste trabalho (Proposta) apresenta uma vantagem significativa em relação a adaptação personalizada (Personalizada). No entanto a adaptação prévia (Prévia) oferece o melhor desempenho nesta comparação pois realiza apenas uma operação para cada versão adaptada.

Este comportamento é notado pois o serviço de adaptação proposto utilizou como estratégia, realizar as adaptações apenas nos nós que pertencem aos anéis da rede, de forma que o fluxo de vídeo adaptado é reutilizado para usuários com o mesmo perfil e que estejam localizados no mesmo nó ou em nós adjacentes aos anéis da rede.

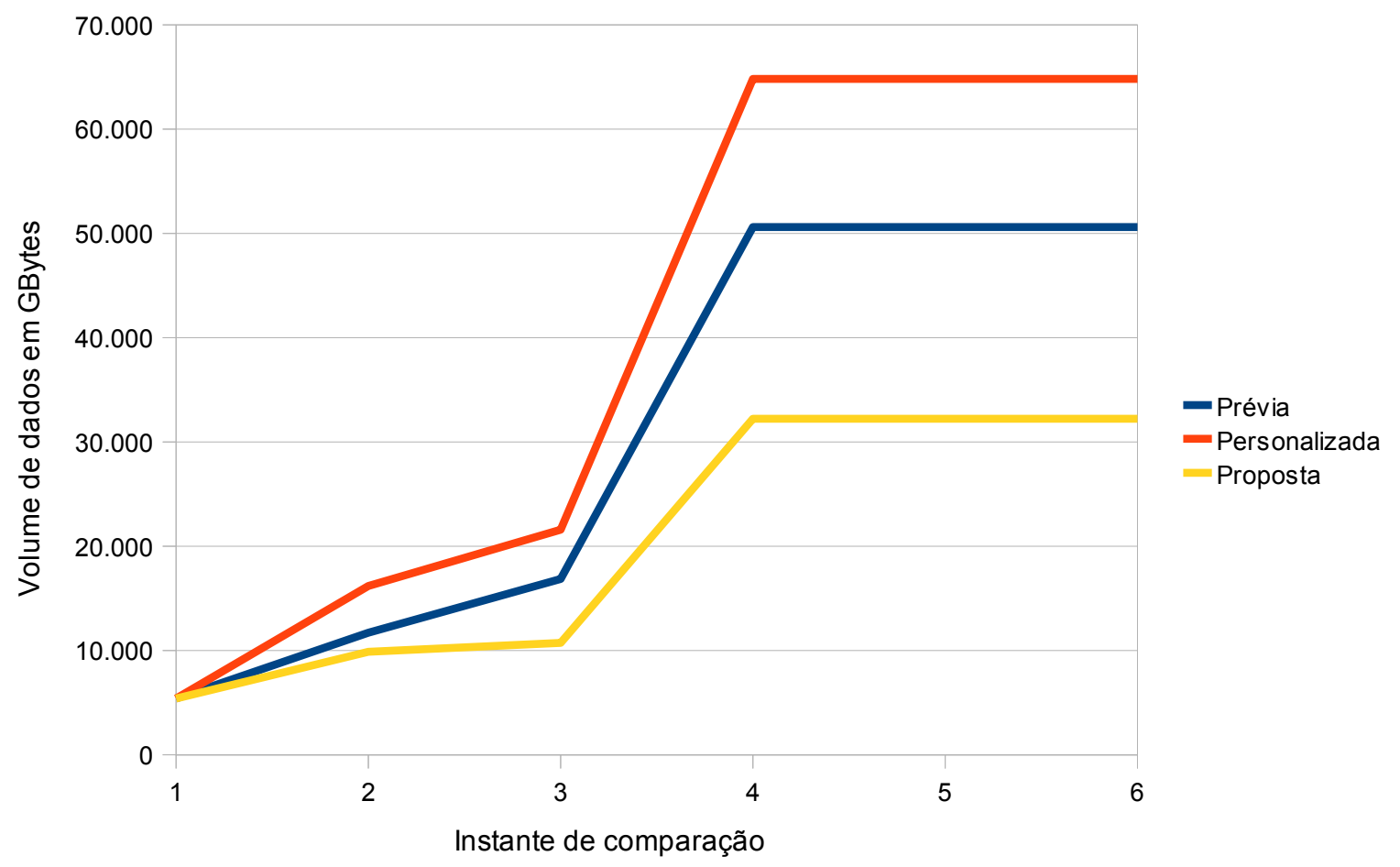

Figura 19: Volume de dados armazenados.

O teste que compara o impacto das estratégias de adaptação com relação ao volume de dados armazenados é representado na figura 19, obtido através da soma do volume de dados do servidor fonte e dos servidores cache. Por meio destes resultados pode-se afirmar que o serviço de adaptação de vídeo proposto neste trabalho, quando comparados com as outras duas estratégias, permite o uso de forma mais eficiente dos recursos de uma CDN, no que se refere ao volume de dados armazenados. 


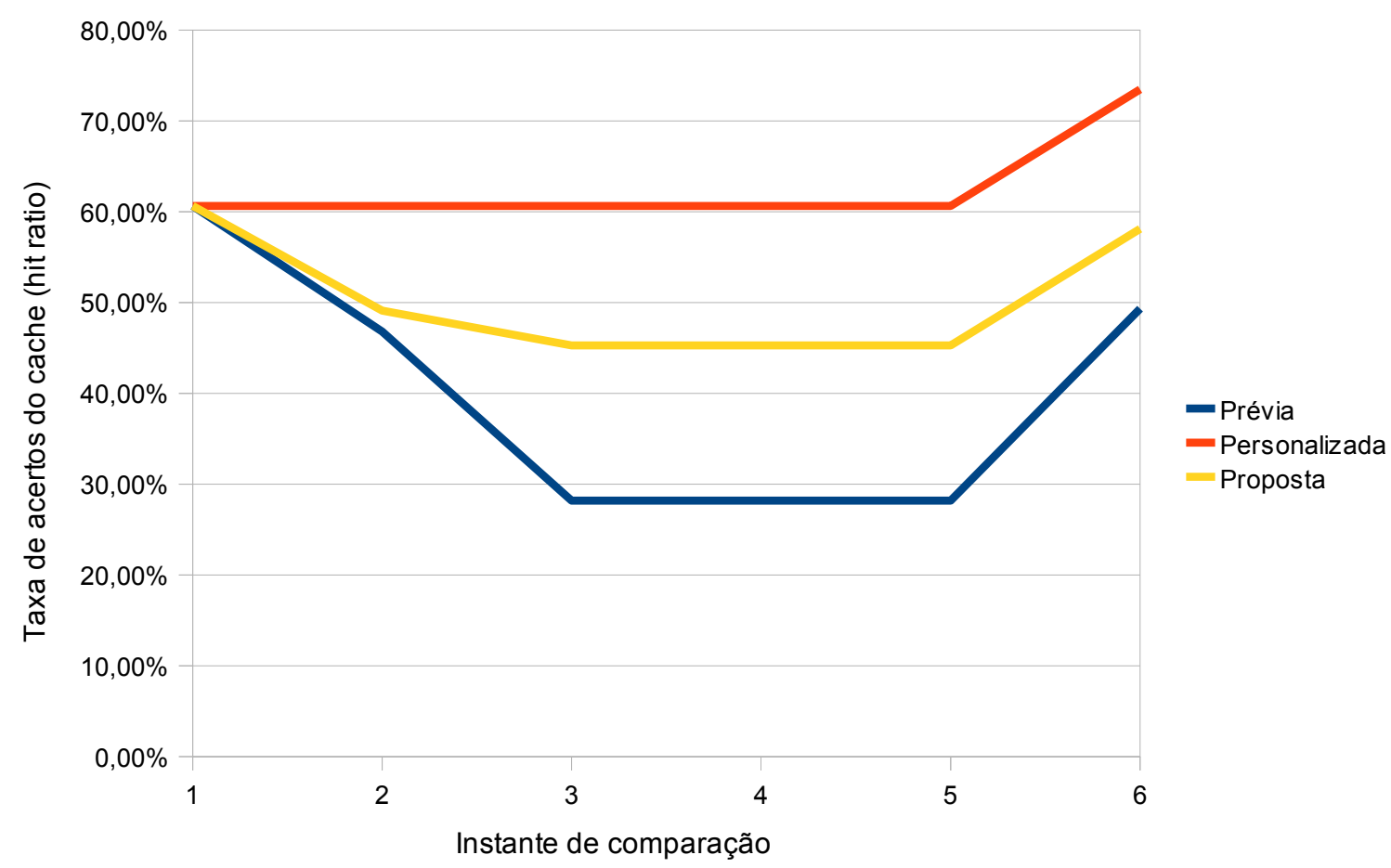

Figura 20: Taxa de acerto (hit ratio) do cache.

A figura 20 expressa a reutilização do fluxo de vídeo ao longo da rede, isto é, o número de vezes que um vídeo já adaptado e armazenado em cache, é reutilizado. Neste teste, a adaptação prévia apresenta os índices de menor desempenho, enquanto a adaptação personalizada, os índices de melhor desempenho. O serviço de adaptação de vídeo proposto tem desempenho superior se comparado a adaptação prévia, mas apresenta desvantagem em relação adaptação personalizada.

No entanto, conforme a figura 21 a adaptação personalizada tem um consumo maior nos enlaces, ao passo que o serviço de adaptação de vídeo proposto faz melhor uso da rede. Tal efeito é notado pois, na adaptação personalizada, apesar do fluxo de vídeo ser reutilizado desde a fonte até o agente de adaptação próximo ao cliente, a versão do vídeo transmitida é a de maior resolução, que tem um grande volume de dados. Por outro lado, o serviço de adaptação proposto aplica a adaptação em agentes distribuídos em pontos intermediários, de forma que nos enlaces próximos ao cliente, o vídeo já está em uma versão com um volume de dados menor. 


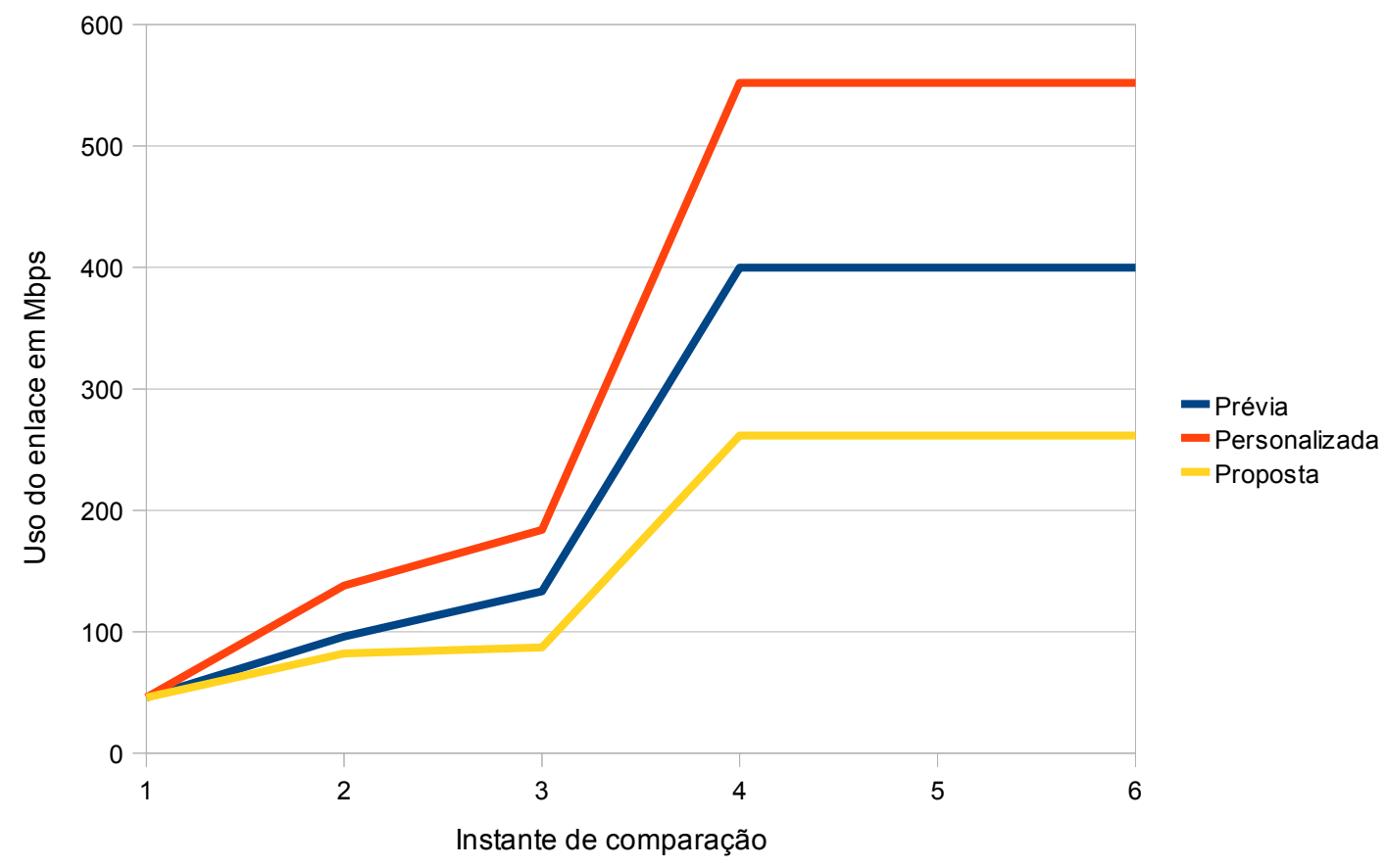

Figura 21: Utilização dos enlaces

\subsection{Análise dos Resultados}

Analisando os resultados apresentados na seção anterior, fica evidente que a proposta de serviço de adaptação de vídeo apresentada aqui, trás vários benefícios ao serviço de distribuição de vídeo no que diz respeito a utilização dos recursos disponíveis.

O primeiro, e de maior destaque, se refere ao uso eficiente dos enlaces de rede e do espaço em disco, tanto do servidor fonte, como dos servidores cache. Tal benefício ocorre pelo fato de que o serviço proposto é estruturado de maneira a atuar de forma conjunta com as técnicas de otimização aplicadas na rede, cache e multicast, tendo efeito semelhante tanto para serviços de vídeo sob demanda como para fluxos ao vivo.

O segundo benefício, e um dos grandes entraves ao uso da adaptação de forma ampla em CDNs, é a redução do custo computacional no processamento da adaptação. O serviço de adaptação proposto, pelo fato de atuar de forma integrada com os serviços de cache e multicast, permite minimizar ao máximo o número de operações de adaptação necessário para atender um grupo de usuários que estejam consumindo o mesmo vídeo, e que possuam restrições de acesso semelhantes. 
Outro item relevante a ser discutido, é a questão do uso de codecs escaláveis, que tem sido o foco de diversas pesquisas em adaptação de vídeo. Embora o uso destas técnicas reduzam o custo de processamento na adaptação de vídeo, como já citado, geram fluxos menos otimizados, em termos de taxa de compressão, quando comparados aos codecs "não escaláveis". Além disso, ainda são poucas as implementação destes codecs, de forma que poucos clientes são compatíveis com esses fluxos.

Assim, apesar da implementação utilizada para a realização dos testes neste artigo não fazer uso destes codecs escaláveis, a restrição a estes na implementação corrente advém do fato de que o agente de adaptação utiliza como engine de adaptação o GStreamer, que ainda não tem suporte a este tipo de codec. Entretanto, isso não é uma limitação do serviço de adaptação de vídeo proposto, dado que a sua especificação não define quais as operações de adaptação devem ser suportadas, de forma que futuras implementações poderão agregar o suporte a novas técnicas. 


\section{Conclusão}

No cenário atual as aplicações de distribuição de vídeo digital encontram-se em evidência. Aliado a isto, a diversidade de dispositivos à disposição do usuário é enorme, onde a maioria deles tem suporte a vídeo digital e conexão à Internet, como é o caso de laptops, palmtops e smartphones. Com isso, um número cada vez maior de serviços de distribuição de vídeo, em diferentes formatos, estão surgindo, tais como as bibliotecas de vídeos, os sistemas de IPTV e as WebTVs. Ao acessar estes serviços, o usuário tem a expectativa de ser atendido de acordo com os recursos disponíveis (dispositivo e conexão de rede) e do contexto em que ele se encontra, por isso a importância de desenvolver mecanismos de adaptação que garantam tanto o bom atendimento ao usuário quanto a boa utilização dos recursos do sistema e da rede.

A partir deste trabalho pode-se verificar que o uso de técnicas de adaptação de vídeo requer a análise de uma série de fatores. Tratar adequadamente estes fatores é chave para a provisão de uma solução aplicável, em que deve ser considerado um cenário bastante amplo onde os usuários possam consumir vídeos fazendo uso de diferentes dispositivos e utilizando diferentes tecnologias de rede para o acesso ao serviço. Ademais, é necessário ponderar se os impactos que cada estratégia de implementação do serviço de adaptação de vídeo poderão implicar negativamente nas técnicas de otimização (cache e multicast) utilizados pelas redes de distribuição de vídeo.

Dentro deste contexto, este trabalho desenvolveu um serviço de adaptação de vídeo que atenta a estas questões. Para isso, associa o uso de um modelo de adaptação baseado em perfís e o conceito de redes de serviços sobrepostos. Desta forma é possível implementar um serviço de adaptação de forma integrada com os demais serviços de distribuição de conteúdo usado nas CDNs. Sendo assim, o serviço proposto aqui pode trazer grandes benefícios ao ser integrado à diferentes sistemas de distribuição de vídeos, como IPTV, WebTVs e bibliotecas de vídeos digitais.

Para a avaliação do serviço, foram realizados um conjunto de testes experimentais e comparados os resultados a outras duas abordagem que tratam a questão de adaptação de vídeo. A partir destes resultados, verificou-se diversos benefícios do serviços de adaptação de vídeo proposto neste trabalho. 


\subsection{Contribuições}

As contribuições deste trabalho estão voltadas à um dos grandes desafios da adaptação de vídeo descritos na seção 2.2, a "Integração de Sistemas", apresentando uma nova abordagem de implantação de um serviço de adaptação utilizando redes de serviços sobrepostas. Assim, as principais contribuições decorrentes deste trabalho foram:

- Especificação de um serviço de adaptação de vídeo que atende às necessidades de uma CDN de forma integrada aos demais serviços utilizados por esta, de forma a minimizar os impactos negativos que a adaptação de vídeo pode causar.

- Implementação de um protótipo do serviço de adaptação capaz de realizar a adaptação de vídeo em tempo real ${ }^{1}$.

- Melhorias no protocolo OCP para suportar novos serviços de forma transparente, utilizado no contexto deste trabalho, para incluir o serviço de adaptação de vídeo (apêndice A).

- Análise dos impactos que as principais estratégias de adaptação causam em uma CDN, possibilitando identificar os custos para a sua implementação.

\subsection{Trabalhos Futuros}

Através das pesquisas realizadas para o desenvolvimento deste trabalho, foram identificadas algumas evoluções deste trabalho, são estas:

- O serviço de adaptação proposto neste trabalho, permite que a adaptação de vídeo possa ser realizada em diversos pontos da rede de distribuição, de forma que os efeitos da adaptação na rede podem variar conforme a localização onde a adaptação é realizada. Assim, é necessário elaborar modelos e algorítimos capazes

\footnotetext{
${ }^{1}$ Adaptação em tempo real no sentido que a adaptação é realizada no momento da transmissão, considerando que o processo de transcodificação do vídeo implica no acréscimo da latência da transmissão.
} 
de identificar a localização ótima dos agentes de adaptação na rede, considerando todos os aspectos de restrições do contexto de distribuição já pesquisados neste trabalho.

- O desenvolvimento de um simulador capaz de calcular os impactos da adaptação em uma rede também é um ponto a ser explorado. Tal simulador poderia avaliar os modelos e algorítimos que identificam a melhor localização dos agentes de adaptação.

- Outro ponto a ser pesquisado é o uso do serviço de adaptação em contextos intradomínio. Um dos tópicos a ser explorado neste sentido é a criação de mecanismos de contabilização (accounting) e faturamento (billing) para este tipo de serviço. Além disso, é necessário o desenvolvimento de protocolos de negociação do uso deste tipo de serviço.

- A implementação de um agente de adaptação com suporte a operações de transcodificação otimizadas (XIN; LIN; SUN, 2005) e a codecs escaláveis também é item a ser explorado. Neste caso é interessante que este seja capaz de realizar operações de "seleção de camadas"em fluxos de vídeo escaláveis e "transcodificação" entre um vídeo não escalável e um escalável. 


\section{Referências}

ANDERSEN, D. et al. Resilient overlay networks. ACM SIGCOMM Computer Communication Review, v. 32, n. 1, p. 66, janeiro 2002. ISSN 01464833.

ASADI, M. K. Adaptation de Contenu Multimédia avec MPEG-21 : Conversion de Ressources et Adaptation Sémantique de Scènes. 206 p. Tese (Doutorado) - École Nationale Supérieure des Télécommunications, 2005.

BöSZöRMéNYI, L. et al. Metadata driven adaptation in the ADMITS project. Signal Processing: Image Communication, Elsevier, v. 18, n. 8, p. 749-766, 2003.

BURNETT, I. et al. MPEG-21: Goals and Achievements. IEEE Multimedia, v. 10, n. 4, p. 60-70, 2003.

CHANG, S.; VETRO, A. Video adaptation: concepts, technologies, and open issues. Proceedings of the IEEE, v. 93, n. 1, p. 148-158, 2005.

CHANG, S.-f. et al. Overview of the MPEG-7 Standard. IEEE Transactions on Circuits and Systems for Video Technology, v. 11, n. 6, p. 688-695, 2001.

CLARK, D. et al. Overlay Networks and the Future of the Internet. Communications and Strategies, Citeseer, v. 63, n. 63, p. 109, 2006.

CRANOR, C. et al. Enhanced streaming services in a content distribution network. IEEE Internet Computing, v. 5, n. 4, p. 66-75, 2001. ISSN 10897801.

DIOT, C. et al. Deployment issues for the IP multicast service and architecture. IEEE Network, Citeseer, v. 14, n. 1, p. 78-88, 2000.

EBERHARD, M. et al. An interoperable delivery framework for scalable media resources. IEEE Wireless Communications, IEEE Press, v. 16, n. 5, p. 58-63, 2009.

GSTREAMER. GStreamer. 2010. Disponível em: <http://gstreamer.freedesktop.org/ Acesso em: 01 jun. 2010>.

GSTREAMER-JAVA. gstreamer-java. 2010. Disponível em: <http://code.google.com/p/gstreamer-java/ Acesso em: 01 jun. 2010>.

HLAVác, V. MPEG: A Video Compression Standard for Multimedia Applications. 2010. Disponível em: <http://erdos.csie.ncnu.edu.tw/slash hychen/multimedia/M Acesso em: 01 jun. $20>$. 
IQBAL, R.; SHIRMOHAMMADI, S. A light-weight federated video adaptation system for P2P overlays. In: IEEE International Conference on Multimedia and Expo. [S.I.: s.n.], 2009. p. $1126-1129$.

ISO/IEC 21000-7. Information Technology - Multimedia Framework - Part 7: Digital Item Adaptation. 2004.

KALVA, H. Issues in H.264/MPEG-2 Video Transcoding. In: First IEEE Consumer Communications and Networking Conference. Las Vegas, USA: IEEE Communications Society, 2004. p. 657-659.

KLYNE, G. et al. Composite Capability/Preference Profiles (CC/PP): Structure and Vocabularies 1.0. 2004.

KROPFBERGER, M. Multimedia streaming over best effort networks using multi-level adaptation and buffer smoothing algorithms. $177 \mathrm{p}$. Tese (Doutorado) Universitat Klagenfurt, 2004.

LACHNER, J. et al. Challenges toward user-centric multimedia. In: Proceedings of the Second International Workshop on Semantic Media Adaptation and Personalization. Washington, DC, USA: IEEE Computer Society, 2007. p. 159-164.

LAN, J.-W. D. S.-Y. Quality-Adaptive Proxy Caching for Peer-to-Peer Video Streaming Using Multiple Description Coding. Journal of Information Science and Engineering, v. 25, p. 687-701, 2009.

LAO, L. et al. A comparative study of multicast protocols: top, bottom, or in the middle? In: Proceedings IEEE INFOCOM 2005. 24th Annual Joint Conference of the IEEE Computer and Communications Societies. Miami, Florida USA: IEEE Communications Society, 2005. v. 4, p. 13-17.

LI, B.; LIU, J. Multirate video multicast over the internet: An overview. IEEE network, v. 17, n. 1, p. 24-29, 2003.

LI, Z. Resiliency and quality-of-service (qos) support in multicasting and overlay networks. 187 p. Tese (Doutorado) - University of California Davis, 2005.

LI, Z.; MOHAPATRA, P. QRON: QoS-aware routing in overlay networks. IEEE Journal on Selected Areas in Communications, v. 22, n. 1, p. 29-40, janeiro 2004. ISSN 0733-8716. 
MA, W.-Y. et al. Framework for adaptive content delivery in heterogeneous network environments. In: NAHRSTEDT, K.; FENG, W.-c. (Ed.). Multimedia Computing and Networking 2000. San Jose, CA, USA: Spie, 1999. p. 86-100. ISSN 0277786X.

MACINNIS, A. G. MPEG-2 systems. In: RODRIGUEZ, A. A. (Ed.). Society of PhotoOptical Instrumentation Engineers (SPIE) Conference Series. [S.I.]: SPIE, 1994. p. 274-278.

MATUSHIMA, R. Desenvolvimento de aplicações multimídia baseado em arquitetura orientada a serviços e nos padrões mpeg-7 e mpeg-21. 102 p. Dissertação (Mestrado) — Universidade de São Paulo, 2007.

MICROSOFT. O comprimento máximo da URL é de 2.083 caracteres no Internet Explorer. 2007.

MUNSIL, D.; SPEARS, S. DVD Benchmark The Chroma Upsampling Error and The 4:2:0 Interlaced Chroma Problem. 2003. Disponível em: $<$ http://www.hometheaterhifi.com/volumeackslash_8\_2/dvd-benchmark-special-report-chroma-bug-4-2001.html Acesso em: 01 jun. 2010>.

NAM, J. et al. Visual content adaptation according to user perception characteristics. IEEE Transactions on Multimedia, v. 7, n. 3, p. 435-445, 2005.

PANIS, G. et al. Bitstream syntax description: a tool for multimedia resource adaptation within MPEG-21. Signal Processing: Image Communication, Elsevier, v. 18, n. 8, p. 721-747, setembro 2003.

PEREIRA, F.; BURNETT, I. Universal multimedia experiences for tomorrow. IEEE Signal Processing Magazine, v. 20, n. 2, p. 63-73, 2003.

RADHA, H. M.; SCHAAR, M. V. D.; CHEN, Y. The MPEG-4 Fine-Grained Scalable Video Coding Method for Multimedia Streaming Over IP. IEEE Transactions on Multimedia, v. 3, n. 1, p. 53-68, 2001.

RNP. Rede Ipê. 2010. Disponível em: <http://www.rnp.br/backbone/ Acesso em: 01 jun. 2010>.

RO, Y. M.; YANG, S. Color Adaptation for Anomalous Trichromats. International Journal of Imaging Systems and Technology, v. 14, n. 1, p. 16--20, 2004. 
RYU, J.; SOHN, Y.; KIM, M. MPEG-7 Metadata Authoring Tool. In: MULTIMEDIA '02: Proceedings of the tenth ACM international conference on Multimedia. Juan-les-Pins, France: ACM, 2002. p. 267-270.

SAMIMI, F. et al. Service Clouds: Distributed infrastructure for adaptive communication services. IEEE Transactions on Network and Service Management, v. 4, n. 2, p. 84-95, 2007.

SCHWARZ, H.; MARPE, D.; WIEGAND, T. Overview of the Scalable Video Coding Extension of the H.264/AVC Standard. IEEE Transactions on Circuits and Systems for Video Technology, v. 17, n. 9, p. 1103-1120, setembro 2007. ISSN 1051-8215.

SMITH, J.; MOHAN, R.; LI, C. Scalable multimedia delivery for pervasive computing. In: Proceedings of the seventh ACM international conference on Multimedia. Orlando, Florida, United States: ACM, 1999. p. 131-140.

UCHOA, D. et al. A Management Platform for Multimedia Distribution in Country-wide Networks. In: Network Operations and Management Symposium, LANOMS.

Petrópolis, Brazil: [s.n.], 2007a. p. 20-27.

UCHOA, D. D. C. et al. Oversea: Towards a scalable and effective architecture for overlay networks. In: XIII Brazilian Symposium on Multimedia and the Web (WebMedia). Gramado, Brazil: ACM, 2007b.

VETRO, A. MPEG-21 digital item adaptation: enabling universal multimedia access. IEEE multimedia, Citeseer, v. 11, n. 1, p. 84-87, 2004.

VETRO, A.; CHRISTOPOULOS, C.; EBRAHIMI, T. Universal multimedia access. IEEE Signal Processing Magazine, v. 20, n. 2, p. 16, 2003.

VETRO, A.; CHRISTOPOULOS, C.; SUN, H. Video transcoding architectures and techniques: an overview. IEEE Signal Processing Magazine, v. 20, n. 2, p. 18-29, 2003.

VETRO, A.; TIMMERER, C. Digital item adaptation: overview of standardization and research activities. IEEE Transactions on Multimedia, Citeseer, v. 7, n. 3, p. 418-426, 2005.

WANG, X. et al. The MPEG-21 Rights Expression Language and Rights Data Dictionary. IEEE Transactions on Multimedia, v. 7, n. 3, p. 408-417, 2005. 
WEE, S.; APOSTOLOPOULOS, J. Secure scalable streaming and secure transcoding with JPEG-2000. In: Proceedings 2003 International Conference on Image Processing. [S.I.]: leee, 2003. p. 14-17. ISBN 0-7803-7750-8.

XIN, J.; LIN, C.; SUN, M. Digital video transcoding. Proceedings of the IEEE, v. 93, n. 1, p. 84-97, 2005.

YOUSSEF, A. JPEG AND MPEG STANDARDS. 2010. Disponível em: $<$ http://www.seas.gwu.edu $\wedge$ ayoussef/cs225/standards Acesso em: 01 jun. $20>$. 


\section{A Melhorias no Protocolo OCP}

As melhorias realizadas no protocolo OCP (Oversea Communication Protocol) são destinadas a tornar o uso do protocolo mais flexível, de forma que este possa transportar os dados de outros serviços implementados em uma rede de serviços sobrepostos, suportando assim o serviço de adaptação proposto neste trabalho.

A figura 22 ilustra a mensagem do protocolo OCP implementado no projeto GT-Overlay 2 , antes das melhorias.

\begin{tabular}{|c|c|c|c|c|c|c|c|c|}
\hline header & ocp-service & method $t$ & timestamp & keyld & cmac & & & \\
\hline \multirow{4}{*}{ body } & clientIP $\mathrm{m}$ & mediaService & mediald & \multicolumn{2}{|c|}{\begin{tabular}{|l|} 
medialnstance \\
\end{tabular}} & \multicolumn{2}{|c|}{ parameters } & \\
\hline & \multicolumn{8}{|c|}{ hidden path... } \\
\hline & hidden path & address & \begin{tabular}{||l|l} 
address & \\
\end{tabular} & address & address & hops & keyld & cmac \\
\hline & \multicolumn{2}{|c|}{ path address address } & s address & address & s hops & & & \\
\hline
\end{tabular}

Figura 22: Mensagem OCP

Esta mensagem é codificada como uma url (conhecida como rota) para ser usada pelo cliente (player de vídeo) no acesso a uma mídia localizada em um servidor. Para isso, os campos da mensagem são organizados como uma sequência de parâmetros da url, conforme o exemplo a seguir:

http://10.0.0.1:7000/ocp?s=SessionManagerIF\&t=1253308472874\&k=AAERFw..\& m=zZ_0qUJv6kU.\&c=j2tvyg..\&ms=dlive\& md=rnpNqnQccDI8_6BgkJR-8qVSISxmHEfED3WysGvVkdX1eo.\&mn=0\&p=dataProto_http-encoder_wme-format_wmv-resource_teste\& $h p=7 y A g q L G C S Z s . x L d F S 45 h i B 8 . j 2 t v \_A A A G W Q . \& v p=7 y A g q L G C S Z s . x L d F S 45 h i B 8 . j 2 t v \_A A A G W Q . \& h=A A A A A w . . \& e=0 \&$

A mensagem é codificada desta forma para minimizar o número de caracteres utilizados por esta, de modo que é possível gerar uma rota incluindo 100 nós sobrepostos com aproximadamente 600 caracteres, o que representa um pouco mais de 1/4 da url suportada pelo Internet Explorer (versão 4 a 7), que é de 2048 caracteres (MICROSOFT, 2007).

No entanto, o formato desta mensagem tem a limitação de dar suporte apenas ao serviço de multicast sobreposto, que era o foco do projeto GT-Overlay. Assim, as melhorias decor- 
rentes deste trabalho garantem maior flexibilidade ao protocolo pois permitem agregar diversos serviços de forma independente entre si, isto é, cada agente só precisa interpretar as informações referentes ao seu serviço. A figura 23 ilustra o formato da mensagem OCP após as melhorias desenvolvidas.

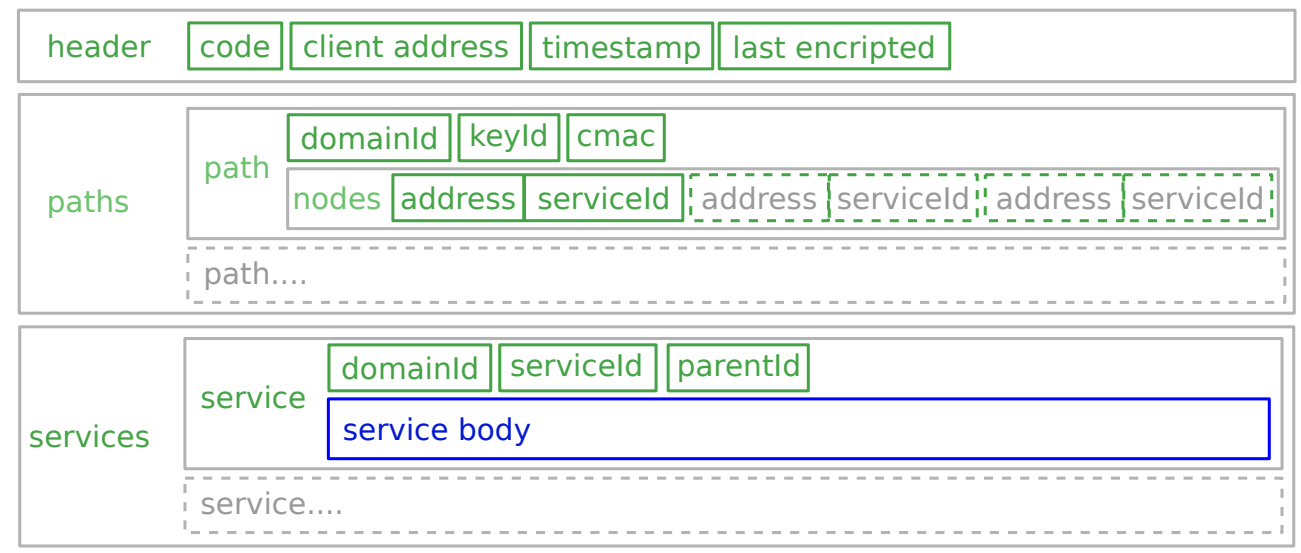

Figura 23: Mensagem OCP

Estas modificações implicaram em mudanças na forma como a mensagem é codificada como url, isto porque o novo formato da mensagem utiliza estruturas hierárquicas, necessárias para representar todos os dados. Como consequência, foi desenvolvida uma nova forma de codificar a mensagem em url, utilizando os caracteres "(" e ")" para representar as informações de forma aninhadas e o caractere " " para separa as sequências, conforme o exemplo a baixo:

http://10.0.0.1:8080/adaptation?ocp=m(c(0)t (AAABKSlce-I.) a (fwAAAQAAB9o.) e(0)p((h(AAGGmOkDrtMegj_K) \I

n (cYuo9V9n'Ru04VmOV' OLOTrF9R' qHGvHebU ' Cx7Z7jmy)) ' (h (AALbw6zRiRDJD_6Q)n (NKWmi4qM'Fz-1lz52' 'MOOm28Tj'AAF_AAQE))) \। $\mathrm{s}(($ h (AAEAAAAAAAI.)b(id2))' (h(AAIAAAAAAAE.)b(id1))))

Com estas modificações, além de possibilitar incluir o serviço de adaptação na mensagem OCP, integrando os serviços de multicast / cache e adaptação, possibilita que novos serviços possam ser adicionados sem que seja necessário novas modificações no protocolo. 


\section{B Metadados Utilizados}

Tabela 5: Informações de Contexto

\begin{tabular}{|l|}
\hline Características da Mídia (Camada de Aplicação - “Portal”) \\
\hline mpeg7:MediaFormatType:FileFormat \\
mpeg7:MediaFormatType:BitRate \\
mpeg7:MediaFormatType:VisualCoding:Format \\
mpeg7:MediaFormatType:VisualCoding:colorDomain \\
mpeg7:MediaFormatType:VisualCoding:Frame:height \\
mpeg7:MediaFormatType:VisualCoding:Frame:width \\
mpeg7:MediaFormatType:VisualCoding:Frame:rate \\
mpeg7:MediaFormatType:AudioCoding:Format \\
mpeg7:MediaFormatType:AudioCoding:Sample:rate \\
mpeg7:MediaFormatType:AudioCoding:Sample:bitsPer \\
\hline Preferências do Usuário (Camada de Aplicação - "Portal”) \\
\hline mpeg7:SourcePreferences:MediaFormatType:VisualCoding:Format \\
mpeg7:SourcePreferences:MediaFormatType:VisualCoding:Frame:height \\
mpeg7:SourcePreferences:MediaFormatType:VisualCoding:Frame:width \\
mpeg7:SourcePreferences:MediaFormatType:VisualCoding:Frame:rate \\
mpeg7:SourcePreferences:MediaFormatType:AudioCoding:Format \\
mpeg7:SourcePreferences:MediaFormatType:AudioCoding:Sample:rate \\
mpeg7:SourcePreferences:MediaFormatType:AudioCoding:Sample:bitsPer \\
\hline Capacidades do Terminal de Acesso (Camada de Aplicação - “Portal”) \\
\hline mpeg21:dia:DisplayCapabilitiesType:Resolution:horizontal \\
mpeg21:dia:DisplayCapabilitiesType:Resolution:vertical \\
mpeg21:dia:AudioOutputCapabilitiesType:samplingFrequency \\
mpeg21:dia:AudioOutputCapabilitiesType:numChannels \\
\hline Capacidades e Condições da Rede (Camada BOS) \\
\hline mpeg21:dia:NetworkCapability:maxCapacity \\
mpeg21:dia:NetworkCapability:minGuarenteed \\
mpeg21:dia:NetworkCondition:AvailableBandwidth:minimum \\
mpeg21:dia:NetworkCondition:AvailableBandwidth:maximum \\
mpeg21:dia:NetworkCondition:AvailableBandwidth:average \\
mpeg21:dia:NetworkCondition:AvailableBandwidth:interval \\
\hline Condições do Nó de Serviço (Camada BOS) \\
\hline snmp:UCD-SNMP-MIB::ssCpuldle \\
snmp:UCD-SNMP-MIB::memAvailReal \\
snmp:IF-MIB::ifSpeed \\
snmp:IF-MIB::iflnOctets \\
snmp:IF-MIB::ifOutOctets \\
snmp:IF-MIB::ifOutQLen \\
\hline Capacidades do Nó de Serviço (Camada SoN) \\
\hline oversea:Son:adaptation:operationsSupported \\
\hline
\end{tabular}


Tabela 6: Informações enviadas aos agentes de adaptação \begin{tabular}{l}
\hline oversea:son:adaptation:muxer \\
oversea:son:adaptation:video:codec \\
oversea:son:adaptation:video:frame:horizontal \\
oversea:son:adaptation:video:frame:vertical \\
oversea:son:adaptation:video:frame:rate \\
oversea:son:adaptation:video:bitrate \\
oversea:son:adaptation:audio:codec \\
oversea:son:adaptation:audio:numChhannels \\
oversea:son:adaptation:audio:samplingFrequency \\
oversea:son:adaptation:audio:bitare
\end{tabular} 


\section{Detalhamento dos Resultados dos Testes}

Os valores utilizados para a comparação das estratégias estão descritos nas tabelas a seguir. Estes valores foram calculados a partir dos valores obtidos com os testes utilizando o protótipo implementado. Nos testes de taxa de acerto do cache não são considerados os valores dos nós p13 ao p24 por não representarem valores significativos para a comparação, pois são iguais em todas as estratégias.

Tabela 7: Instantes da avaliação.

\begin{tabular}{|c|c|c|c|}
\hline Instante & Vídeos & Versões & Clientes por $\Delta$ (localidade) \\
\hline 1 & 1 & SD & 1 \\
2 & 1 & HD e SD & 1 \\
3 & 1 & FullHD, HD, SD e LD & 1 \\
4 & 3 & FullHD, HD, SD e LD & 1 \\
5 & 3 & FullHD, HD, SD e LD & 2 \\
6 & 3 & FullHD, HD, SD e LD & 3 \\
\hline
\end{tabular}

Tabela 8: Operações de adaptação realizadas: adaptação prévia

\begin{tabular}{|c|c|c|c|c|c|c|}
\hline Nó & Instante 1 & Instante 2 & Instante 3 & Instante 4 & Instante 5 & Instante 6 \\
\hline \hline p1 & 0 & 0 & 0 & 0 & 0 & 0 \\
\hline p2 & 0 & 0 & 0 & 0 & 0 & 0 \\
\hline p3 & 0 & 0 & 0 & 0 & 0 & 0 \\
\hline p4 & 0 & 1 & 3 & 9 & 9 & 9 \\
\hline \hline p5 & 0 & 0 & 0 & 0 & 0 & 0 \\
\hline p6 & 0 & 0 & 0 & 0 & 0 & 0 \\
\hline p7 & 0 & 0 & 0 & 0 & 0 & 0 \\
\hline p8 & 0 & 0 & 0 & 0 & 0 & 0 \\
\hline \hline p9 & 0 & 0 & 0 & 0 & 0 & 0 \\
\hline p10 & 0 & 0 & 0 & 0 & 0 & 0 \\
\hline p11 & 0 & 0 & 0 & 0 & 0 & 0 \\
\hline p12 & 0 & 0 & 0 & 0 & 0 & 0 \\
\hline p13 & 0 & 0 & 0 & 0 & 0 & 0 \\
\hline \hline p14 & 0 & 0 & 0 & 0 & 0 & 0 \\
\hline p15 & 0 & 0 & 0 & 0 & 0 & 0 \\
\hline p16 & 0 & 0 & 0 & 0 & 0 & 0 \\
\hline p17 & 0 & 0 & 0 & 0 & 0 & 0 \\
\hline p18 & 0 & 0 & 0 & 0 & 0 & 0 \\
\hline \hline p19 & 0 & 0 & 0 & 0 & 0 & 0 \\
\hline p20 & 0 & 0 & 0 & 0 & 0 & 0 \\
\hline p21 & 0 & 0 & 0 & 0 & 0 & 0 \\
\hline \hline p22 & 0 & 0 & 0 & 0 & 0 & 0 \\
\hline p23 & 0 & 0 & 0 & 0 & 0 & 0 \\
\hline p24 & 0 & 0 & 0 & 0 & 0 & 0 \\
\hline
\end{tabular}


Tabela 9: Operações de adaptação realizadas: adaptação personalizada

\begin{tabular}{|c|c|c|c|c|c|c|}
\hline Nó & Instante 1 & Instante 2 & Instante 3 & Instante 4 & Instante 5 & Instante 6 \\
\hline \hline p1 & 0 & 0 & 0 & 0 & 0 & 0 \\
\hline p2 & 0 & 0 & 0 & 0 & 0 & 0 \\
\hline p3 & 0 & 0 & 0 & 0 & 0 & 0 \\
\hline p4 & 0 & 0 & 0 & 0 & 0 & 0 \\
\hline p5 & 0 & 1 & 2 & 6 & 12 & 18 \\
\hline p6 & 0 & 1 & 1 & 3 & 6 & 9 \\
\hline p7 & 0 & 0 & 1 & 3 & 6 & 9 \\
\hline p8 & 0 & 0 & 1 & 3 & 6 & 9 \\
\hline \hline p9 & 0 & 0 & 1 & 3 & 6 & 9 \\
\hline p10 & 0 & 0 & 0 & 0 & 0 & 0 \\
\hline p11 & 0 & 1 & 1 & 3 & 6 & 9 \\
\hline p12 & 0 & 0 & 1 & 3 & 6 & 9 \\
\hline p13 & 0 & 0 & 1 & 3 & 6 & 9 \\
\hline \hline p14 & 0 & 1 & 1 & 3 & 6 & 9 \\
\hline p15 & 0 & 1 & 1 & 3 & 6 & 9 \\
\hline p16 & 0 & 1 & 1 & 3 & 6 & 9 \\
\hline p17 & 0 & 1 & 1 & 3 & 6 & 9 \\
\hline p18 & 0 & 1 & 1 & 3 & 6 & 9 \\
\hline \hline p19 & 0 & 1 & 1 & 3 & 6 & 9 \\
\hline p20 & 0 & 1 & 1 & 3 & 6 & 9 \\
\hline p21 & 0 & 1 & 1 & 3 & 6 & 9 \\
\hline \hline p22 & 0 & 1 & 1 & 3 & 6 & 9 \\
\hline p23 & 0 & 1 & 1 & 3 & 6 & 9 \\
\hline p24 & 0 & 1 & 1 & 3 & 6 & 9 \\
\hline & & & & & & \\
\hline
\end{tabular}

Tabela 10: Operações de adaptação realizadas: serviço proposto

\begin{tabular}{|c|c|c|c|c|c|c|}
\hline Nó & Instante 1 & Instante 2 & Instante 3 & Instante 4 & Instante 5 & Instante 6 \\
\hline \hline p1 & 0 & 1 & 1 & 3 & 3 & 3 \\
\hline p2 & 0 & 1 & 1 & 3 & 3 & 3 \\
\hline p3 & 0 & 1 & 1 & 3 & 3 & 3 \\
\hline p4 & 0 & 1 & 1 & 3 & 3 & 3 \\
\hline \hline p5 & 0 & 1 & 2 & 6 & 6 & 6 \\
\hline p6 & 0 & 1 & 2 & 6 & 6 & 6 \\
\hline p7 & 0 & 0 & 1 & 3 & 3 & 3 \\
\hline p8 & 0 & 1 & 2 & 6 & 6 & 6 \\
\hline \hline p9 & 0 & 0 & 1 & 3 & 3 & 3 \\
\hline p10 & 0 & 1 & 1 & 3 & 3 & 3 \\
\hline p11 & 0 & 1 & 2 & 6 & 6 & 6 \\
\hline p12 & 0 & 0 & 1 & 3 & 3 & 3 \\
\hline p13 & 0 & 0 & 2 & 6 & 6 & 6 \\
\hline \hline p14 & 0 & 0 & 0 & 0 & 0 & 0 \\
\hline p15 & 0 & 0 & 0 & 0 & 0 & 0 \\
\hline p16 & 0 & 0 & 0 & 0 & 0 & 0 \\
\hline p17 & 0 & 0 & 0 & 0 & 0 & 0 \\
\hline p18 & 0 & 0 & 0 & 0 & 0 & 0 \\
\hline \hline p19 & 0 & 0 & 0 & 0 & 0 & 0 \\
\hline p20 & 0 & 0 & 0 & 0 & 0 & 0 \\
\hline p21 & 0 & 0 & 0 & 0 & 0 & 0 \\
\hline \hline p22 & 0 & 0 & 0 & 0 & 0 & 0 \\
\hline p23 & 0 & 0 & 0 & 0 & 0 & 0 \\
\hline p24 & 0 & 0 & 0 & 0 & 0 & 0 \\
\hline
\end{tabular}


Tabela 11: Volume de dados armazenados: adaptação prévia

\begin{tabular}{|c|c|c|c|c|c|c|}
\hline Nó & Instante 1 & Instante 2 & Instante 3 & Instante 4 & Instante 5 & Instante 6 \\
\hline \hline p1 & 225 & 900 & 1843 & 5529 & 5529 & 5529 \\
\hline p2 & 225 & 900 & 1125 & 3375 & 3375 & 3375 \\
\hline p3 & 225 & 900 & 1843 & 5529 & 5529 & 5529 \\
\hline p4 & 225 & 900 & 1843 & 5529 & 5529 & 5529 \\
\hline p5 & 225 & 900 & 943 & 2829 & 2829 & 2829 \\
\hline p6 & 225 & 225 & 268 & 804 & 804 & 804 \\
\hline p7 & 225 & 675 & 675 & 2025 & 2025 & 2025 \\
\hline p8 & 225 & 900 & 1700 & 5100 & 5100 & 5100 \\
\hline p9 & 225 & 900 & 943 & 2829 & 2829 & 2829 \\
\hline p10 & 225 & 225 & 268 & 804 & 804 & 804 \\
\hline p11 & 225 & 225 & 268 & 804 & 804 & 804 \\
\hline p12 & 225 & 675 & 1575 & 4725 & 4725 & 4725 \\
\hline p13 & 225 & 900 & 1800 & 5400 & 5400 & 5400 \\
\hline p14 & 225 & 225 & 225 & 675 & 675 & 675 \\
\hline p15 & 225 & 225 & 225 & 675 & 675 & 675 \\
\hline p16 & 225 & 225 & 255 & 765 & 765 & 765 \\
\hline p17 & 225 & 225 & 225 & 675 & 675 & 675 \\
\hline p18 & 225 & 225 & 43 & 129 & 129 & 129 \\
\hline p19 & 225 & 225 & 225 & 675 & 675 & 675 \\
\hline p20 & 225 & 225 & 43 & 129 & 129 & 129 \\
\hline p21 & 225 & 225 & 225 & 675 & 675 & 675 \\
\hline p22 & 225 & 225 & 43 & 129 & 129 & 129 \\
\hline p23 & 225 & 225 & 43 & 129 & 129 & 129 \\
\hline p24 & 225 & 225 & 225 & 675 & 675 & 675 \\
\hline
\end{tabular}

Tabela 12: Volume de dados armazenados: adaptação personalizada

\begin{tabular}{|c|c|c|c|c|c|c|}
\hline Nó & Instante 1 & Instante 2 & Instante 3 & Instante 4 & Instante 5 & Instante 6 \\
\hline \hline p1 & 225 & 675 & 900 & 2700 & 2700 & 2700 \\
\hline p2 & 225 & 675 & 900 & 2700 & 2700 & 2700 \\
\hline p3 & 225 & 675 & 900 & 2700 & 2700 & 2700 \\
\hline p4 & 225 & 675 & 900 & 2700 & 2700 & 2700 \\
\hline p5 & 225 & 675 & 900 & 2700 & 2700 & 2700 \\
\hline p6 & 225 & 675 & 900 & 2700 & 2700 & 2700 \\
\hline p7 & 225 & 675 & 900 & 2700 & 2700 & 2700 \\
\hline p8 & 225 & 675 & 900 & 2700 & 2700 & 2700 \\
\hline p9 & 225 & 675 & 900 & 2700 & 2700 & 2700 \\
\hline p10 & 225 & 675 & 900 & 2700 & 2700 & 2700 \\
\hline p11 & 225 & 675 & 900 & 2700 & 2700 & 2700 \\
\hline p12 & 225 & 675 & 900 & 2700 & 2700 & 2700 \\
\hline p13 & 225 & 675 & 900 & 2700 & 2700 & 2700 \\
\hline p14 & 225 & 675 & 900 & 2700 & 2700 & 2700 \\
\hline p15 & 225 & 675 & 900 & 2700 & 2700 & 2700 \\
\hline p16 & 225 & 675 & 900 & 2700 & 2700 & 2700 \\
\hline p17 & 225 & 675 & 900 & 2700 & 2700 & 2700 \\
\hline p18 & 225 & 675 & 900 & 2700 & 2700 & 2700 \\
\hline p19 & 225 & 675 & 900 & 2700 & 2700 & 2700 \\
\hline p20 & 225 & 675 & 900 & 2700 & 2700 & 2700 \\
\hline p21 & 225 & 675 & 900 & 2700 & 2700 & 2700 \\
\hline p22 & 225 & 675 & 900 & 2700 & 2700 & 2700 \\
\hline p23 & 225 & 675 & 900 & 2700 & 2700 & 2700 \\
\hline p24 & 225 & 675 & 900 & 2700 & 2700 & 2700 \\
\hline
\end{tabular}


Tabela 13: Volume de dados armazenados: serviço proposto

\begin{tabular}{|c|c|c|c|c|c|c|}
\hline Nó & Instante 1 & Instante 2 & Instante 3 & Instante 4 & Instante 5 & Instante 6 \\
\hline \hline p1 & 225 & 675 & 900 & 2700 & 2700 & 2700 \\
\hline p2 & 225 & 675 & 900 & 900 & 900 & 900 \\
\hline p3 & 225 & 675 & 900 & 2700 & 2700 & 2700 \\
\hline p4 & 225 & 675 & 900 & 2700 & 2700 & 2700 \\
\hline p5 & 225 & 675 & 675 & 2025 & 2025 & 2025 \\
\hline p6 & 225 & 225 & 225 & 675 & 675 & 675 \\
\hline p7 & 225 & 675 & 675 & 2025 & 2025 & 2025 \\
\hline p8 & 225 & 675 & 900 & 2700 & 2700 & 2700 \\
\hline p9 & 225 & 675 & 675 & 2025 & 2025 & 2025 \\
\hline p10 & 225 & 225 & 225 & 675 & 675 & 675 \\
\hline p11 & 225 & 225 & 225 & 675 & 675 & 675 \\
\hline p12 & 225 & 675 & 900 & 2700 & 2700 & 2700 \\
\hline p13 & 225 & 675 & 900 & 2700 & 2700 & 2700 \\
\hline p14 & 225 & 225 & 225 & 675 & 675 & 675 \\
\hline p15 & 225 & 225 & 225 & 675 & 675 & 675 \\
\hline p16 & 225 & 225 & 225 & 675 & 675 & 675 \\
\hline p17 & 225 & 225 & 225 & 675 & 675 & 675 \\
\hline p18 & 225 & 225 & 43 & 129 & 129 & 129 \\
\hline p19 & 225 & 225 & 225 & 675 & 675 & 675 \\
\hline p20 & 225 & 225 & 43 & 129 & 129 & 129 \\
\hline p21 & 225 & 225 & 225 & 675 & 675 & 675 \\
\hline p22 & 225 & 225 & 43 & 129 & 129 & 129 \\
\hline p23 & 225 & 225 & 43 & 129 & 129 & 129 \\
\hline p24 & 225 & 225 & 225 & 675 & 675 & 675 \\
\hline
\end{tabular}

Tabela 14: Taxa de acerto (hit ratio) do cache: adaptação prévia

\begin{tabular}{|c|c|c|c|c|c|}
\hline p1 75,00\% & $66,67 \%$ & $50,00 \%$ & $50,00 \%$ & $55,56 \%$ & $60,00 \%$ \\
\hline p2 $66,67 \%$ & $33,33 \%$ & $33,33 \%$ & $33,33 \%$ & $50,00 \%$ & $60,00 \%$ \\
\hline p3 $80,00 \%$ & $75,00 \%$ & $60,00 \%$ & $60,00 \%$ & $63,64 \%$ & $66,67 \%$ \\
\hline p4 100,00\% & $100,00 \%$ & $100,00 \%$ & $100,00 \%$ & $100,00 \%$ & $100,00 \%$ \\
\hline p5 75,00\% & $50,00 \%$ & $40,00 \%$ & $40,00 \%$ & $57,14 \%$ & $66,67 \%$ \\
\hline p6 50,00\% & $50,00 \%$ & $0,00 \%$ & $0,00 \%$ & $33,33 \%$ & $50,00 \%$ \\
\hline p7 0,00\% & $0,00 \%$ & $0,00 \%$ & $0,00 \%$ & $50,00 \%$ & $66,67 \%$ \\
\hline p8 75,00\% & $50,00 \%$ & $25,00 \%$ & $25,00 \%$ & $50,00 \%$ & $62,50 \%$ \\
\hline p9 50,00\% & $0,00 \%$ & $0,00 \%$ & $0,00 \%$ & $25,00 \%$ & $40,00 \%$ \\
\hline p10 50,00\% & $50,00 \%$ & $33,33 \%$ & $33,33 \%$ & $33,33 \%$ & $33,33 \%$ \\
\hline p11 50,00\% & $50,00 \%$ & $0,00 \%$ & $0,00 \%$ & $33,33 \%$ & $50,00 \%$ \\
\hline p12 50,00\% & $50,00 \%$ & $0,00 \%$ & $0,00 \%$ & $50,00 \%$ & $66,67 \%$ \\
\hline p13 66,67\% & $33,33 \%$ & $25,00 \%$ & $25,00 \%$ & $40,00 \%$ & $50,00 \%$ \\
\hline
\end{tabular}

Tabela 15: Taxa de acerto (hit ratio) do cache: adaptação personalizada

\begin{tabular}{|c|c|c|c|c|c|}
\hline p1 75,00\% & $75,00 \%$ & $75,00 \%$ & $75,00 \%$ & $80,00 \%$ & $83,33 \%$ \\
\hline p2 $66,67 \%$ & $66,67 \%$ & $66,67 \%$ & $66,67 \%$ & $75,00 \%$ & $80,00 \%$ \\
\hline p3 80,00\% & $80,00 \%$ & $80,00 \%$ & $80,00 \%$ & $83,33 \%$ & $85,71 \%$ \\
\hline p4 100,00\% & $100,00 \%$ & $100,00 \%$ & $100,00 \%$ & $100,00 \%$ & $100,00 \%$ \\
\hline p5 75,00\% & $75,00 \%$ & $75,00 \%$ & $75,00 \%$ & $83,33 \%$ & $87,50 \%$ \\
\hline p6 50,00\% & $50,00 \%$ & $50,00 \%$ & $50,00 \%$ & $66,67 \%$ & $75,00 \%$ \\
\hline p7 0,00\% & $0,00 \%$ & $0,00 \%$ & $0,00 \%$ & $50,00 \%$ & $66,67 \%$ \\
\hline p8 75,00\% & $75,00 \%$ & $75,00 \%$ & $75,00 \%$ & $83,33 \%$ & $85,71 \%$ \\
\hline p9 50,00\% & $50,00 \%$ & $50,00 \%$ & $50,00 \%$ & $66,67 \%$ & $75,00 \%$ \\
\hline p10 50,00\% & $50,00 \%$ & $50,00 \%$ & $50,00 \%$ & $50,00 \%$ & $50,00 \%$ \\
\hline p11 50,00\% & $50,00 \%$ & $50,00 \%$ & $50,00 \%$ & $66,67 \%$ & $75,00 \%$ \\
\hline p12 50,00\% & $50,00 \%$ & $50,00 \%$ & $50,00 \%$ & $75,00 \%$ & $83,33 \%$ \\
\hline p13 66,67\% & $66,67 \%$ & $66,67 \%$ & $66,67 \%$ & $75,00 \%$ & $80,00 \%$ \\
\hline
\end{tabular}


Tabela 16: Taxa de acerto (hit ratio) do cache: serviço proposto

\begin{tabular}{|c|c|c|c|c|c|}
\hline p1 75,00\% & $60,00 \%$ & $60,00 \%$ & $60,00 \%$ & $66,67 \%$ & $71,43 \%$ \\
\hline p2 $66,67 \%$ & $50,00 \%$ & $50,00 \%$ & $50,00 \%$ & $60,00 \%$ & $66,67 \%$ \\
\hline p3 $80,00 \%$ & $66,67 \%$ & $66,67 \%$ & $66,67 \%$ & $71,43 \%$ & $75,00 \%$ \\
\hline p4 100,00\% & $75,00 \%$ & $75,00 \%$ & $75,00 \%$ & $75,00 \%$ & $75,00 \%$ \\
\hline p5 75,00\% & $60,00 \%$ & $57,14 \%$ & $57,14 \%$ & $66,67 \%$ & $72,73 \%$ \\
\hline p6 50,00\% & $50,00 \%$ & $40,00 \%$ & $40,00 \%$ & $50,00 \%$ & $57,14 \%$ \\
\hline p7 0,00\% & $0,00 \%$ & $0,00 \%$ & $0,00 \%$ & $50,00 \%$ & $66,67 \%$ \\
\hline p8 75,00\% & $60,00 \%$ & $50,00 \%$ & $50,00 \%$ & $62,50 \%$ & $70,00 \%$ \\
\hline p9 50,00\% & $50,00 \%$ & $33,33 \%$ & $33,33 \%$ & $50,00 \%$ & $60,00 \%$ \\
\hline p10 50,00\% & $33,33 \%$ & $33,33 \%$ & $33,33 \%$ & $33,33 \%$ & $33,33 \%$ \\
\hline p11 50,00\% & $33,33 \%$ & $50,00 \%$ & $50,00 \%$ & $60,00 \%$ & $66,67 \%$ \\
\hline p12 50,00\% & $50,00 \%$ & $33,33 \%$ & $33,33 \%$ & $60,00 \%$ & $71,43 \%$ \\
\hline p13 66,67\% & $50,00 \%$ & $40,00 \%$ & $40,00 \%$ & $50,00 \%$ & $57,14 \%$ \\
\hline
\end{tabular}

Tabela 17: Utilização dos enlaces: adaptação prévia

\begin{tabular}{|c|c|c|c|c|c|c|}
\hline Enlace & Instante 1 & Instante 2 & Instante 3 & Instante 4 & Instante 5 & Instante 6 \\
\hline \hline $\mathrm{p} 1-\mathrm{p} 4$ & 2 & 8 & 16,3 & 48,9 & 48,9 & 48,9 \\
\hline $\mathrm{p} 4-\mathrm{p} 3$ & 2 & 8 & 16,3 & 48,9 & 48,9 & 48,9 \\
\hline $\mathrm{p} 3-\mathrm{p} 2$ & 2 & 8 & 10 & 30 & 30 & 30 \\
\hline $\mathrm{p} 2-\mathrm{p} 1$ & 0 & 0 & 0 & 0 & 0 & 0 \\
\hline $\mathrm{p} 1-\mathrm{p} 5$ & 2 & 8 & 8,3 & 24,9 & 24,9 & 24,9 \\
\hline $\mathrm{p} 5-\mathrm{p} 6$ & 2 & 2 & 2,3 & 6,9 & 6,9 & 6,9 \\
\hline $\mathrm{p} 6-\mathrm{p} 7$ & 0 & 0 & 0 & 0 & 0 & 0 \\
\hline $\mathrm{p} 7-\mathrm{p} 8$ & 2 & 6 & 6 & 18 & 18 & 18 \\
\hline $\mathrm{p} 8-\mathrm{p} 1$ & 2 & 8 & 16 & 48 & 48 & 48 \\
\hline $\mathrm{p} 3-\mathrm{p9}$ & 2 & 8 & 8,3 & 24,9 & 24,9 & 24,9 \\
\hline $\mathrm{p} 9-\mathrm{p} 10$ & 2 & 2 & 2,3 & 6,9 & 6,9 & 6,9 \\
\hline $\mathrm{p} 10-\mathrm{p} 11$ & 2 & 2 & 2,3 & 6,9 & 6,9 & 6,9 \\
\hline $\mathrm{p} 11-\mathrm{p} 12$ & 0 & 0 & 0 & 0 & 0 & 0 \\
\hline $\mathrm{p} 12-\mathrm{p} 13$ & 2 & 6 & 14 & 42 & 42 & 42 \\
\hline $\mathrm{p} 13-\mathrm{p3}$ & 2 & 8 & 16 & 48 & 48 & 48 \\
\hline \hline $\mathrm{p} 1-\mathrm{p} 14$ & 2 & 2 & 2 & 6 & 6 & 6 \\
\hline $\mathrm{p} 2-\mathrm{p} 15$ & 2 & 2 & 2 & 6 & 6 & 6 \\
\hline $\mathrm{p} 2-\mathrm{p} 16$ & 2 & 2 & 2 & 6 & 6 & 6 \\
\hline $\mathrm{p} 3-\mathrm{p} 17$ & 2 & 2 & 2 & 6 & 6 & 6 \\
\hline $\mathrm{p} 4-18$ & 2 & 2 & 0,3 & 0,9 & 0,9 & 0,9 \\
\hline \hline $\mathrm{p} 5-\mathrm{p} 19$ & 2 & 2 & 2 & 6 & 6 & 6 \\
\hline $\mathrm{p} 6-\mathrm{p} 20$ & 2 & 2 & 0,3 & 0,9 & 0,9 & 0,9 \\
\hline $\mathrm{p} 8-\mathrm{p} 21$ & 2 & 2 & 2 & 6 & 6 & 6 \\
\hline \hline $\mathrm{p} 10-\mathrm{p} 22$ & 2 & 2 & 0,3 & 0,9 & 0,9 & 0,9 \\
\hline $\mathrm{p} 11-\mathrm{p} 23$ & 2 & 2 & 0,3 & 0,9 & 0,9 & 0,9 \\
\hline $\mathrm{p} 13-\mathrm{p} 24$ & 2 & 2 & 2 & 6 & 6 & 6 \\
\hline
\end{tabular}


Tabela 18: Utilização dos enlaces: adaptação personalizada

\begin{tabular}{|c|c|c|c|c|c|c|}
\hline Enlace & Instante 1 & Instante 2 & Instante 3 & Instante 4 & Instante 5 & Instante 6 \\
\hline \hline p1-p4 & 2 & 6 & 8 & 24 & 24 & 24 \\
\hline p4-p3 & 2 & 6 & 8 & 24 & 24 & 24 \\
\hline p3-p2 & 2 & 6 & 8 & 24 & 24 & 24 \\
\hline p2-p1 & 0 & 0 & 0 & 0 & 0 & 0 \\
\hline \hline p1-p5 & 2 & 6 & 8 & 24 & 24 & 24 \\
\hline p5-p6 & 2 & 6 & 8 & 24 & 24 & 24 \\
\hline p6-p7 & 0 & 0 & 0 & 0 & 0 & 0 \\
\hline p7-p8 & 2 & 6 & 8 & 24 & 24 & 24 \\
\hline p8-p1 & 2 & 6 & 8 & 24 & 24 & 24 \\
\hline \hline p3-p9 & 2 & 6 & 8 & 24 & 24 & 24 \\
\hline p9-p10 & 2 & 6 & 8 & 24 & 24 & 24 \\
\hline p10-p11 & 2 & 6 & 8 & 24 & 24 & 24 \\
\hline p11-p12 & 0 & 0 & 0 & 0 & 0 & 0 \\
\hline p12-p13 & 2 & 6 & 8 & 24 & 24 & 24 \\
\hline p13-p3 & 2 & 6 & 8 & 24 & 24 & 24 \\
\hline \hline p1-p14 & 2 & 6 & 8 & 24 & 24 & 24 \\
\hline p2-p15 & 2 & 6 & 8 & 24 & 24 & 24 \\
\hline p2-p16 & 2 & 6 & 8 & 24 & 24 & 24 \\
\hline p3-p17 & 2 & 6 & 8 & 24 & 24 & 24 \\
\hline p4-18 & 2 & 6 & 8 & 24 & 24 & 24 \\
\hline \hline p5-p19 & 2 & 6 & 8 & 24 & 24 & 24 \\
\hline p6-p20 & 2 & 6 & 8 & 24 & 24 & 24 \\
\hline p8-p21 & 2 & 6 & 8 & 24 & 24 & 24 \\
\hline \hline p10-p22 & 2 & 6 & 8 & 24 & 24 & 24 \\
\hline p11-p23 & 2 & 6 & 8 & 24 & 24 & 24 \\
\hline p13-p24 & 2 & 6 & 8 & 24 & 24 & 24 \\
\hline
\end{tabular}

Tabela 19: Utilização dos enlaces: serviço proposto

\begin{tabular}{|c|c|c|c|c|c|c|}
\hline Enlace & Instante 1 & Instante 2 & Instante 3 & Instante 4 & Instante 5 & Instante 6 \\
\hline \hline $\mathrm{p} 1-\mathrm{p} 4$ & 2 & 6 & 8 & 24 & 24 & 24 \\
\hline $\mathrm{p} 4-\mathrm{p} 3$ & 2 & 6 & 8 & 24 & 24 & 24 \\
\hline $\mathrm{p} 3-\mathrm{p} 2$ & 2 & 6 & 8 & 24 & 24 & 24 \\
\hline $\mathrm{p} 2-\mathrm{p} 1$ & 0 & 0 & 0 & 0 & 0 & 0 \\
\hline \hline $\mathrm{p} 1-\mathrm{p} 5$ & 2 & 6 & 6 & 18 & 18 & 18 \\
\hline $\mathrm{p} 5-\mathrm{p} 6$ & 2 & 2 & 2 & 6 & 6 & 6 \\
\hline $\mathrm{p} 6-\mathrm{p} 7$ & 0 & 0 & 0 & 0 & 0 & 0 \\
\hline $\mathrm{p} 7-\mathrm{p} 8$ & 2 & 6 & 6 & 18 & 18 & 18 \\
\hline $\mathrm{p} 8-\mathrm{p} 1$ & 2 & 6 & 8 & 24 & 24 & 24 \\
\hline \hline $\mathrm{p} 3-\mathrm{p} 9$ & 2 & 6 & 6 & 18 & 18 & 18 \\
\hline $\mathrm{p} 9-\mathrm{p} 10$ & 2 & 2 & 2 & 6 & 6 & 6 \\
\hline $\mathrm{p} 10-\mathrm{p} 11$ & 2 & 2 & 2 & 6 & 6 & 6 \\
\hline $\mathrm{p} 11-\mathrm{p} 12$ & 0 & 0 & 0 & 0 & 0 & 0 \\
\hline $\mathrm{p} 12-\mathrm{p} 13$ & 2 & 6 & 8 & 24 & 24 & 24 \\
\hline $\mathrm{p} 13-\mathrm{p} 3$ & 2 & 6 & 8 & 24 & 24 & 24 \\
\hline $\mathrm{p} 1-\mathrm{p} 14$ & 2 & 2 & 2 & 6 & 6 & 6 \\
\hline $\mathrm{p} 2-\mathrm{p} 15$ & 2 & 2 & 2 & 6 & 6 & 6 \\
\hline $\mathrm{p} 2-\mathrm{p} 16$ & 2 & 2 & 2 & 6 & 6 & 6 \\
\hline $\mathrm{p} 3-\mathrm{p} 17$ & 2 & 2 & 2 & 6 & 6 & 6 \\
\hline $\mathrm{p} 4-18$ & 2 & 2 & 0,3 & 0,9 & 0,9 & 0,9 \\
\hline \hline $\mathrm{p} 5-\mathrm{p} 19$ & 2 & 2 & 2 & 6 & 6 & 6 \\
\hline $\mathrm{p} 6-\mathrm{p} 20$ & 2 & 2 & 0,3 & 0,9 & 0,9 & 0,9 \\
\hline $\mathrm{p} 8-\mathrm{p} 21$ & 2 & 2 & 2 & 6 & 6 & 6 \\
\hline \hline $\mathrm{p} 10-\mathrm{p} 22$ & 2 & 2 & 0,3 & 0,9 & 0,9 & 0,9 \\
\hline $\mathrm{p} 11-\mathrm{p} 23$ & 2 & 2 & 0,3 & 0,9 & 0,9 & 0,9 \\
\hline $\mathrm{p} 13-\mathrm{p} 24$ & 2 & 2 & 2 & 6 & 6 & 6 \\
\hline
\end{tabular}

